NIST Technical Note 1669

\title{
An Experimental and Computational Study of Steel Moment Connections under a Column Removal Scenario
}

Fahim Sadek

Joseph A. Main

H.S. Lew

Stephen D. Robert

Vincent P. Chiarito

Sherif El-Tawil

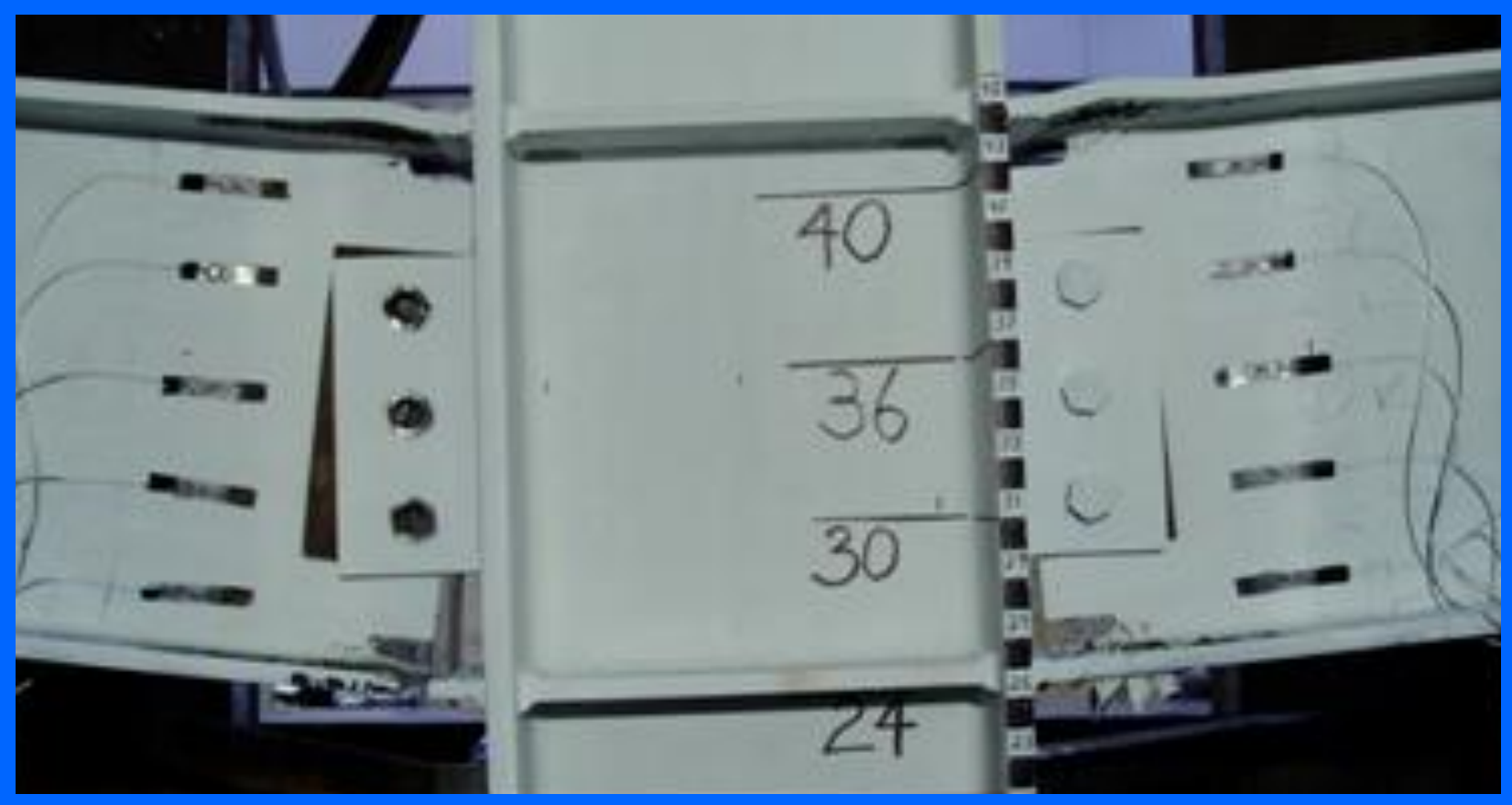

National Institute of Standards and Technology • U.S. Department of Commerce 



\section{NIST Technical Note 1669}

\section{An Experimental and Computational Study of Steel Moment Connections under a Column Removal Scenario}

Fahim Sadek

Joseph A. Main

H.S. Lew

Building and Fire Research Laboratory National Institute of Standards and Technology

Stephen D. Robert

Vincent P. Chiarito

Engineer Research and Development Center

U.S. Army Corps of Engineers

Sherif El-Tawil Department of Civil and Environmental Engineering University of Michigan

September 2010

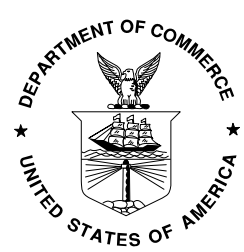




\section{$\underline{\text { Disclaimer }}$}

The policy of the National Institute of Standards and Technology is to use metric units in all its published materials. Because this report is intended for the U.S. building construction industry which uses in-pound units, it is more practical and less confusing to use inch-pound units, in some cases, rather than metric units within quoted text. However, in most cases, units are presented in metric and the inch-pound system.

\section{$\underline{\text { Disclaimer }}$}

Certain commercial entities, equipment, products, or materials are identified in this document in order to describe a procedure or concept adequately or to trace the history of the procedures and practices used. Such identification is not intended to imply recommendation, endorsement, or implication that the entities, products, materials, or equipment are necessarily the best available for the purpose. 


\section{ABSTRACT}

This report presents an experimental and computational study of two steel beam-column assemblies, each comprising three columns and two beams. The two beam-column assemblies represent portions of the structural framing system of two ten-story steel frame buildings, which were designed as part of the National Institute of Standards and Technology research program aimed at prevention of disproportionate structural collapse. One building was designed for Seismic Design Category C (SDC C) and the other for Seismic Design Category D (SDC D). The beam-column assemblies were taken from the exterior moment-resisting frames of these buildings. One test specimen, which was part of the SDC C building, had welded unreinforced flange-bolted web (WUF-B) connections, and the other, which was part of the SDC D building, had reduced beam section (RBS) connections. The specimens were subjected to monotonically increasing vertical displacement of the unsupported center stub column to observe their behavior under a simulated column removal scenario, including the development of catenary action in the beams. The test was terminated when a collapse mechanism of each assembly was developed and the vertical load-carrying capacity was depleted. The primary test specimen response characteristics were measured. These included vertical and horizontal displacements at specific locations, rotations at beam ends, strains at various locations, and the applied load. In addition, a high speed video camera was used to record the specimen response, including the failure mode and sequence of the beam-to-column connections at the center column.

For both the WUF-B and RBS test specimens, the beam-column assemblies remained initially in the elastic range at small displacements of the center column, where the behavior of the beams was dominated by flexure. With increased vertical displacement, the beam connections exhibited yielding and large tensile axial forces developed in the beams. The axial tension in the beams increased until the connections could no longer sustain the combined bending and axial stresses, and the beam-column assemblies failed.

The failure of the WUF-B test specimen was characterized by the following sequence: (1) local buckling of the top flanges of the beams near the center column, (2) successive shear fracture of the lowest and middle bolts connecting the beam web to a shear tab at the center column, and (3) fracture of the bottom flange near the weld access hole. The failure of the RBS test specimen was characterized by the fracture of the bottom flange in the middle of the reduced section near the center column. The fracture propagated through the web until the vertical load-carrying capacity of the beam was lost.

Computational simulations of the beam-column assembly tests were carried out using two levels of modeling complexity: (1) detailed models with a large number of elements, primarily solid and shell elements, and (2) reduced models with a limited number of elements, primarily beam and spring elements. The analyses conducted using these models provided insight into the behavior and failure modes of the connections, including their capacity to carry the tensile forces that developed in the beams. The analyses showed a good agreement between the experimental results and the computational predictions. Both detailed and reduced models were capable of capturing the primary response characteristics and failure modes. The validated reduced models developed in this study will be valuable in the analysis of complete structural systems for assessing the reserve capacity and robustness of building structures. The analyses confirm that the ultimate loads under this column removal scenario are 
primarily resisted through catenary action, wherein axial tension develops in the beams. These tensile forces increase until the connection can no longer sustain the combined tensile and flexural stresses and failure occurs.

The test results show that the rotational capacities of both the WUF-B and the RBS connections under monotonic column displacement are about twice as large as those based on seismic test data. The rotations at peak load were about $0.081 \mathrm{rad}$ and $0.140 \mathrm{rad}$ for the WUF-B and RBS connections, respectively, whereas the rotational capacities of these connections based on seismic testing data are approximately $0.047 \mathrm{rad}$ and $0.073 \mathrm{rad}$, respectively.

Keywords: buildings; computational model; computer simulation; design standards; disproportionate collapse; finite element analysis; moment resisting connections; progressive collapse; steel structures; structural robustness; testing. 


\section{Preface}

This research was carried out by the National Institute of Standards and Technology (NIST) in partnership with the Engineer Research and Development Center (ERDC) of the U.S. Army Corps of Engineers. NIST designed the test specimens, one with welded unreinforced flange, bolted web (WUFB) connections and the other with reduced beam section (RBS) connections. These connections were part of steel frame buildings designed for Seismic Design Categories C and D, respectively. Detailed design of the buildings was carried out by S. K. Ghosh and Associates. The design was guided by a panel of experts who reviewed the design and provided valuable comments. The following experts served on the panel: David R. Bonneville (Degenkolb Engineers, San Francisco, CA), Donald O. Dusenberry (Simpson, Gumpertz \& Heger, Waltham, MA), Ramon Gisanz (Gilsanz, Murray, Steficek, LLP, New York, NY), Thomas A. Sabol (Englekirk \& Sabol, Los Angeles, CA), Andrew W. Taylor (KPFF Consulting Engineers, Seattle, WA).

ERDC fabricated and erected the test specimens, deployed the instruments, performed the test, and collected the test data. NIST developed the finite-element based computational models and performed pre-test analyses to guide the development of the instrumentation plan, test setup, and loading procedure for each test. NIST validated the computational models against experimental data and used the models to study the behavior and failure modes of the connections.

The study reported herein was supported partially by the following organization and federal agencies: the American Institute of Steel Construction, the Air Force Research Laboratory, and the Defense Threat Reduction Agency.

The authors gratefully acknowledge the thorough review of the report by Therese P. McAllister of NIST and Ronald O. Hamburger of Simpson, Gupertz \& Heger. 
This page intentionally left blank. 


\section{TABLE OF CONTENTS}

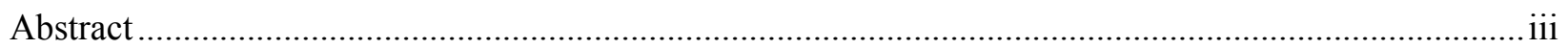

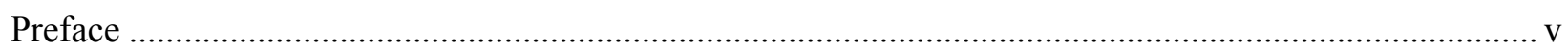

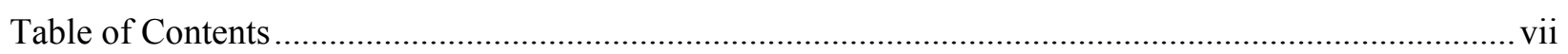

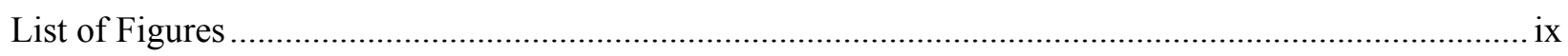

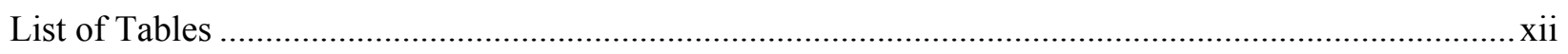

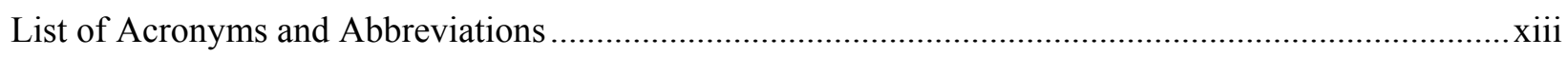

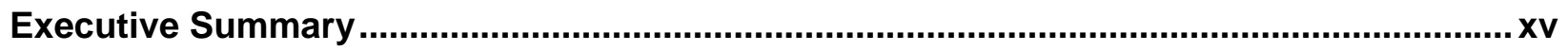

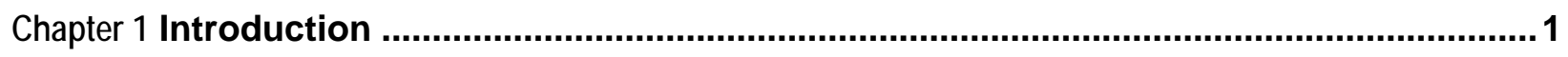

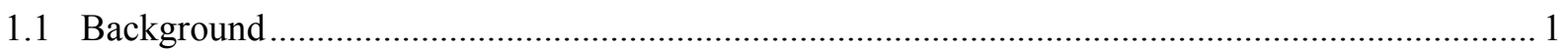

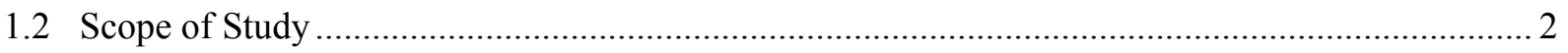

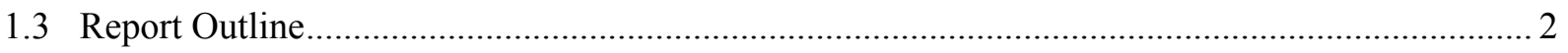

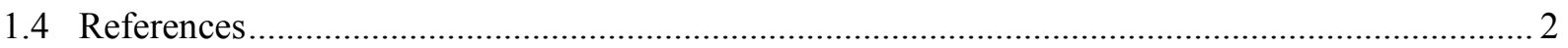

Chapter 2 Description of Prototype Building Designs ...................................................... 3

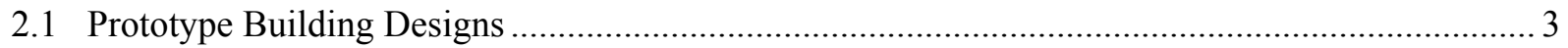

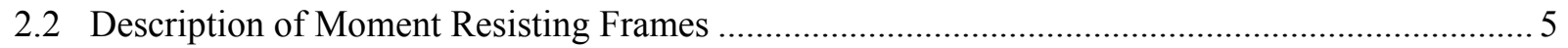

2.2.1 Welded Unreinforced Flange-Bolted Web (WUF-B) Connection ...................................... 7

2.2.2 Reduced Beam Section (RBS) Connection .................................................................. 9

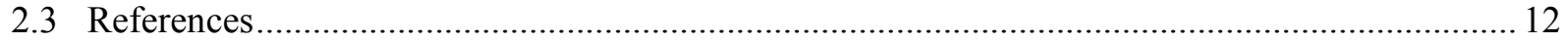

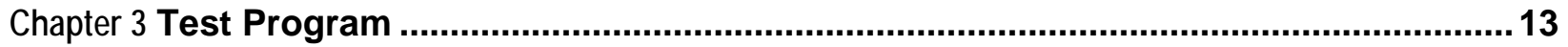

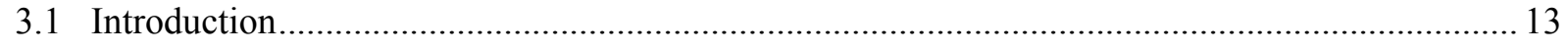

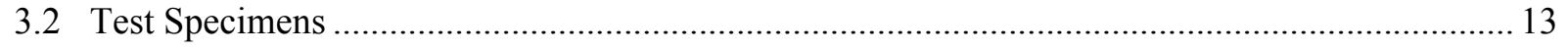

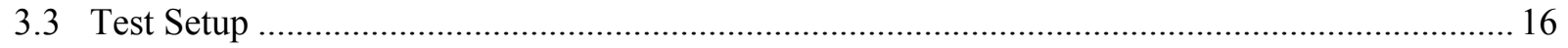

3.4 Loading Aparatus and Test Sequence …............................................................................. 19

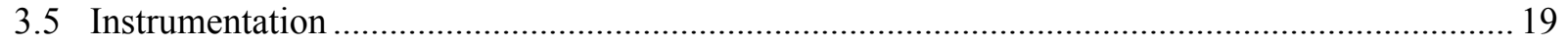

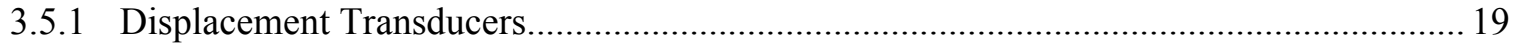

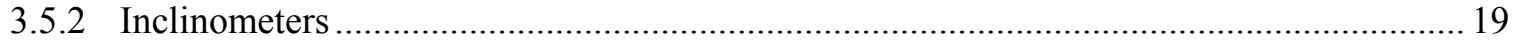

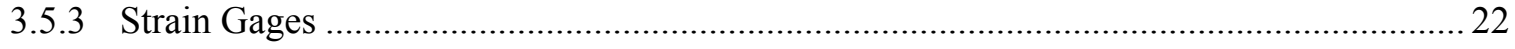

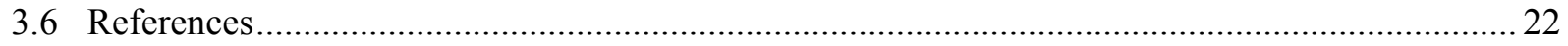




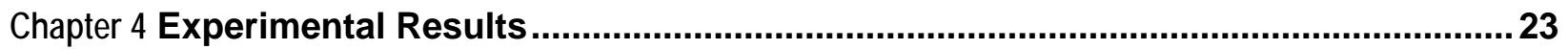

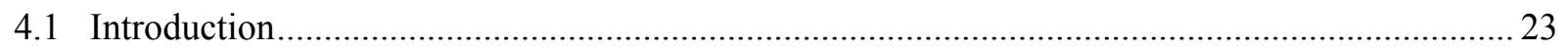

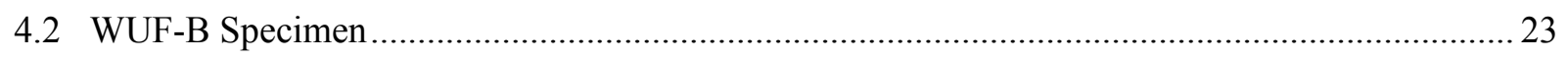

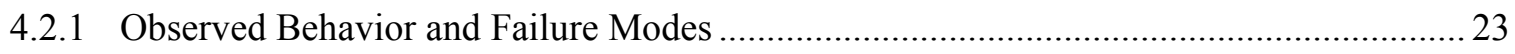

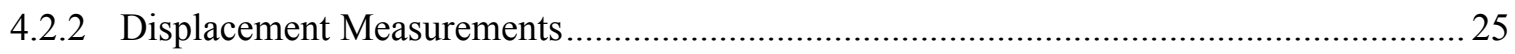

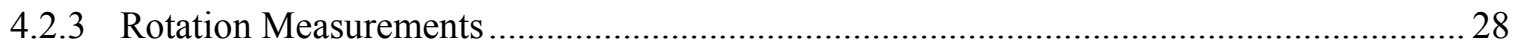

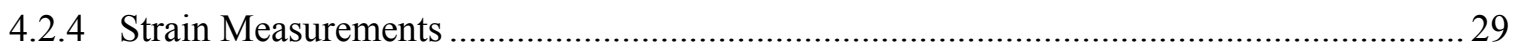

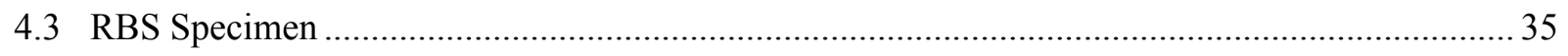

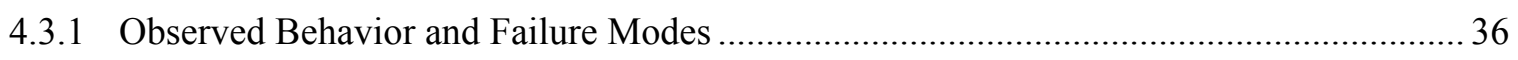

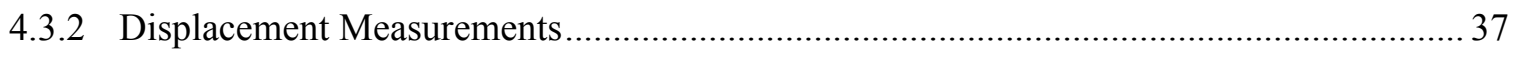

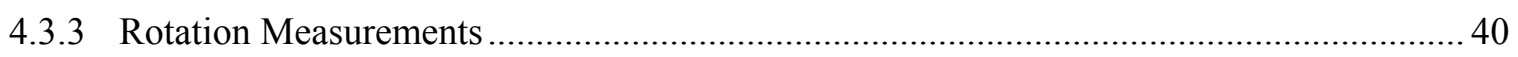

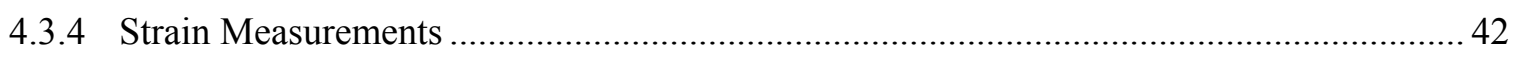

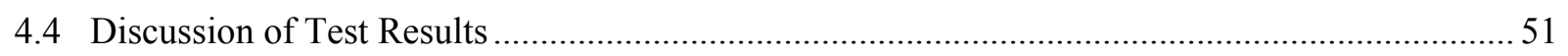

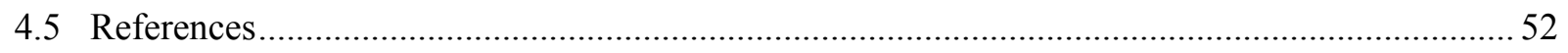

Chapter 5 Computational Modeling and Analysis of Test Specimens.................................53

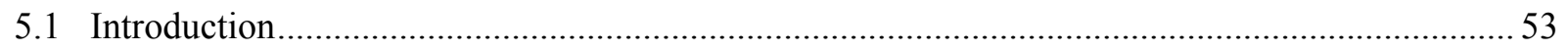

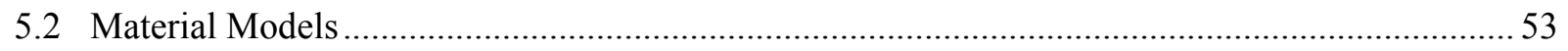

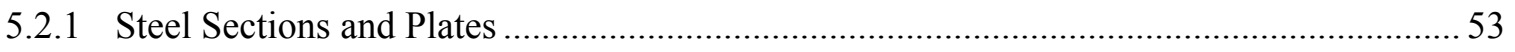

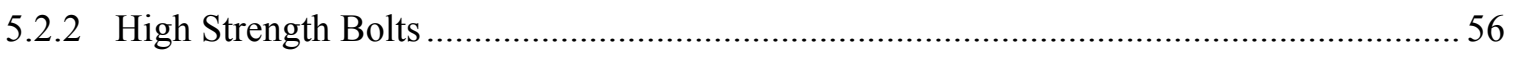

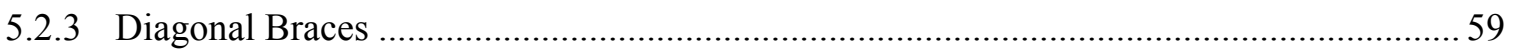

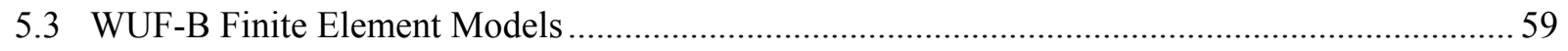

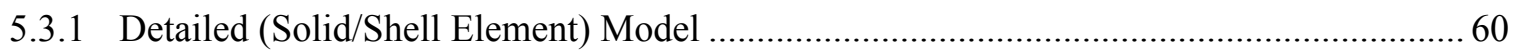

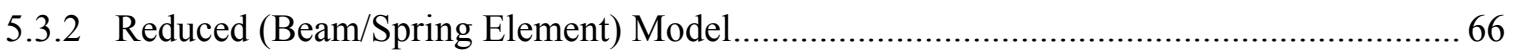

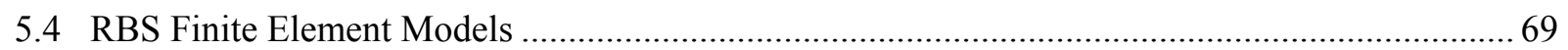

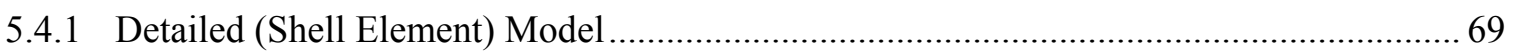

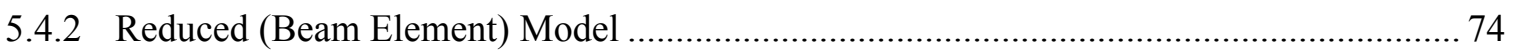

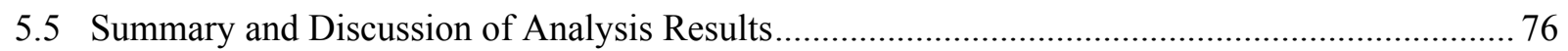

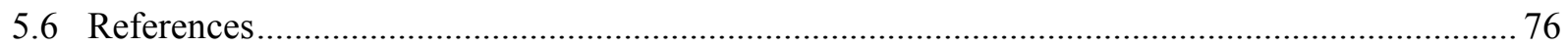

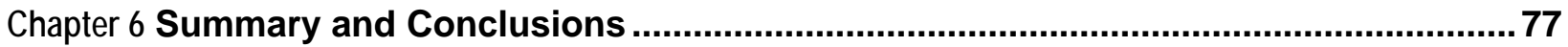




\section{LIST OF FIGURES}

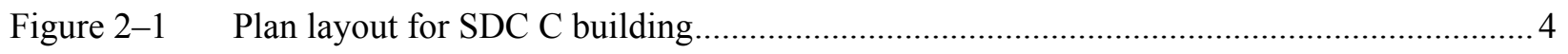

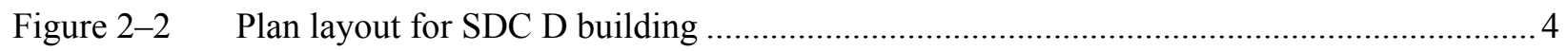

Figure 2-3 East-west elevation of the steel frame buildings ...........................................................5

Figure 2-4 WUF-B connection details - N-S frames, second floor of SDC C building ...................... 9

Figure 2-5 Detail of weld access holes for the WUF-B connection................................................. 9

Figure 2-6 RBS connection details - N-S frames, second floor of SDC D building ........................ 11

Figure 2-7 RBS connection details - plan view of beam's top and bottom flanges............................ 11

Figure 2-8 Detail of weld access holes for the WUF-B connection.................................................. 12

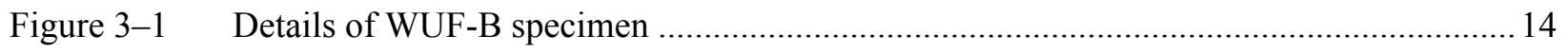

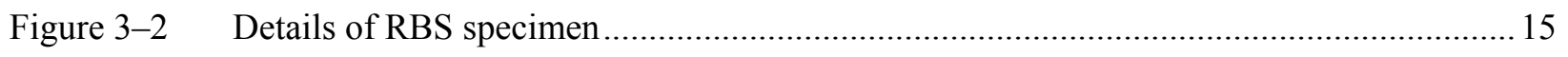

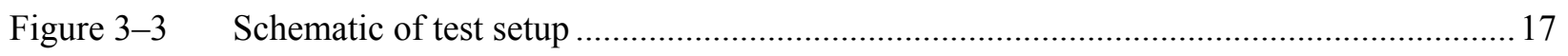

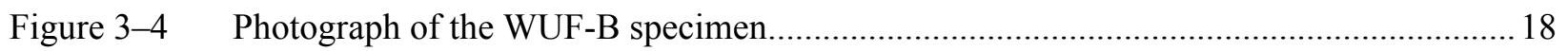

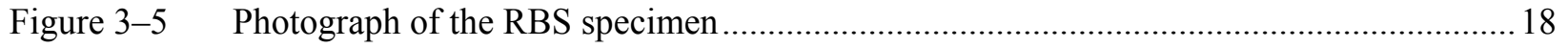

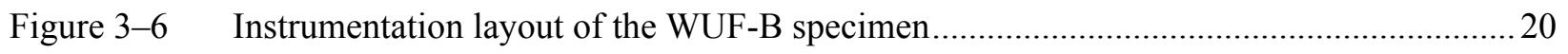

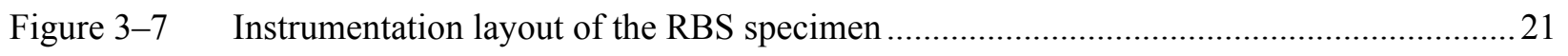

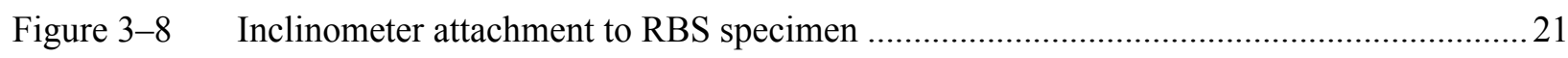

Figure 4-1 Overall view of the WUF-B specimen subjected to large displacements..........................24

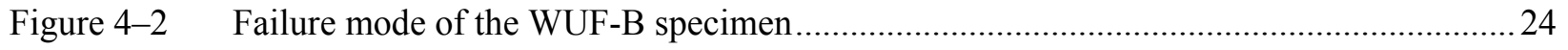

Figure 4-3 Applied vertical load versus vertical displacements at (a) 1/4 span of beams (D2 and D9), (b) 1/2 span of beams (D3 and D8), (c) 3/4 span of beams (D4 and D7), and (d) center

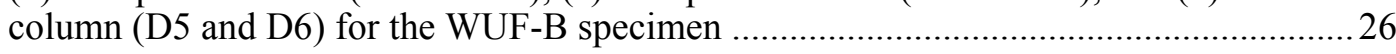

Figure 4-4 Vertical displacement profiles of beams corresponding to indicated vertical loads for the WUF-B specimen (displacements magnified).....

Figure 4-5 Horizontal displacement of end columns at beam mid-height (D1, D10, and their average) versus vertical displacement of center column for the WUF-B specimen ..........................2 27

Figure 4-6 Applied vertical load versus angles of rotation at (a) connections to end columns and (b)

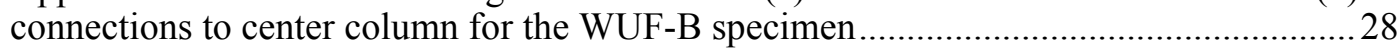

Figure 4-7 Angle of rotation at (a) connections to end columns and (b) connections to center column versus vertical displacement of center column for the WUF-B specimen ..........................2 29

Figure 4-8 Locations of cross sections with strain gages for the WUF-B specimen.......................... 30

Figure 4-9 Mid-span strain gage measurements at (a) Section B2 and (b) Section B5 versus vertical displacement of center column for the WUF-B specimen................................................. 31

Figure 4-10 Average strains at Sections B2 and B5 versus vertical displacement of center column for

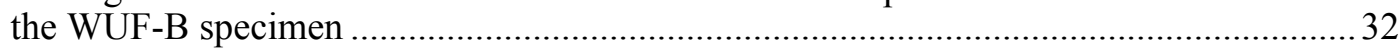

Figure 4-11 Axial force in the beams versus vertical displacement of center column for the WUF-B specimen. 
Figure 4-12 Strain distributions along the depth of the beam at (a) Section B1 and (b) Section B6 near the connections to the end columns for the WUF-B specimen

Figure 4-13 Strain distributions along the depth of the beam at (a) Section B3 and (b) Section B4 near the connections to the center column for the WUF-B specimen ................................. 34

Figure 4-14 Strain gage measurements at Sections C1 and C2, along with their average, versus vertical displacement at center column for the WUF-B specimen ................................... 35

Figure 4-15 Axial forces in the end columns versus vertical displacement of center column for the WUF-B specimen 35

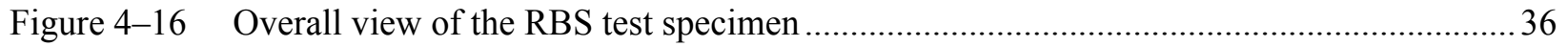

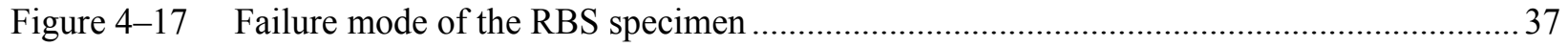

Figure 4-18 Applied vertical load versus vertical displacements at (a) 1/3 span of beams (D3 and D8), (b) 2/3 span of beams (D4 and D7), and (c) center column (D5 and D6) for the RBS

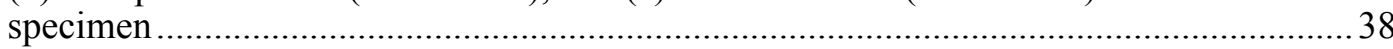

Figure 4-19 Vertical displacement profiles of beams corresponding to indicaged vertical loads for the RBS specimen (displacements magnified) .......................................................................... 39

Figure 4-20 Horizontal displacements of end columns at (a) column top and (b) beam mid-height versus center column displacement for RBS specimen.....

Figure 4-21 Vertical load versus angle of rotation at connections to end and center columns for RBS specimen

Figure 4-22 Angle of rotation at connections to end column and center column versus center column

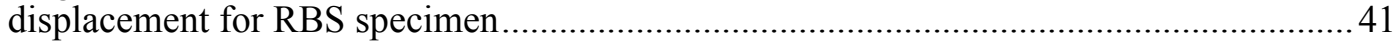

Figure 4-23 Locations of cross sections with strain gages .............................................................42

Figure 4-24 Strain versus center column displacement at (a) Section B2 and (b) Section B7 of RBS

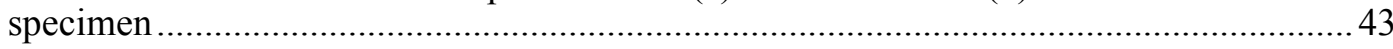

Figure 4-25 Average strains at Sections B2 and B7 versus center column displacement of RBS

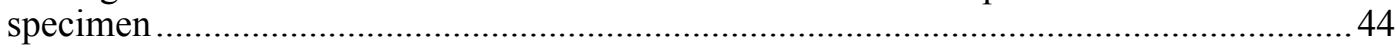

Figure 4-26 Axial force in beams versus center column displacement of RBS specimen ....................44

Figure 4-27 Strain distributions along the depth of beam at (a) Section B1 and (b) Section B8 near the connections to the end columns of RBS specimen ...........................................................4 46

Figure 4-28 Strain distributions along the depth of beam at (a) Section B4 and (b) Section B5 near the connections to the center column of RBS specimen

Figure 4-29 Strain distributions along the depth of beam at (a) Sections B2 and B7, and (b) Sections

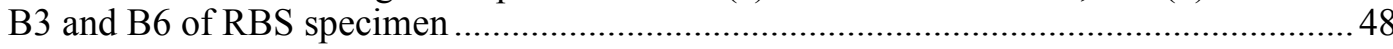

Figure 4-30 Strain measurements at Sections C1 and C2, along with their average, versus center

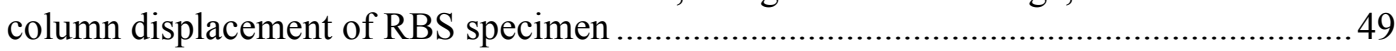

Figure 4-31 Axial force in end columns versus center column displacement of RBS specimen...... 49

Figure 4-32 Strain measurements at Sections W1 and W2, along with their average, versus center column displacement of RBS specimen .... .50

Figure 4-33 Axial compressive force in each diagonal brace versus center column displacement of RBS specimen

Figure 5-1 Example finite element models of ASTM 370 coupon tensile samples: (a) solid element model with 0.18 in $(4.6 \mathrm{~mm})$ element size; (b) shell element model with 0.75 in $(19 \mathrm{~mm})$ element size 
Figure 5-2 True stress-strain curves for the solid, shell, and beam elements used in modeling the beam flanges of the WUF-B specimen.

Figure 5-3 Engineering stress-strain curves obtained from coupon tests and from the analysis using solid and shell elements for modeling the beam flanges of the WUF-B specimen .............56

Figure 5-4 True stress-strain curve for the solid elements used in modeling the bolts of the WUF-B

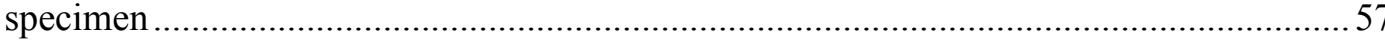

Figure 5-5 Finite element model of a bolt double shear test ..........................................................57

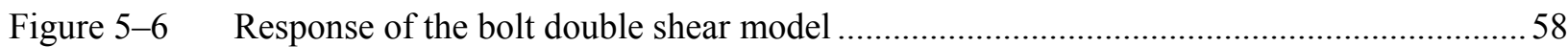

Figure 5-7 Measured and calculated shear load-deformation curves for 1 in, A490 bolt ...................58

Figure 5-8 Axial load-displacement curve for diagonal braces for the WUF-B and RBS specimens . 60

Figure 5-9 Overview of the detailed model of the WUF-B specimen ............................................ 61

Figure 5-10 Detailed views of the WUF-B connection in the detailed model of the WUF-B specimen62

Figure 5-11 Deflected shape of WUF-B detailed model at a center column vertical displacement of 19 in $(483 \mathrm{~mm})$. Contours represent vertical displacements in inches.

Figure 5-12 Failure mode of the WUF-B detailed model. Contours represent plastic strains

Figure 5-13 (a) Applied vertical load, (b) beam axial force, (c) horizontal displacement of end column at beam mid-height, and (d) end column axial force; all plotted against vertical displacement of center column for the WUF-B specimen

Figure 5-14 Comparison of the WUF-B connection moment-axial interaction diagram with the limit interaction diagram of the gross beam cross section 65

Figure 5-15 Overview of reduced model of the WUF-B specimen ................................................66

Figure 5-16 Detailed view of the WUF-B connection in the reduced model of the WUF-B specimen.66

Figure 5-17 Shear load-deformation curves for bolted lap joint .68

Figure 5-18 Deflected shape of WUF-B reduced model (fixed columns) at a center column vertical displacement of 20.1 in $(511 \mathrm{~mm})$.

Figure 5-19 Failure sequence from the WUF-B reduced model ......................................................69

Figure 5-20 Overview of the detailed model of the RBS specimen............................................... 70

Figure 5-21 Detailed view of the RBS connection in the detailed model of the RBS specimen ...........70

Figure 5-22 Deflected shape of RBS detailed model at a center column vertical displacement of 37 in $(944 \mathrm{~mm})$. Contours represent (a) vertical and (b) horizontal displacements in inches. ... 71

Figure 5-23 Failure mode from the RBS detailed model. Contours represent plastic strains ............ 72

Figure 5-24 Vertical displacement of center column versus applied vertical load, and individual member forces and displacements of RBS specimen

Figure 5-25 Comparison of RBS connection moment-axial interaction diagram with the interaction diagram of gross beam cross section ............................................................................ 74

Figure 5-26 Overview of the reduced model of the RBS specimen .................................................75

Figure 5-27 Deflected shape of RBS reduced model (fixed columns) at a center column displacement of 34.1 in $(866 \mathrm{~mm})$. 


\section{LIST OF TABLES}

Table 2-1. Member sizes for moment resisting frames of SDC C building .............................................. 6

Table 2-2. Member sizes for moment resisting frames for SDC D building......................................... 7

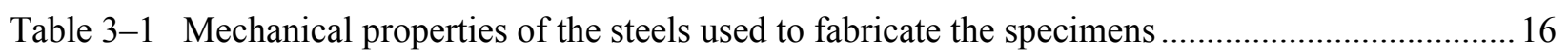

Table 4-1. Comparison of rotation capacities of WUF-B and RBS connections based on seismic data and

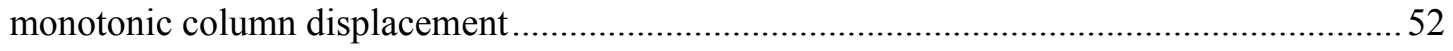




\section{LIST OF ACRONYMS AND ABBREVIATIONS}

\section{Acronyms}

$\begin{array}{ll}\text { AISC } & \text { American Institute of Steel Construction } \\ \text { ASCE } & \text { American Society of Civil Engineers } \\ \text { D } & \text { Dead load } \\ \text { DoD } & \text { U.S. Department of Defense } \\ \text { DTRA } & \text { Defense Threat Reduction Agency of the U.S. DoD } \\ \text { FE } & \text { Finite element } \\ \text { FEMA } & \text { Federal Emergency Management Agency of the U.S. Department of Homeland Security } \\ \text { GSA } & \text { U.S. General Services Administration } \\ \text { L } & \text { Live load } \\ \text { LRFD } & \text { Load and resistance factor design } \\ \text { SDC } & \text { Seismic Design Category } \\ \text { UFC } & \text { Unified Facilities Criteria } \\ \text { U.S. } & \text { United States }\end{array}$

\section{Unit Abbreviations}

$\begin{array}{ll}\mathrm{ft} & \text { foot } \\ f_{y} & \text { specified yield strength of steel } \\ \mathrm{h} & \text { hour } \\ \mathrm{in} & \text { inch } \\ \mathrm{kip} & 1000 \mathrm{lbf} \\ \mathrm{kN} & \text { kilonewton } \\ \mathrm{kPa} & \text { kilopascal } \\ \mathrm{ksi} & \text { kip per square inch } \\ \mathrm{lbf} & \text { pound-force } \\ \mathrm{m} & \text { meter } \\ \mathrm{mm} & \text { millimeter } \\ \mathrm{MPa} & \text { megapascal }\end{array}$




$\begin{array}{ll}\text { psf } & \text { pound-force per square foot } \\ \text { psi } & \text { pound-force per square inch } \\ \text { S } & \text { second }\end{array}$




\section{EXECUTIVE SUMMARY}

Since the destruction of the Alfred P. Murrah Federal Building in 1995, caused by a truck bomb attack, and the collapse of the World Trade Center towers in 2001, caused by the impact of large passenger jets, greater attention has been paid to the performance of buildings that may be subjected to local damage from abnormal events. In the U.S., the American Society of Civil Engineers Standard 7 (ASCE 7) and the guidelines of the U.S. General Services Administration and the Department of Defense provide guidance to prevent disproportionate collapse (also known as progressive collapse). Disproportionate collapse occurs when an initial local failure spreads progressively, resulting in total collapse or collapse of a disproportionately large part of a structure. Resistance to disproportionate collapse is achieved either implicitly, by providing minimum levels of strength, continuity, and ductility; or explicitly, by (1) providing alternate load paths so that local damage is absorbed and major collapse is averted or (2) providing sufficient strength to structural members that are critical to global stability. In the alternate path method, the structural integrity is assessed through analysis to ascertain whether the structural system can bridge over failed structural members. In order to assure the efficacy of the analytical procedure, physical tests must be conducted to validate computational methods. In assessing the potential for disproportionate collapse, accurate characterization of the nonlinear, large-deformation behavior associated with the transfer of forces through structural connections is essential.

This report presents an experimental and computational study of two steel beam-column assemblies, each comprising three columns and two beams. The two beam-column assemblies represent portions of the structural framing system of two ten-story steel frame buildings. One building was designed for Seismic Design Category C (SDC C) and the other for Seismic Design Category D (SDC D). The beam-column assemblies were taken from the exterior moment resisting frames of these buildings. One test specimen, which was part of the SDC C building, had welded unreinforced flange-bolted web (WUF-B) connections, and the other, which was part of the SDC D building, had reduced beam section (RBS) connections. The specimens were subjected to monotonically increasing vertical displacement of the unsupported center stub column to observe their behavior under a simulated column removal scenario, including the development of catenary action in the beams. The vertical displacement of the center column was increased until the vertical load-carrying capacity was depleted.

The overall behavior of each beam-column assembly was analyzed using two levels of modeling complexity: (1) detailed models with a large number of elements, primarily solid and shell elements, and (2) reduced models with a limited number of elements, primarily beam and spring elements. The analyses conducted using these models provided insight into the behavior and failure modes of the connections, including their capacity to carry tensile forces that developed in the beams.

The tests and associated computational models help fill the gap in defining the response characteristics of the moment-resisting connections under collapse scenarios and contribute to establishing a library of validated connection models that can be used to assess the robustness of structural systems.

Based on the study reported herein, the following conclusions are reached: 
1. For both the WUF-B and RBS connection assemblies, the behavior of the beams was dominated by flexure in the early stages of the response. With increased vertical displacement of the center column, the beam connections exhibited yielding, and tensile axial forces developed in the beams, indicating catenary action.

2. Distinct modes of failure were observed for each of the two test specimens. The failure of the WUF-B test specimen was characterized by: (1) local buckling of the top flanges of the beams near the center column, (2) successive shear fractures of the lowest and middle bolts connecting the beam web to a shear tab at the center column, and (3) fracture of the bottom flange near the weld access hole immediately thereafter. The failure of the RBS test specimen was characterized by: (1) fracture of the bottom flange in the middle of the reduced section and (2) propagation of the fracture through the web until the vertical load-carrying capacity was depleted.

3. The test results show that the rotational capacities of both the WUF-B and RBS connections under monotonic column displacement are about twice as large as those based on seismic test data. The beam chord rotations at peak load were about $0.081 \mathrm{rad}$ and $0.140 \mathrm{rad}$ for the WUF-B and RBS connections respectively, whereas the rotational capacities of these connections based on seismic testing data are approximately $0.047 \mathrm{rad}$ and $0.073 \mathrm{rad}$, respectively.

4. This study indicates generally good agreement between the experimental and the computational results. Both detailed and reduced models were capable of capturing the primary response characteristics and failure modes of the test specimens.

In summary, this study shows that analysis using reduced models composed of beam and spring elements can predict the response characteristics of both the WUF-B and the RBS connections. Furthermore, the validated reduced models developed in this study would be valuable in the analysis of complete structural systems for assessing reserve capacity and robustness of building structures. 


\section{Chapter 1 \\ INTRODUCTION}

\section{$1.1 \quad$ BACKGROUND}

Since the destruction of the Alfred P. Murrah Federal Building in 1995, caused by a truck bomb attack, (FEMA 1996) and the collapse of the World Trade Center towers in 2001, caused by the impact of large passenger jetliners (NIST 2005), the engineering community, including codes and standards development organizations and public regulatory agencies, has paid greater attention to the performance of buildings when subjected to local damage sustained from abnormal events. In the U.S., the American Society of Civil Engineers Standard 7 (ASCE 2010, Section C1.4), and the guidelines of the U.S. General Services Administration (GSA 2003) and the Department of Defense (DOD 2009) provide guidance to prevent disproportionate collapse (also known as progressive collapse). Disproportionate collapse occurs when an initial local failure spreads progressively, resulting in total collapse or collapse of a disproportionately large part of a structure. Resistance to disproportionate collapse is achieved either implicitly, by providing minimum levels of strength, continuity, and ductility; or explicitly, by (1) providing alternate load paths so that local damage is absorbed and major collapse is averted or (2) providing sufficient strength to structural members that are critical to global stability.

In the alternate path method, the structural integrity is assessed through analysis, to ascertain whether the structural system can bridge over failed structural members. For example, if a column is damaged, continuity of the beams adjacent to the top of the damaged column is required to redistribute the loads formerly carried by the damaged column. The analysis must demonstrate the adequacy of the beams and their connections to redistribute these loads, potentially through catenary action. An accurate characterization of the nonlinear, large-deformation behavior associated with the transfer of forces through the connections in such scenarios is critical in assessing the potential for disproportionate collapse. Physical tests are indispensible to validate the analytical models used to represent nonlinear connection behavior in such scenarios. At present, design and evaluation of structures for disproportionate collapse potential are typically based on acceptance criteria obtained from seismic research (e.g., FEMA 350, 2000). As will be shown in this study, using this approach to predict the response to monotonic loading similar to that expected during column removal scenarios underestimates the rotational capacities of the connections.

The National Institute of Standards and Technology (NIST) is conducting a comprehensive research program to study the behavior of structures that, when exposed to abnormal loads, might experience disproportionate collapse. To understand the behavior of structural systems near their ultimate-strength limit states and to develop reliable tools to quantify the reserve capacity and robustness of structural systems, the NIST study proposes to develop three-dimensional models of building structures with various materials and structural systems. To validate these models, full-scale tests of beam-column assemblies representing portions of a structural system are carried out. The experimental results are used to validate reduced connection models that will be incorporated into the three-dimensional models for analysis of disproportionate collapse vulnerability. 


\subsection{SCOPE OF STUDY}

The study reported herein includes both full-scale testing and finite-element based analysis of two steel beam-column assemblies, each comprising three columns and two beams and representing part of the second floor framing of a ten-story building. While both test specimens have moment resisting beam-tocolumn connections, one specimen has welded unreinforced flange-bolted web (WUF-B) connections, which are typically used for intermediate moment frames, and the other has reduced beam section (RBS) connections, which are typically used for special moment resisting frames. The specimens are subjected to monotonically increasing vertical displacement of the unsupported center column to observe their behavior under a simulated column removal scenario, including the development of catenary action in the beams. The test is terminated upon reaching the collapse mechanism of the assembly. Both detailed and reduced finite element models of the test specimens are developed, and the model predictions show good agreement with the experimental results. The reduced models can be used for analysis of complete structural systems to assess their vulnerability to disproportionate collapse.

The tests and associated computational models help fill the gap in defining the response characteristics of the moment-resisting connections under collapse scenarios and contribute to establishing a library of validated connection models that can be used to assess the robustness of structural systems.

\section{$1.3 \quad$ REPORT OUTLINE}

The report summarizes the experimental and computational approaches used in this study for the two moment resisting connections, along with the results of both tests and analyses. Chapter 2 provides a description of the prototype steel building designs that have been developed by NIST. Special emphasis is placed on describing the details of the moment resisting connections used in this study. Chapter 3 presents the test setup for both specimens, including the test configuration, the loading apparatus and sequence, and the instrumentation used. Chapter 4 summarizes the test results, including the observed behavior and failure modes of each specimen, and presents the measured responses, including displacements, rotations, strains, and loads. Chapter 5 describes the various finite element models used in the analysis of the test specimens and presents the results of these analyses, including validation of the models against experimental results. Chapter 6 presents a summary and conclusions of the report.

\section{$1.4 \quad$ REFERENCES}

ASCE (2010). Minimum Design Loads for Buildings and Other Structures, SEI/ASCE 7-10, American Society of Civil Engineers, Reston, VA

DOD (2009). Design of Buildings to Resist Progressive Collapse, Unified Facilities Criteria (UFC) 4023-03, Department of Defense, 25 January 2009.

FEMA (1996). The Oklahoma City Bombing: Improving building performance through multi-hazard mitigation, FEMA Report 277, Federal Emergency Management Agency, Washington, D.C.

FEMA (2000). Recommended Seismic Design Criteria for New Steel Moment-Frame buildings, FEMA 350, SAC Joint Venture and Federal Emergency Management Agency, Washington, D.C.

General Services Administration (GSA ), (2003), "Progressive Collapse Analysis Design Guidelines for New Federal Office Buildings and Major Modernization Projects," GSA, Washington, D.C.

NIST (2005). The Collapse of the World Trade Center Towers, NIST NCSTAR 1, National Institute of Standards and Technology, Gaithersburg, MD. 


\section{Chapter 2 \\ DESCRIPTION OF PROTOTYPE BuILDING DEsignS}

\section{$2.1 \quad$ PROTOTYPE BUILDING DESIGNS}

The National Institute of Standards and Technology (NIST), working with a panel of practicing structural engineers across the U.S., developed the overall configuration and dimensions of the prototype buildings to be considered in this research program. For simplicity of design and analysis, a 10-story building with rectangular plan for office occupancy was chosen as the prototype building. For the study reported herein, two steel frame buildings were designed, each having the plan dimensions of $100 \mathrm{ft} \times 150 \mathrm{ft}(30.5 \mathrm{~m} \times$ $45.7 \mathrm{~m}$ ), with five bays in both longitudinal and transverse directions. The detailed design of the building was carried out by a consulting engineering firm (Liang et al., 2008).

To examine the effectiveness of seismic design and detailing, including seismic connections, in resisting disproportionate collapse, one building was designed for Seismic Design Category (SDC) C and the other for SDC D. The lateral loads are resisted by exterior moment resisting frames. All interior frames were designed to support gravity loads only. The types of moment resisting frames for the two Seismic Design Categories are:

- $\quad$ SDC C - (Atlanta, Georgia), which resulted in a design using Intermediate Moment Frames (IMF) for the lateral load resisting system as defined in the American Institute of Steel Construction (AISC) Seismic Provisions (2002), and

- $\quad$ SDC D - (Seattle, Washington), which resulted in a design using Special Moment Frames (SMF) for the lateral load resisting system.

Plan views of the buildings in the SDC C and SDC D regions are shown in Figure 2-1 and Figure 2-2, respectively, and elevation views are shown in Figure 2-3.

The buildings were designed according to the American Society of Civil Engineers (ASCE 7-02) standard. The material design standards used in the design of the members and their connections were those referenced in ASCE 7-02, including:

- The American Institute of Steel Construction (AISC) Load and Resistance Factor Design (LRFD) Specification for Structural Steel Buildings (1999), hereafter referred to as AISC LRFD.

- The AISC Seismic Provisions for Structural Steel Buildings (2002), hereafter referred to as AISC Seismic Provisions.

- FEMA Recommended Seismic Design Criteria for New Steel Moment-Frame Buildings (2000), hereafter referred to as FEMA 350. 


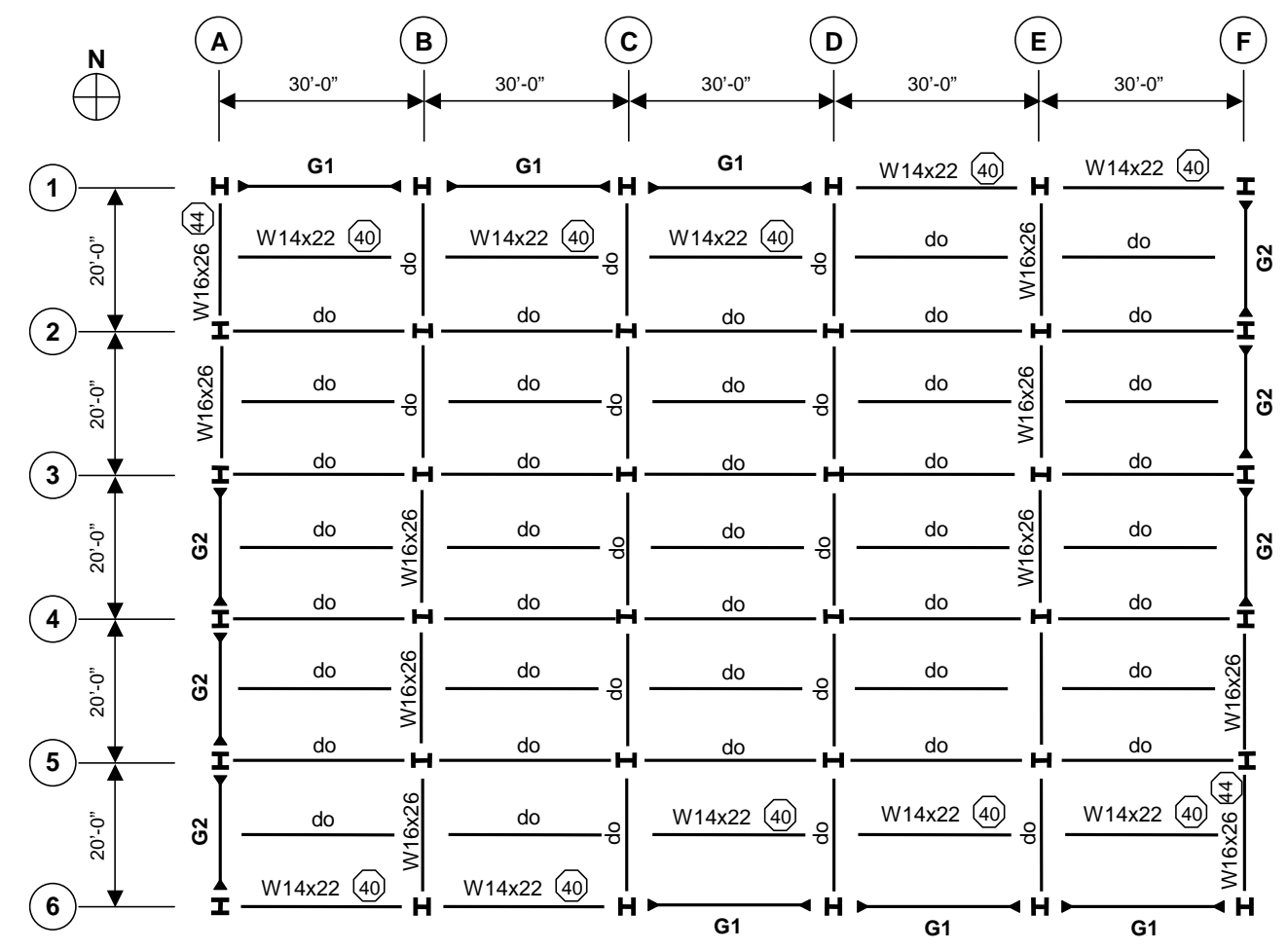

Figure 2-1 Plan layout for SDC $\mathrm{C}$ building

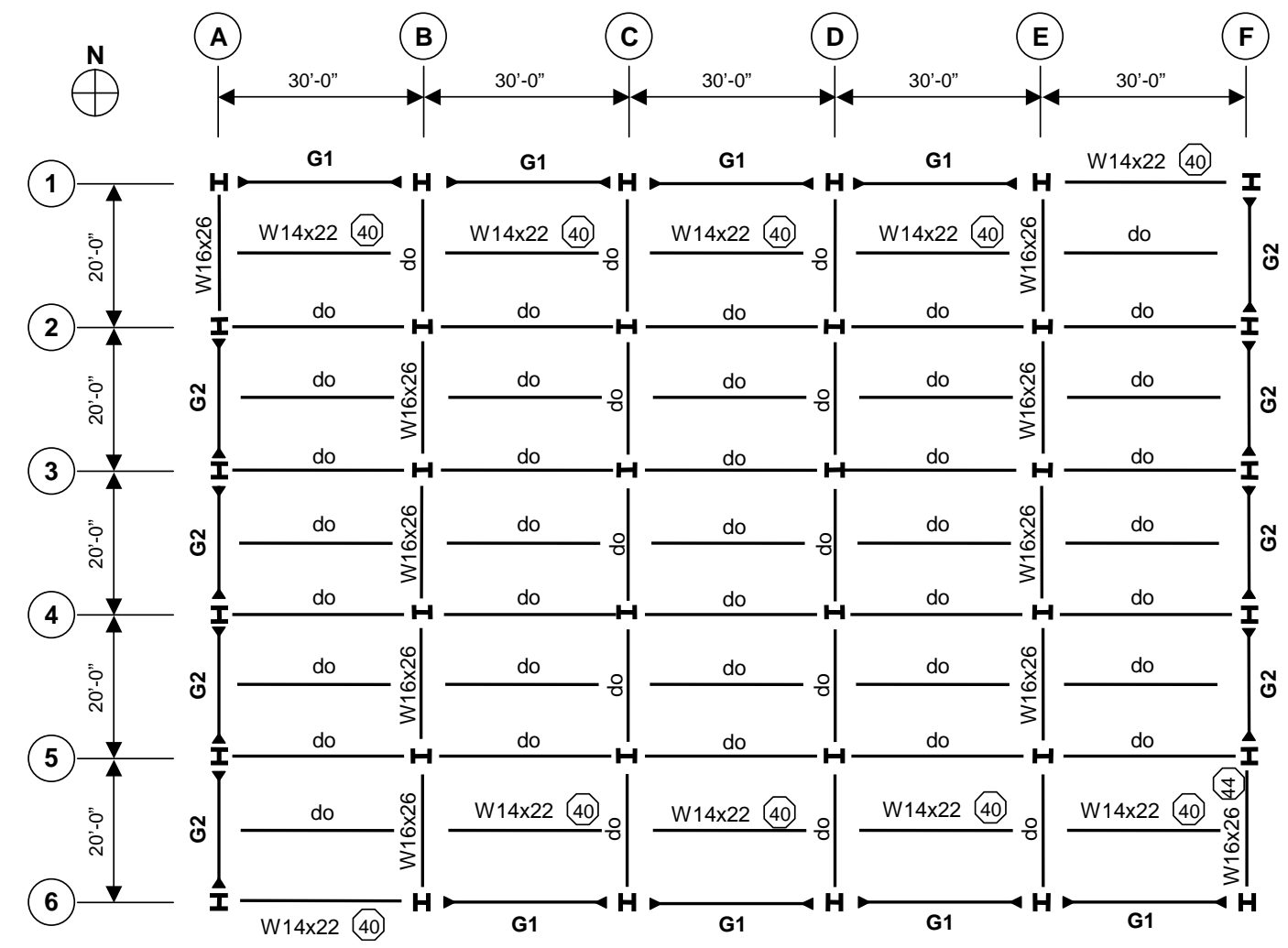

Figure 2-2 Plan layout for SDC D building 


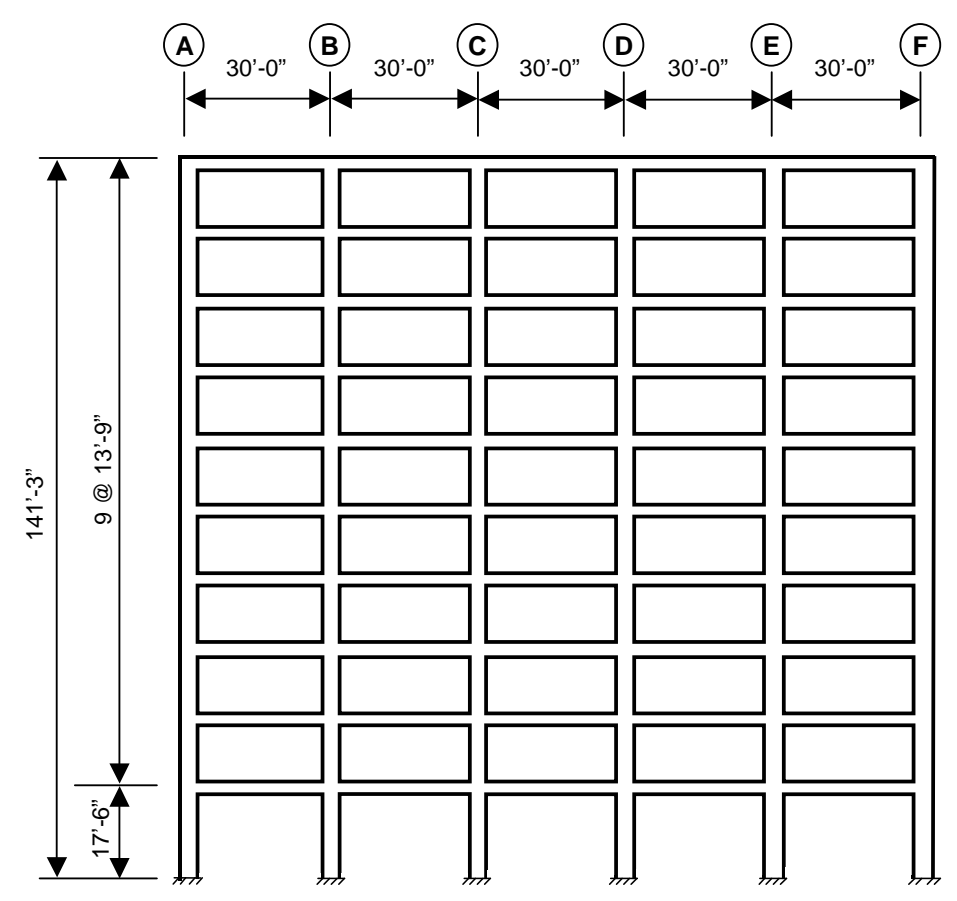

Figure 2-3 East-west elevation of the steel frame buildings

For typical floors, the dead load consisted of the self-weight of the floor of $46 \mathrm{psf}\left(2.2 \mathrm{kN} / \mathrm{m}^{2}\right)$ and a superimposed dead load of $30 \mathrm{psf}\left(1.44 \mathrm{kN} / \mathrm{m}^{2}\right)$, and a design live load of $100 \mathrm{psf}\left(4.79 \mathrm{kN} / \mathrm{m}^{2}\right)$. For the roof, the self-weight of the slab was $46 \mathrm{psf}\left(2.2 \mathrm{kN} / \mathrm{m}^{2}\right)$, the superimposed dead load was $10 \mathrm{psf}$ $\left(0.48 \mathrm{kN} / \mathrm{m}^{2}\right)$, and the design live load was $20 \mathrm{psf}\left(0.96 \mathrm{kN} / \mathrm{m}^{2}\right)$. The reduction of live loads was based on Section 1607.9.1 of IBC (2003).

Because the lateral load resisting system was located only around the perimeter of both buildings, the design of all interior floors and columns was the same for both buildings. The floor system consisted of $3 \frac{1 / 4}{4}$ in $(83 \mathrm{~mm})$ lightweight concrete $\left(110 \mathrm{pcf}, 17.3 \mathrm{kN} / \mathrm{m}^{3}\right)$ topping on a $3 \mathrm{in}(76 \mathrm{~mm})$ metal deck. The slab acted compositely with the steel beams through shear studs. The steel beams in the gravity frames were connected to the columns using single plate (simple shear) connections.

The lightweight concrete topping slab in the floor system had a nominal compressive strength of $3000 \mathrm{psi}$ (20.7 MPa). ASTM A992 structural steel ( $\left.\mathrm{F}_{\mathrm{y}}=50 \mathrm{ksi}, 344.8 \mathrm{MPa}\right)$ was used in all beams, columns, and doubler plates in the panel zones. ASTM A36 steel ( $\left.\mathrm{F}_{\mathrm{y}}=36 \mathrm{ksi}, 248.2 \mathrm{MPa}\right)$ was used for the shear tabs and continuity plates at beam-column connections. For the bolted moment connections, ASTM A490 high strength bolts were used, and welding requirements followed the recommendations in FEMA 353 (2000).

\section{$2.2 \quad$ DESCRIPTION OF MOMENT RESISTING FRAMES}

Design of the moment-resisting frames was based on three-dimensional analyses of the buildings using a commercially available computer program for linear elastic analysis. Only members that are part of the lateral load resisting system were considered in the model. Fixed-base connections were assumed at the structure-foundation interface. Panel zone deformations were directly included in the analysis, using 
elastic properties of the column and doubler plates, if present. A rigid diaphragm was assigned at every floor level. The contribution of the floor slab to the beam moment capacity was neglected in the momentresisting frames. The designs of the steel frames were governed by story drift limitations specified in Table 9.5.2.8 of ASCE 7-02 rather than by strength requirements.

The members of IMFs used in the SDC C building were designed according to Section 10 of the AISC Seismic Provisions. For the SDC C building, six IMFs were incorporated in the East-West (E-W) and North-South (N-S) directions, see Figure 2-1. The cross sections of the beams and columns are given in Table 2-1.

The members of SMFs used for the SDC D building were designed in accordance with Section 9 of the AISC Seismic Provisions. Eight SMFs were incorporated in the exterior frames in the E-W and N-S directions (see Figure 2-2). The cross sections of the beams and columns for this building are given in Table 2-2. Column sizes were increased in some cases to satisfy the strong column/weak beam requirement and to avoid using doubler plates in the one-sided (exterior) moment connections.

Connections used in the moment resisting frames of both buildings were selected from the prequalified steel connections specified in FEMA 350 (2000):

- Welded Unreinforced Flange-Bolted Web (WUF-B) connections for the IMF in the SDC C building, and

- $\quad$ Reduced Beam Section (RBS) connections for the SMF in the SDC D building.

Table 2-1. Member sizes for moment resisting frames of SDC C building

\begin{tabular}{|c|c|c|}
\hline \multirow{2}{*}{ Member } & Floor Range & Section \\
\hline \multirow{2}{*}{ Girders G1 } & $1-5$ & W24x76 \\
\cline { 2 - 3 } & $6-7$ & W24x62 \\
\cline { 2 - 3 } & $8-10$ & W21x50 \\
\hline \multirow{2}{*}{ Girders G2 } & $1-3$ & W21x73 \\
\cline { 2 - 3 } & $4-6$ & W21x68 \\
\cline { 2 - 3 } Columns A1, A6, B1, C1, C6, D1, & $7-10$ & W21x44 \\
\cline { 2 - 3 } D6, E6, F1, and F6 & $1-3$ & W18x119 \\
\cline { 2 - 3 } & $4-7$ & W18x97 \\
\hline \multirow{2}{*}{ Columns A3, A4, A5, F2, F3, and F4 } & $8-10$ & W18x55 \\
\cline { 2 - 3 } & $1-4$ & W18x119 \\
\cline { 2 - 3 } & $5-7$ & W18x97 \\
\hline
\end{tabular}


Table 2-2. Member sizes for moment resisting frames for SDC D building

\begin{tabular}{|c|c|c|}
\hline Member & Floor Range & Section \\
\hline \multirow{4}{*}{ Girders G1 } & $1-4$ & W27x102 \\
\hline & $5-7$ & W27x94 \\
\hline & $8-9$ & W21x50 \\
\hline & 10 & W16x26 \\
\hline \multirow{4}{*}{ Girders G2 } & $1-5$ & W24x94 \\
\hline & $6-7$ & W24x68 \\
\hline & $8-9$ & W21x44 \\
\hline & 10 & W16x26 \\
\hline \multirow{4}{*}{$\begin{array}{l}\text { Columns A1, B1, C1, D1, E1, B6, } \\
\text { C6, D6, E6, and F6 }\end{array}$} & $1-4$ & W24x146 \\
\hline & $5-7$ & W24x131 \\
\hline & $8-9$ & W24x117 \\
\hline & 10 & W24x84 \\
\hline \multirow{3}{*}{$\begin{array}{l}\text { Columns A2, A3, A4, A5, A6, F1, F2, } \\
\text { F3, F4, and F5 }\end{array}$} & $1-5$ & W24X131 \\
\hline & $6-9$ & W24x117 \\
\hline & 10 & W24x84 \\
\hline
\end{tabular}

For the beam-column assembly tests, two-span beams connected to three columns were selected from the second floor of the moment resisting frames in the transverse direction (N-S direction) of each of the two buildings. The beams had a span length (center to center of columns) of $20 \mathrm{ft}(6.10 \mathrm{~m})$. For the SDC C building with the WUF-B connections, the two spans were selected from the two bays of the moment frame spanning between grid points A3 and A5 in Figure 2-1. For the SDC D building with the RBS connections, the two spans were selected from two bays of the moment frame spanning between grid points A3 and A5 in Figure 2-2. Based on Figure 2-1 and Table 2-1, the beams selected from the SDC C building were W21 73 sections and were connected to W18x119 columns using WUF-B connections. Based on Figure 2-2 and Table 2-2, the beams selected from the SDC D building were W24x94 sections and were connected to W24x131 columns using RBS connections.

\subsubsection{Welded Unreinforced Flange-Bolted Web (WUF-B) Connection}

The WUF-B connection is similar to the connections commonly used prior to the 1994 Northridge earthquake. After significant research (FEMA 355D), it was determined that with several improvements and appropriate quality assurance, this connection can perform reliably. Improvements over the typical pre-Northridge connections included: using weld metal with appropriate toughness; removing weld backing from bottom-beam-flange-to-column-flange welds, back-gouging and addition of a reinforcing fillet weld; using improved weld access hole shape and finish (Figure 2-5); and applying better weld quality control and quality assurance. FEMA 355D (2000) provides extensive information on the testing and performance of the WUF-B connections (pre- and post- Northridge) under seismic loading. 
The WUF-B connections were pre-qualified by FEMA 350 (2000) for use in Ordinary Moment Frames (OMFs). Note that the IMF defined in the AISC Seismic Provisions (2005) is equivalent to the OMF defined in FEMA 350. As such, these connections are also pre-qualified by the AISC Seismic Provisions (2005) for use in IMF. According to the AISC Seismic Provisions (2005), SMF, IMF, and OMF are generally expected to withstand significant (total inter-story drift or rotation in the range of 0.04 radians), limited (total rotation in the range of 0.02 radians), and minimal (total rotation in the range of 0.01 radians) inelastic deformations, respectively, during large seismic events.

The inter-story drift angle or rotation capacity of the WUF-B connection specified in FEMA 350 were based on a statistical analysis of results from cyclic tests of full-scale connection assemblies. The rotation capacity, $\theta_{U}$, corresponding to collapse prevention, characterized by the inability of the connection to maintain its integrity under gravity loading, was estimated for the WUF-B connection as:

$$
\theta_{U}=0.060-0.0006 d_{b}
$$

where $d_{b}$ is the beam depth in inches. The rotation capacity, $\theta_{S D}$, corresponding to initiation of strength degradation, characterized by degradation in connection behavior (e.g., fracture of a weld or a bolt) or framing behavior (e.g., buckling of a beam), was estimated as:

$$
\theta_{S D}=0.031-0.0003 d_{b}
$$

For the W21x73 beam section used with the WUF-B connection in this study, $\theta_{U}=0.047 \mathrm{rad}$ and $\theta_{S D}=$ $0.025 \mathrm{rad}$. The behavior of the WUF-B connections under the monotonic loading conditions expected in disproportionate collapse scenarios, in which connections are subjected to monotonically increasing combined bending and tension, has not been previously studied and is the subject of this report.

In this study, the WUF-B connection was chosen for its popularity, after consulting with several structural engineers in the Atlanta area. Design of the connections followed provisions in the AISC Seismic Provisions and recommendations of FEMA 350. When there was a conflict between these two documents, the requirements of AISC Seismic Provisions were followed. The WUF-B connection used in this study is shown in Figure 2-4. The figure represents both an interior and an exterior connection. In the test specimen (see Chapter 3), exterior connections were used at the end columns and interior connections were used at the center column.

As shown in Figure 2-4, the beam web is connected to the column flange using a shear plate (shear tab), which is fillet welded to the column flange using $5 / 16$ in $(7.94 \mathrm{~mm}$ ) weld (on both sides of the plate) and bolted to the beam web using three 1 in $(25.4 \mathrm{~mm})$ diameter, high strength bolts. The size of the shear tab is $1 / 2$ in $\times 12$ in $\times 6$ in $(12.7 \mathrm{~mm} \times 304.8 \mathrm{~mm} \times 152.4 \mathrm{~mm})$. The bolt holes are standard holes with an edge distance (between the center of the standard hole to the shear plate edge) of 2.75 in $(69.85 \mathrm{~mm})$, resulting in a clear distance (between the edge of the hole and the edge of the shear plate) of 2.25 in $(57.15 \mathrm{~mm})$. The beam flanges are joined to the column flange using complete joint penetration (CJP) groove welds. Weld access holes are cut from the beam flanges per the recommendations of FEMA 350 (2000) as shown in the detail in Figure 2-5. Continuity plates are provided for both interior and exterior columns as shown in Figure 2-4. No doubler plates, however, were required for either column since the shear capacity of the column in the panel zone satisfied the requirements of the AISC LRFD Specification. 


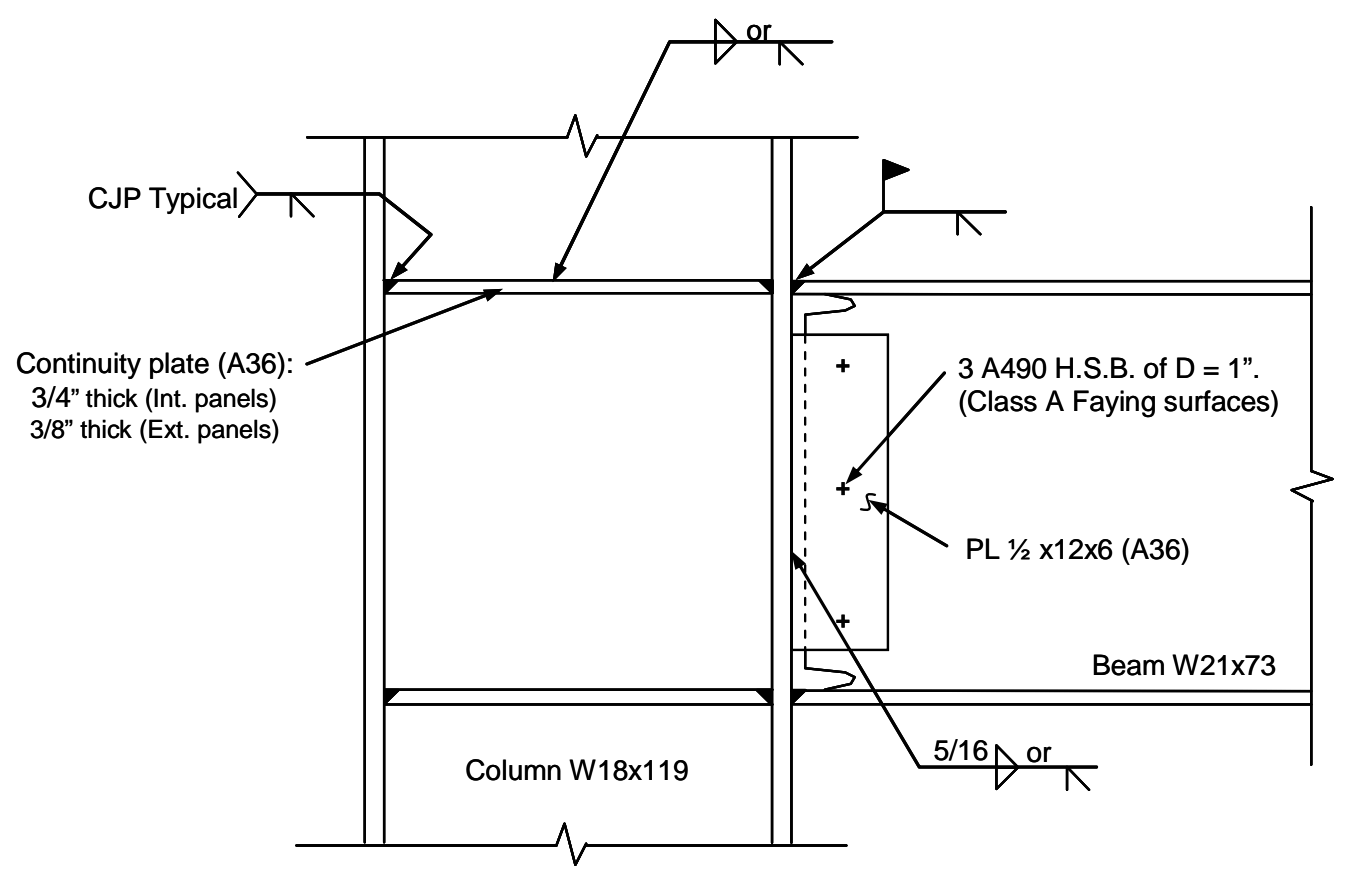

Figure 2-4 WUF-B connection details - N-S frames, second floor of SDC C building

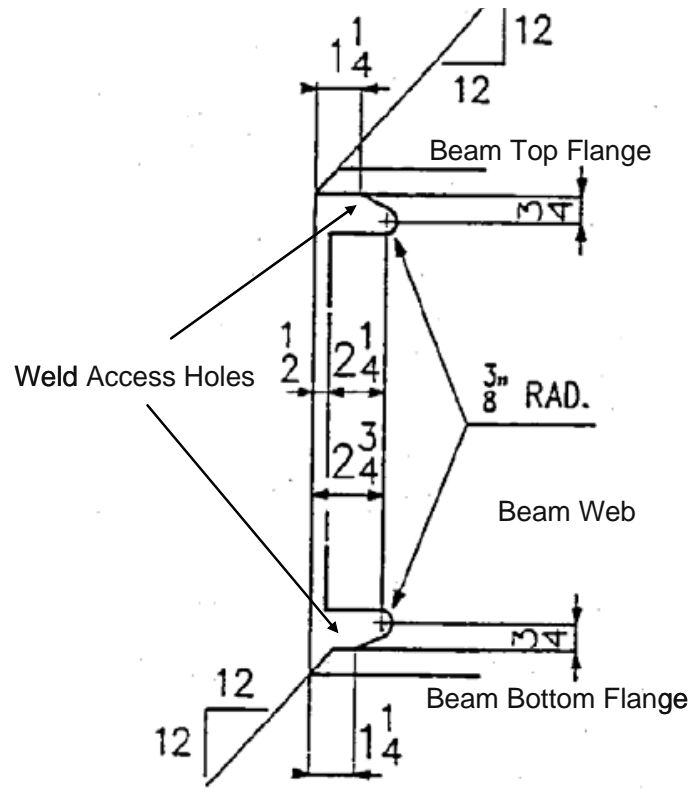

Figure 2-5 Detail of weld access holes for the WUF-B connection

\subsubsection{Reduced Beam Section (RBS) Connection}

The Reduced Beam Section (RBS) connection has been developed as a result of extensive research following the 1994 Northridge earthquake (Chen, 1996, Iwankiw and Carter, 1996, Engelhardt el al., 1996, Engelhardt el al., 1998). The RBS connection is created by cutting away a portion of the top and bottom flanges of the beam at a distance from the beam-column interface so that yielding is concentrated in this reduced area. The reduced section, thus, acts as a fuse to protect the connection against premature 
fracture. Various shapes of the reduced section have been suggested and studied, including straight cut sections, tapered beam sections, and circular radius cuts. Out of the three, the radius cut section was found to yield the most reliable performance. The RBS connection has been commonly used for seismic design since the Northridge earthquake. FEMA 355D (2000) provides extensive information on the testing and performance of the RBS connections under seismic loading.

RBS connections were pre-qualified by FEMA 350 (2000) for use in OMF and SMF. These connections were also pre-qualified by the AISC Seismic Provisions (2005) for use in IMF and SMF. Note that the design of the RBS connections in Liang et al. (2008) specified a bolted single plate shear connection between the beam web and the column per the AISC Seismic Provisions (2002). The latest AISC Seismic Provisions (2005), however, specify that for RBS connections in SMF, the beam web shall be connected to the column flange using a CJP groove weld, extending between the weld access holes. As a result, for the testing and modeling conducted in this study, the connection design in Liang et al. (2008) was modified to meet the requirements of the 2005 edition of the AISC Seismic Provisions.

The inter-story drift angle or rotation capacity of the RBS connection specified in FEMA 350 were based on a statistical analysis of the results from cyclic tests of full-scale connection assemblies. The rotation capacity corresponding to collapse prevention was estimated as:

$$
\theta_{U}=0.080-0.0003 d_{b}
$$

The rotation capacity corresponding to initiation of strength degradation was defined as:

$$
\theta_{S D}=0.060-0.0003 d_{b}
$$

For the W24x94 beam section used with the RBS connection, $\theta_{U}=0.073 \mathrm{rad}$ and $\theta_{S D}=0.053 \mathrm{rad}$. Similar to the WUF-B connection, the behavior of the RBS connection under the monotonic loading conditions expected during disproportionate collapse scenarios has not been previously investigated and is the subject of this report.

In this study, the RBS connection was selected for its popularity and excellent seismic performance, after consulting with several structural engineers in the West Coast. Design of the connections followed provisions in the AISC Seismic Provisions and recommendations of FEMA 350. When there was a conflict between these two documents, the requirements of AISC Seismic Provisions were followed. The RBS connection used in this study is shown in Figure 2-6, after modifying the beam web to column flange connection (see above). The figure represents both an interior and an exterior connection. In the test specimen (see Chapter 3), exterior connections were used at the end columns and interior connection was used at the center column.

As shown in Figure 2-6, the beam flanges and web are connected to the column flange using CJP groove welds. The connections utilize circular radius cuts in both top and bottom flanges of the beam as shown in Figure 2-7. The dimensions of the reduced beam sections are as follows:

$$
\begin{array}{ll}
a \cong 0.55 b_{f} & \text { (limits for } \left.a \cong(0.5 \text { to } 0.75) b_{f}\right) \\
b \cong 0.7 d_{b} & \text { (limits for } \left.b \cong(0.65 \text { to } 0.85) d_{b}\right) \\
c=0.25 b_{f} & \text { (limits for } \left.c \leq 0.25 b_{f}\right)
\end{array}
$$


where $b_{f}$ and $d_{b}$ are the width of the beam flange and the depth of the beam, respectively.

Weld access holes were cut from the beam flanges per the recommendations of FEMA 350 (2000) as shown in the detail in Figure 2-8. Continuity plates are provided for both center and end columns as shown in Figure 2-6. Doubler plates were required only for the center column, based on the design calculations for the shear capacity of the column in the panel zone.

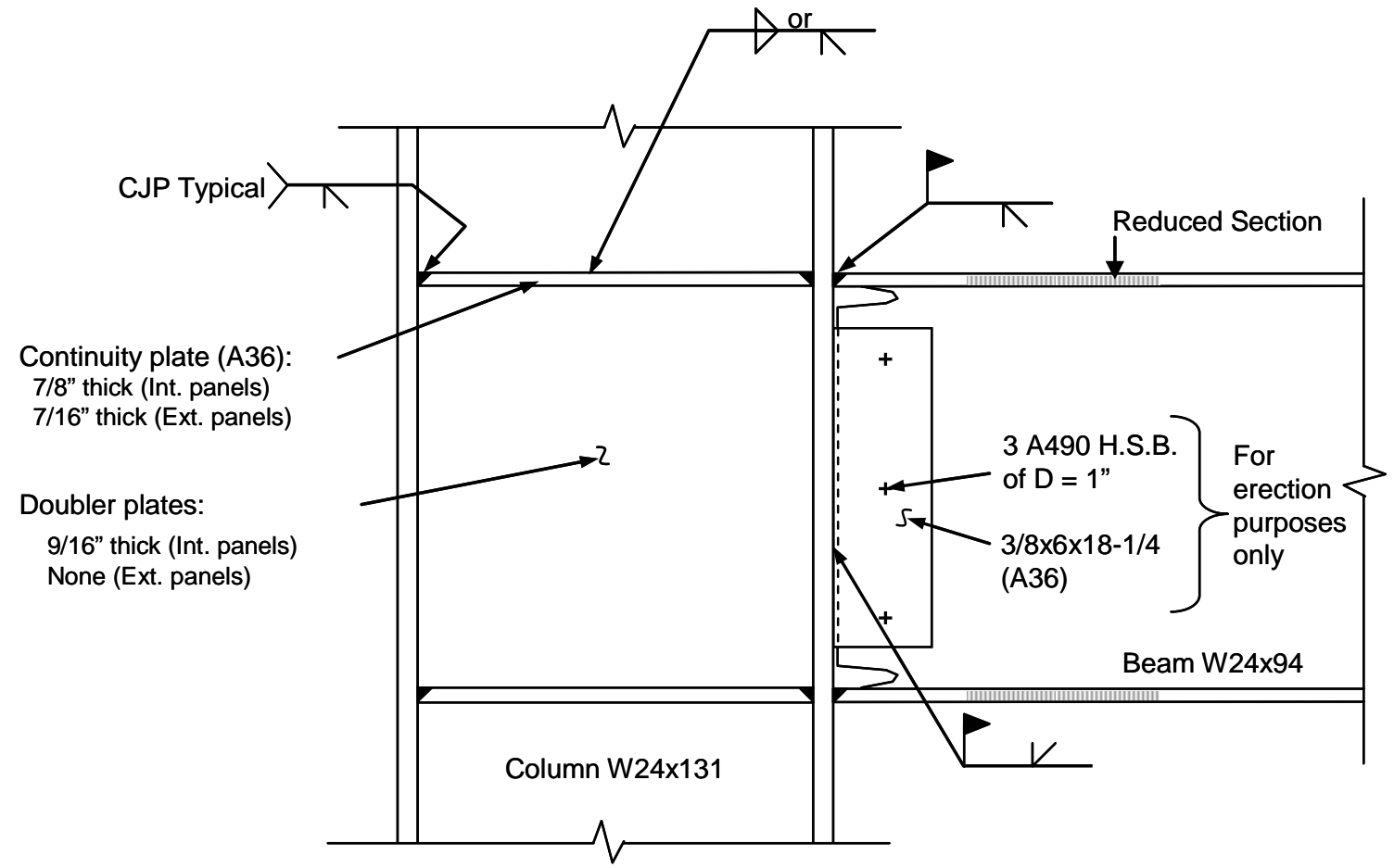

Figure 2-6 RBS connection details - N-S frames, second floor of SDC D building

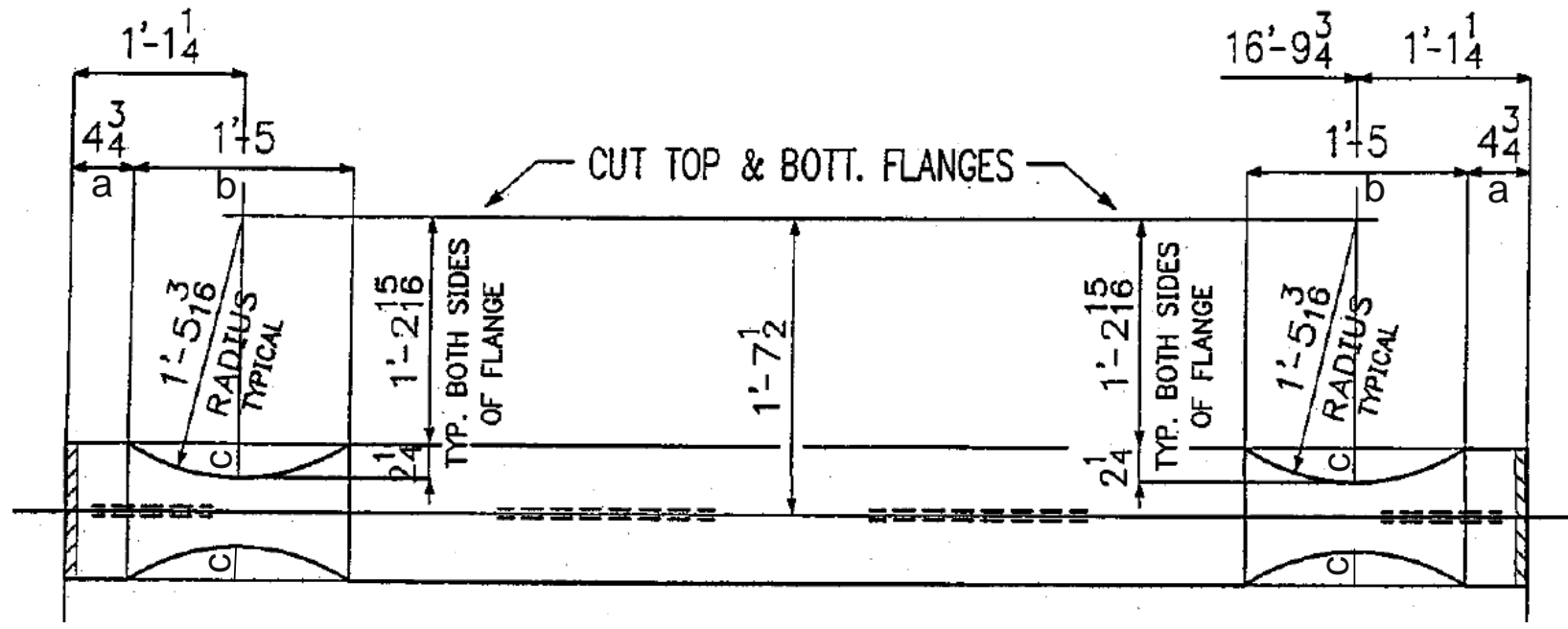

Figure 2-7 RBS connection details - plan view of beam's top and bottom flanges 


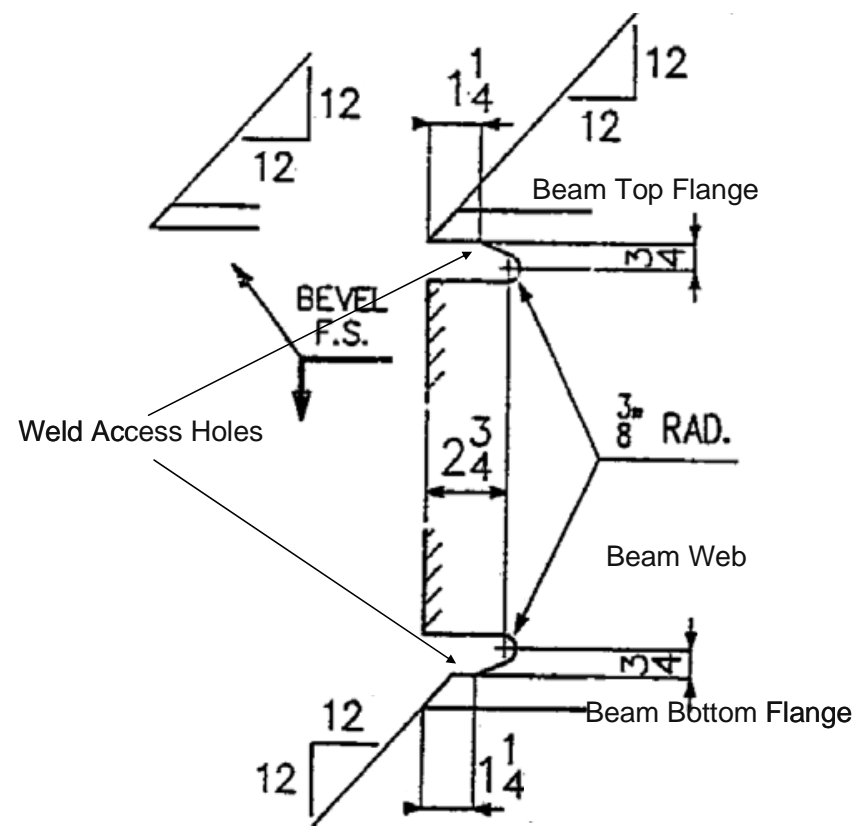

Figure 2-8 Detail of weld access holes for the WUF-B connection

\section{$2.3 \quad$ REFERENCES}

AISC (1999). Load and Resistance Factor Design Specifications for Structural Steel Buildings, American Institute of Steel Construction, Chicago, IL.

AISC (2002). Seismic Provisions for Structural Steel Buildings, American Institute of Steel Construction, Chicago, IL.

AISC (2005). Seismic Provisions for Structural Steel Buildings, Including Supplement No. 1, American Institute of Steel Construction, Chicago, IL.

ASCE (2002). Minimum design loads for buildings and other structures, SEI/ASCE 7-02, American Society of Civil Engineers, Reston, VA.

Chen, S.J., (1996), "A simple and effective retrofit method for steel beam-to-column connections," Seventh US-Japan Workshop on the Improvement of Structural Design and Construction Practices, Applied Technology Council, Redwood City, CA.

Engelhardt, M.D., Winneberger, T., Zekany, A.J., and Potyraj, T.J., (1996), “The dogbone connection: Part II," Modern Steel Construction, 36(8), American Institute of Steel Construction, Chicago, IL.

Engelhardt, M.D., Winneberger, T., Zekany, A.J., and Potyraj, T.J., 1998, "Experimental investigation of dogbone moment connections," Engineering Journal, 35(4), 128-139.

FEMA (2000). Recommended seismic design criteria for new steel moment-frame buildings, FEMA 350, SAC Joint Venture and Federal Emergency Management Agency, Washington, D.C.

FEMA (2000). State of the art report on connection performance, FEMA 355D, SAC Joint Venture and Federal Emergency Management Agency, Washington, D.C.

Iwankiw, N.R., and Carter, C.J., (1996), "The dogbone: A new idea to chew on," Modern Steel Construction, Vol. 36, No. 1, American Institute of Steel Construction, Chicago, IL.

International Code Council (ICC). (2003), International Building Code, Falls Church, VA.

Liang, X., Shen, Q., and Gosh, S. K. (2008), “Assessing ability of seismic structural systems to withstand progressive collapse: Design of steel frame buildings." Report submitted to the Building and Fire Research Laboratory, National Institute of Standards and Technology, Gaithersburg, MD. 


\section{Chapter 3 \\ TEST PROgRam}

\section{$3.1 \quad$ INTRODUCTION}

This chapter describes the overall test program, which includes the design of test specimens, test setup including instrumentation, and test procedure. The primary objectives of these tests are (1) to define the response characteristics of beam-column assemblies under a column removal scenario, including the capacity of the beams and their connections to carry loads through catenary action; and (2) to provide experimental data for validation of beam-column connection models to be used in assessing the robustness of structural systems. The test specimens were beam-column assemblies from the secondfloor framing system of the ten-story buildings described in Chapter 2. Thus, one specimen had WUF-B connections (SDC C building) and the other had RBS connections (SDC D building). Throughout this chapter, the beam-column assembly with the WUF-B connections will be referred to as the WUF-B specimen while the assembly with the RBS connections will be referred to as the RBS specimen.

Section 3.2 presents in detail the description of the test specimens, while Section 3.3 describes the test setup for both specimens including boundary conditions. Section 3.4 describes the loading apparatus and loading sequence, and Section 3.5 presents the instrumentation plan for each of the two tests.

\subsection{TEST SPECIMENS}

Figure 3-1 and Figure 3-2 show layout, member sizes, and beam-to-column connection details for the WUF-B specimen and the RBS specimen, respectively. All beams, columns, and doubler plates were made of ASTM A992 steel. Shear tabs and continuity plates were made of ASTM A36 steel. Note that all three columns of the RBS specimen had 9/16 in $(14 \mathrm{~mm})$ thick doubler plates welded to the column web at the connection, whereas the WUF-B specimen did not have any doubler plates (see Chapter 2). The beam webs of the WUF-B specimen were connected to the shear plate by 1 in diameter ASTM A490 bolts. The beam webs of the RBS specimen and the flanges of the beams of both specimens were welded to the column flanges in accordance with the guides and requirements in the AISC Seismic Provisions in AISC 358-05 (AISC 2005). Note that in Figure 3-2, the 3/8 in (10 mm) plate and the A490 1 in $(25 \mathrm{~mm})$ diameter, high strength bolts were used for erection purposes only. The mechanical properties of the materials used to fabricate the specimens (including yield stress and strain and ultimate stress and strain) were determined by ASTM tensile coupon tests and are given in Table 3-1. Engineering stress and strain values are reported, and the ultimate strain is the strain corresponding to the ultimate stress. Except where indicated, the values shown in the table are averages from three tests. 

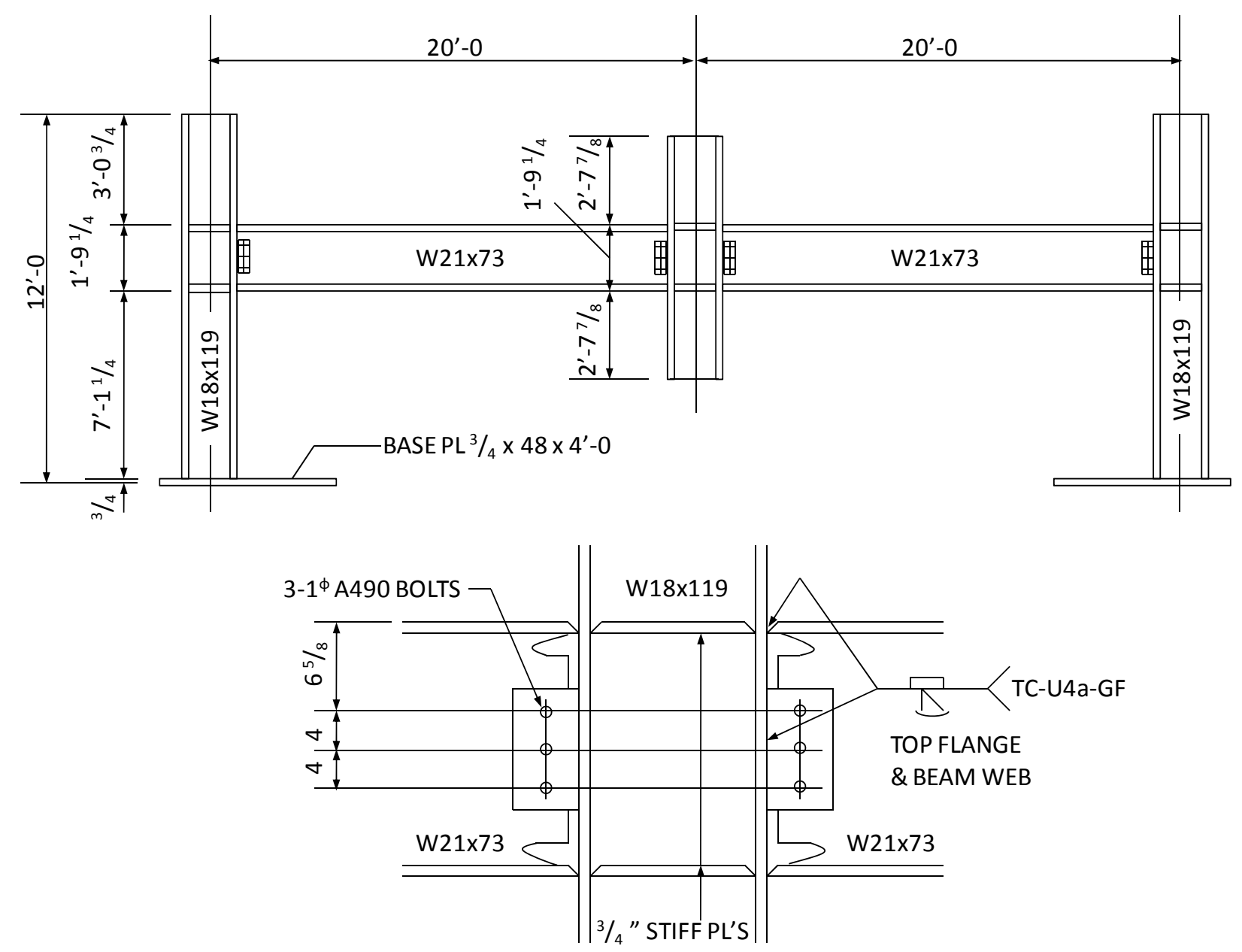

Figure 3-1 Details of WUF-B specimen 

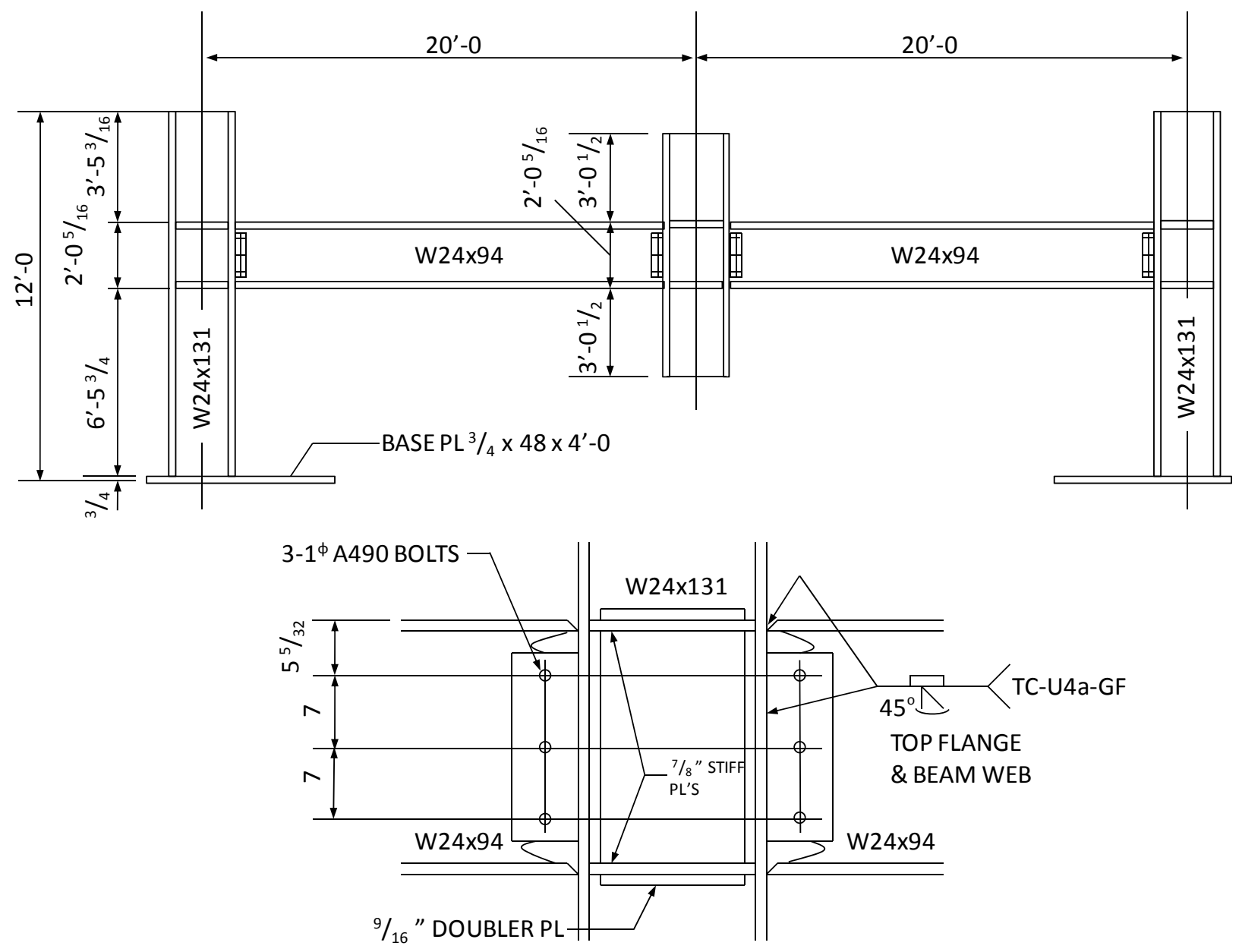

Figure 3-2 Details of RBS specimen 
Table 3-1 Mechanical properties of the steels used to fabricate the specimens

\begin{tabular}{|c|l|c|c|c|c|}
\hline Specimen & \multicolumn{1}{|c|}{ Component } & $\begin{array}{c}\text { Yield Stress } \\
\text { ksi (MPa) }\end{array}$ & $\begin{array}{c}\text { Ultimate Stress } \\
\text { ksi (MPa) }\end{array}$ & Yield Strain * & Ultimate Strain * \\
\hline \multirow{5}{*}{ WUF-B } & Shear tab & $44.9(309)$ & $67.5(465)$ & 0.0016 & 0.183 \\
\cline { 2 - 6 } & Continuity plate & $41.9(288)$ & $65.3(450)$ & 0.0015 & 0.200 \\
\cline { 2 - 6 } & Beam web & $57.3(395)$ & $72.6(500)$ & 0.0019 & 0.189 \\
\cline { 2 - 6 } & Beam flange $\dagger$ & $52.1(359)$ & $72.0(496)$ & 0.0017 & 0.174 \\
\cline { 2 - 6 } & Column $\uparrow$ & $51.2(352)$ & $66.2(456)$ & 0.0018 & 0.190 \\
\hline \multirow{5}{*}{ RBS } & Shear tab & $45.6(317)$ & $65.7(453)$ & 0.0017 & 0.188 \\
\cline { 2 - 6 } & Continuity plate & $40.3(277)$ & $63.5(478)$ & 0.0013 & 0.233 \\
\cline { 2 - 6 } & Doubler plate & $46.2(318)$ & $66.2(457)$ & 0.0016 & 0.180 \\
\cline { 2 - 6 } & Beam web & $66.1(455)$ & $80.4(554)$ & 0.0024 & 0.143 \\
\cline { 2 - 6 } & Column & $54.9(378)$ & $71.6(494)$ & 0.0018 & 0.189 \\
\hline
\end{tabular}

* Strain values reported correspond to a gage length of 2 in $(51 \mathrm{~mm})$.

$\dagger$ Values for the components indicated are averages from two tests; all other values are averages from three tests.

\subsection{TEST SETUP}

A schematic view of the test setup used for both the WUF-B specimen and the RBS specimen is shown in Figure 3-3. For each specimen, the tops of the two end columns were restrained by two diagonal braces for each column, one on each side of the beam. These braces were rigidly attached to the top of the columns and anchored to the strong floor of the test facility. The diagonal braces simulated the bracing effect provided by the upper floors in a multi-story building. A pair of columns straddling each beam at mid-span provided lateral bracing for the beams. Photographs of the loading arrangement and the lateral bracing for the beams at mid-span are shown in Figure 3-4 and Figure 3-5 for the WUF-B specimen and the RBS specimen, respectively. The vertical load was applied to the top of the center stub column by a single hydraulic ram acting through a load cell and a steel plate. The horizontal movements of the steel plate were restrained by four columns positioned at each corner of the plate. These steel columns were welded to base plates and bolted to the test floor. A special roller bearing support arrangement at the four corners of the plate allowed free vertical displacement of the plate along the four columns. The steel plate also restrained the horizontal movements of the top of the center stub column, thereby keeping the applied load in the vertical direction and limiting eccentrically applied loading. A pair of steel plates on each side of the center stub column restrained out-of-plane motion at the lower end of the center stub column. 

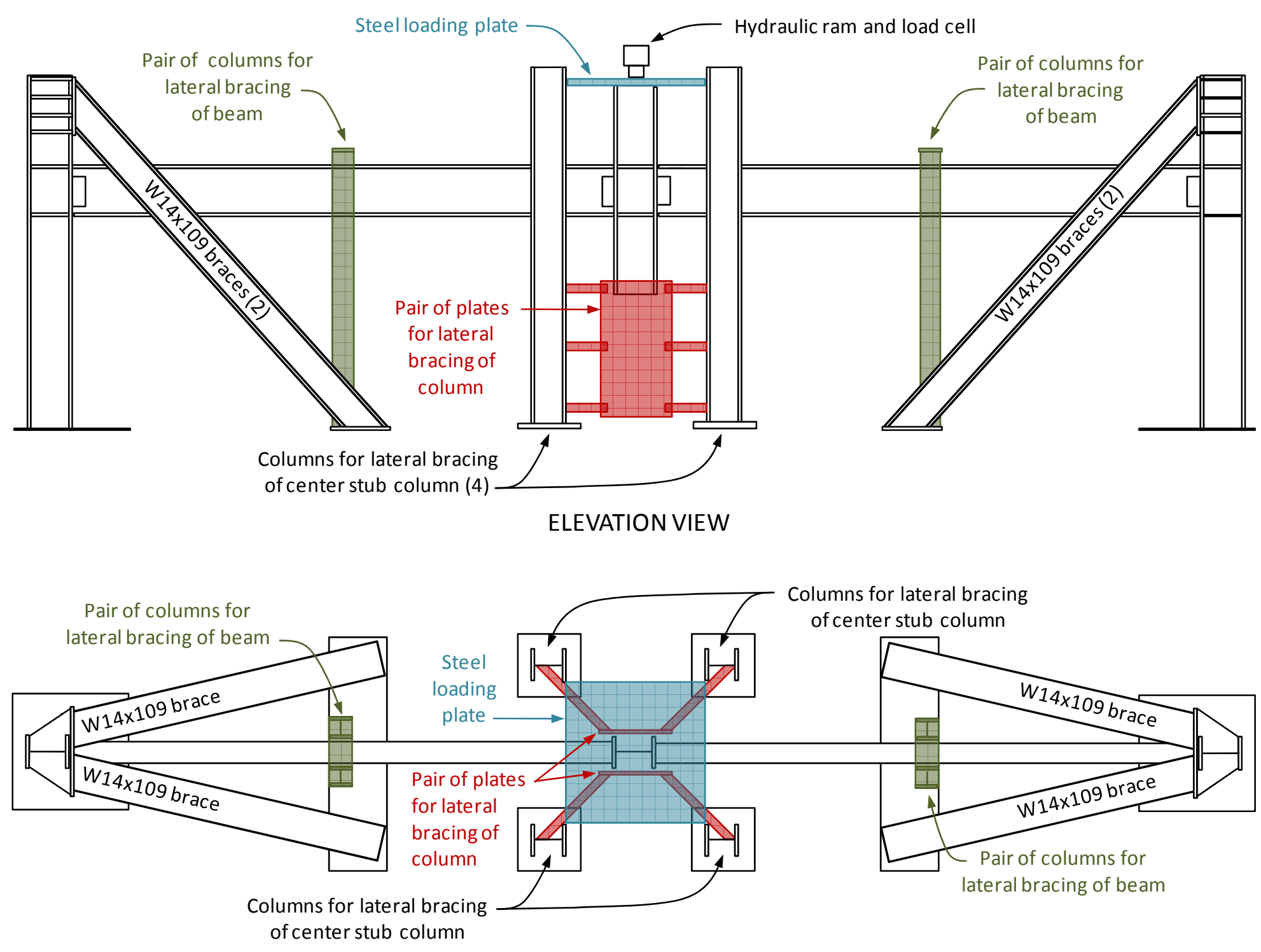

Figure 3-3 Schematic of test setup 


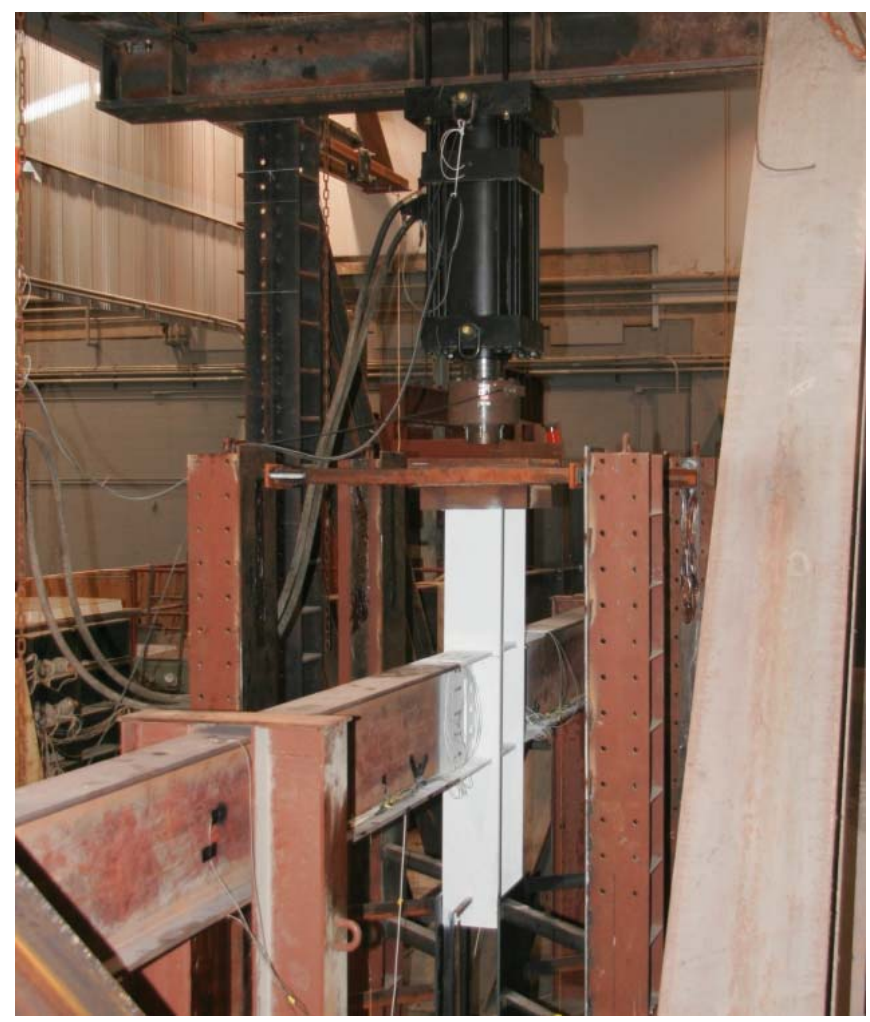

Figure 3-4 Photograph of the WUF-B specimen

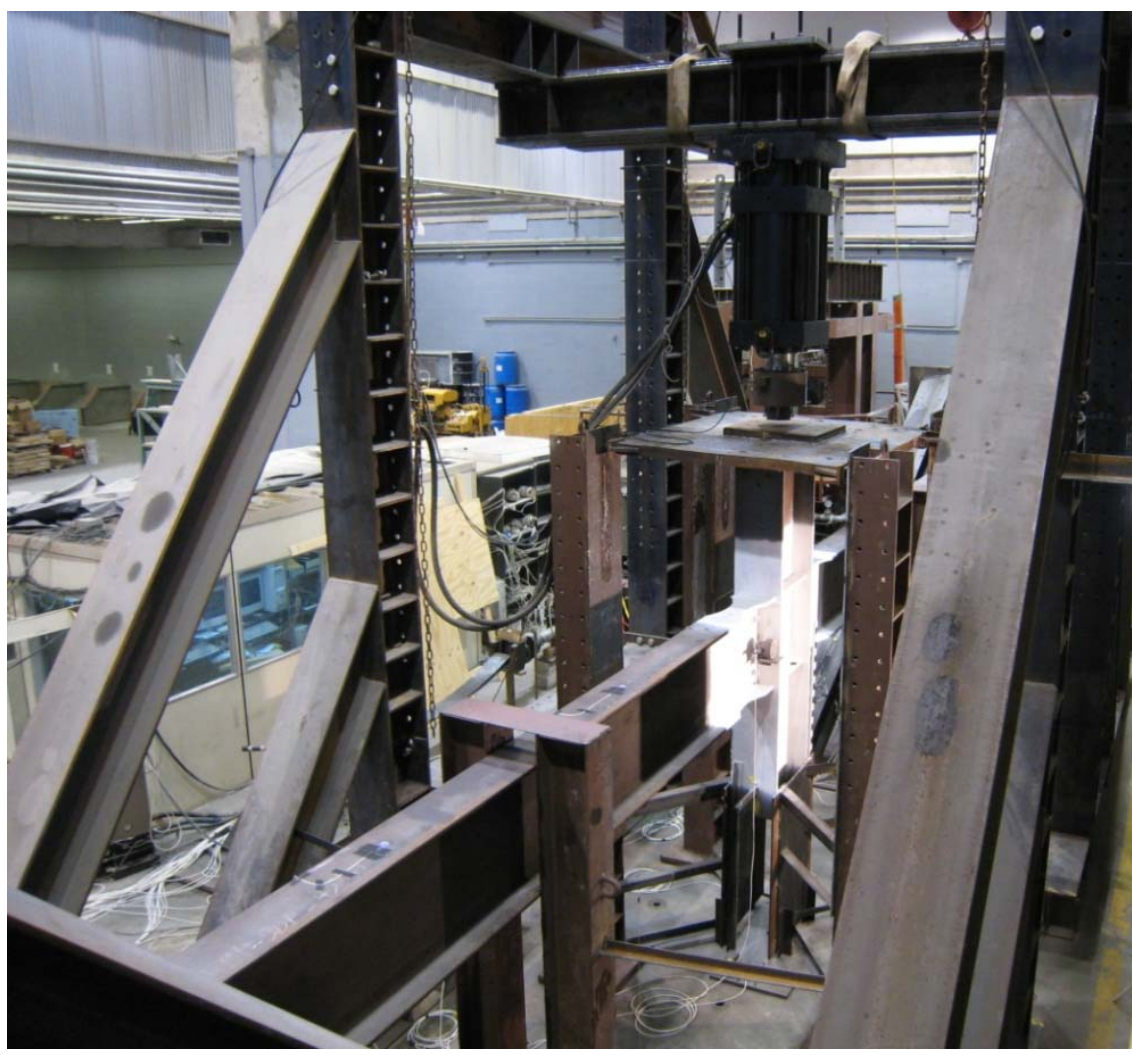

Figure 3-5 Photograph of the RBS specimen 


\subsection{LOADING APARATUS AND TEST SEQUENCE}

A hydraulic ram with a capacity of $600 \mathrm{kip}(2669 \mathrm{kN})$ and a 20 in $(508 \mathrm{~mm})$ stroke was used to apply a vertical downward load to the center column of the test specimens. The load was applied under displacement control at a rate of $1 \mathrm{in} / \mathrm{min}(25 \mathrm{~mm} / \mathrm{min})$.

Pre-test predictions of both the WUF-B and RBS specimens indicated that the stroke capacity of the hydraulic ram was not adequate to accommodate the maximum expected vertical displacement of the center column at failure. To adjust the stroke of the hydraulic ram, the specimen was unloaded when the ram had extended about 18 in $(457 \mathrm{~mm})$. Steel blocks were inserted between the hydraulic ram and the top of the center column, and the specimen was reloaded.

\subsection{INSTRUMENTATION}

Four different types of measurements were taken for each specimen. Figure 3-6 and Figure 3-7 present schematics of the WUF-B and RBS test specimens, respectively, showing the instrumentation layout. The uncertainty in the measured data from the load cells, deflection (D) and strain (S) gages, and inclinometers (I) was within $\pm 1 \%$. In addition to these digital measurements, a high-speed video camera was used to capture the failure sequence of components at the beam-to-column connection zone at the center column. The WUF-B specimen was tested first, and differences between the instrumentation layouts for the RBS specimen (Figure 3-7) and the WUF-B specimen (Figure 3-6) reflect changes made as a result of experience gained from testing of the WUF-B specimen.

\subsubsection{Displacement Transducers}

The center stub column was expected to undergo large displacements of up to 34 in $(860 \mathrm{~mm})$ prior to final failure. To accommodate such large displacements, spring-loaded string-type displacement potentiometers having a 72 in $(1830 \mathrm{~mm})$ range and a 0.001 in $(0.025 \mathrm{~mm})$ accuracy were used. A total of ten potentiometers were used in each test, designated as D1 through D10 in Figure 3-6 and Figure 3-7.

\subsubsection{Inclinometers}

To measure the rotation of the beam ends, digital inclinometers were attached to the beam webs near the column flanges. Figure 3-6 and Figure 3-7 show the locations of four inclinometers designated as I1 through I4. Figure 3-8 shows the general appearance of an inclinometer that was attached to the beam away from the reduced beam section for the RBS specimen. 

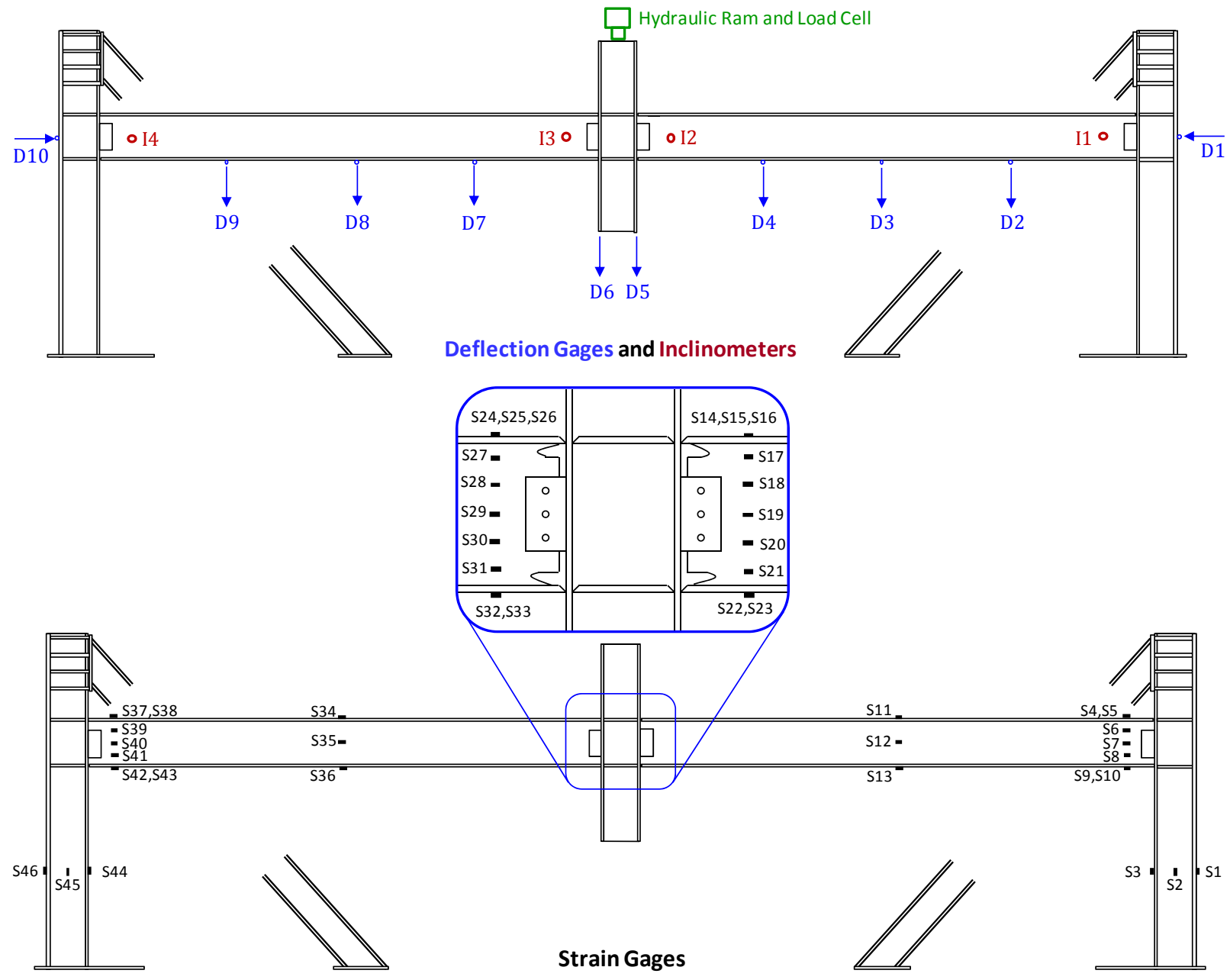

Figure 3-6 Instrumentation layout of the WUF-B specimen 


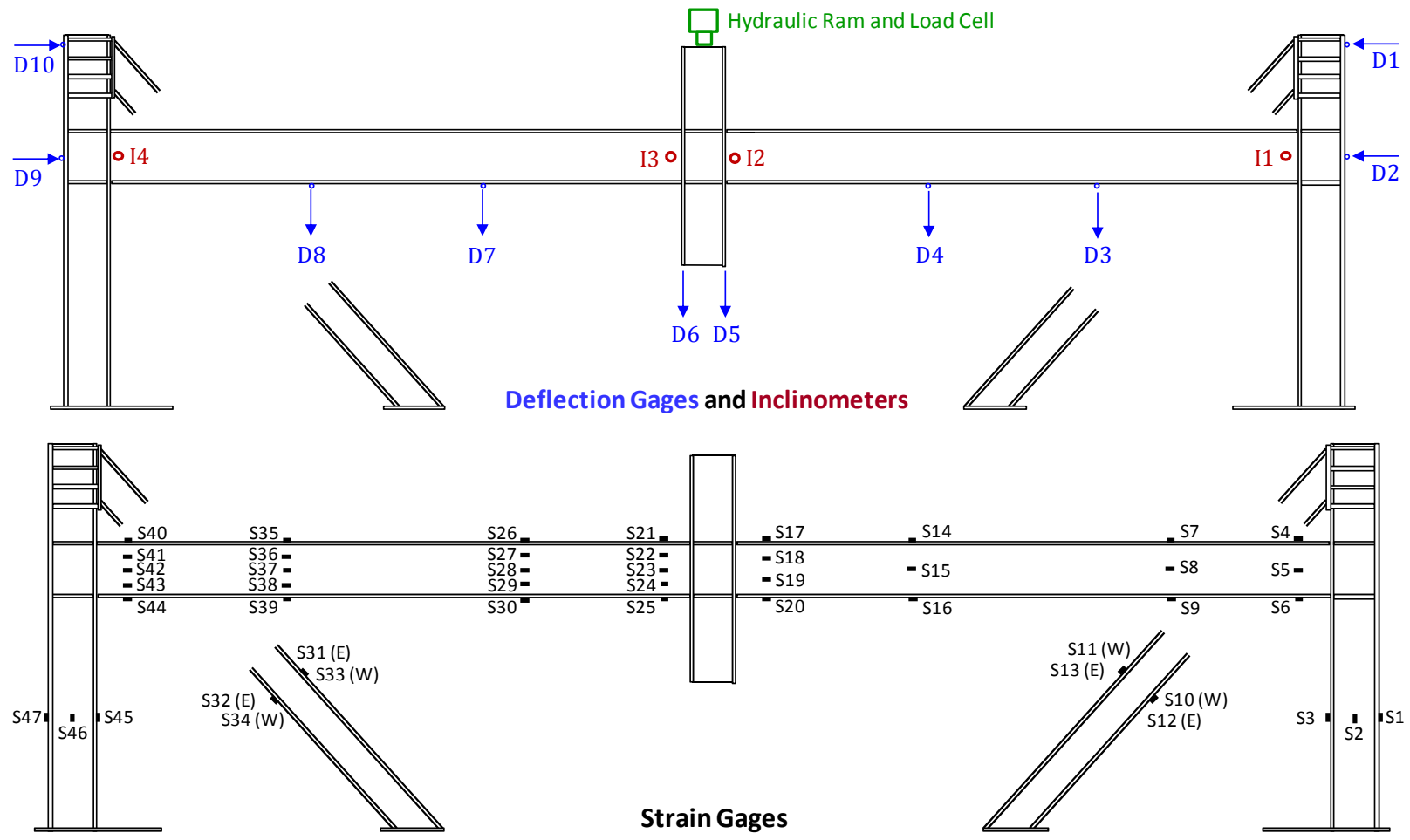

Figure 3-7 Instrumentation layout of the RBS specimen

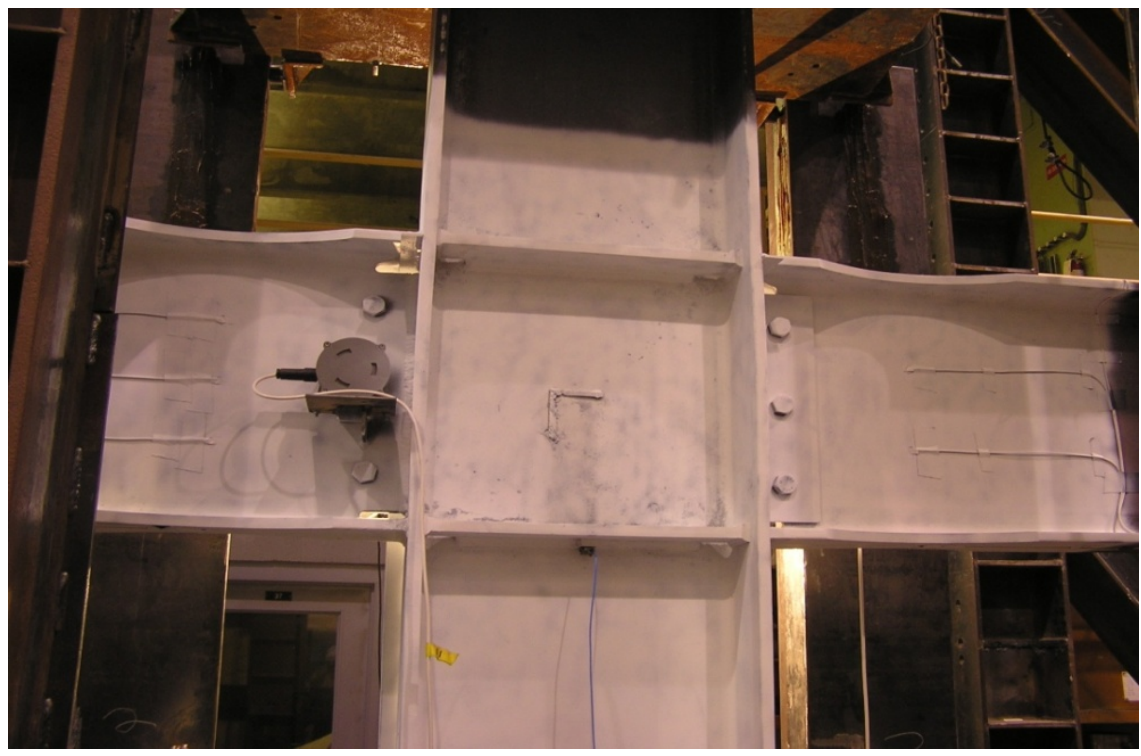

Figure 3-8 Inclinometer attachment to RBS specimen 


\subsubsection{Strain Gages}

A total of 46 and 47 uniaxial strain gages were attached to beam and column surfaces for the WUF-B specimen and the RBS specimen, respectively, to measure strains across the depth of the members. The locations of strain gages are shown in Figure 3-6 and Figure 3-7. The primary purposes of strain measurements were: (1) to compute axial forces in the beams and columns and (2) to observe experimentally the onset of catenary action in the beams. For the RBS test, strain gages were also placed on the diagonal bracing members so that the axial forces in the diagonal bracing members could be determined.

\subsection{REFERENCES}

AISC (2005). Seismic Provisions for Structural Steel Buildings, Including Supplement No. 1, American Institute of Steel Construction, Chicago, IL. 


\section{Chapter 4 \\ EXPERIMENTAL RESULTS}

\subsection{INTRODUCTION}

This chapter presents the test results of both the WUF-B and RBS test specimens, described in Chapter 3. The test results include the observed behavior and failure modes of each specimen, along with the primary response parameters of the test specimens measured during the experiment. Such measurements include vertical and horizontal deflections, rotations of connections at beam ends, and strains and associated forces. The response parameters also include the vertical load applied by the hydraulic ram to the top of the center column, measured using a load cell. Both the observed behavior and the measured response provide insights into the behavior of the specimens prior to and during the failure process. Sections 4.2 and 4.3 provide experimental results obtained from the WUF-B and RBS specimens, respectively, while Section 4.4 presents a summary and discussion of the test results.

\subsection{WUF-B SPECIMEN}

\subsubsection{Observed Behavior and Failure Modes}

Under monotonic vertical displacement of the center column, the WUF-B specimen experienced large deflections and rotations prior to failure (Figure 4-1). A WUF-B connection to the center column failed at a vertical displacement of the center column of about 19.5 in $(495 \mathrm{~mm})$, with a corresponding beam chord rotation of about $0.081 \mathrm{rad}$, obtained by dividing the center column displacement at failure by the centerline-to-centerline beam span of 240.0 in $(6096 \mathrm{~mm})$. At that displacement, the applied vertical load was about $200 \mathrm{kip}(890 \mathrm{kN})$. The failure was characterized by the following sequence (see Figure 4-2): (1) local buckling of the top flanges of the beams near the center column, (2) successive shear failure of the lowest and middle bolts connecting the beam web to a shear tab at the center column, and (3) fracture of the bottom flange near the weld access hole. 


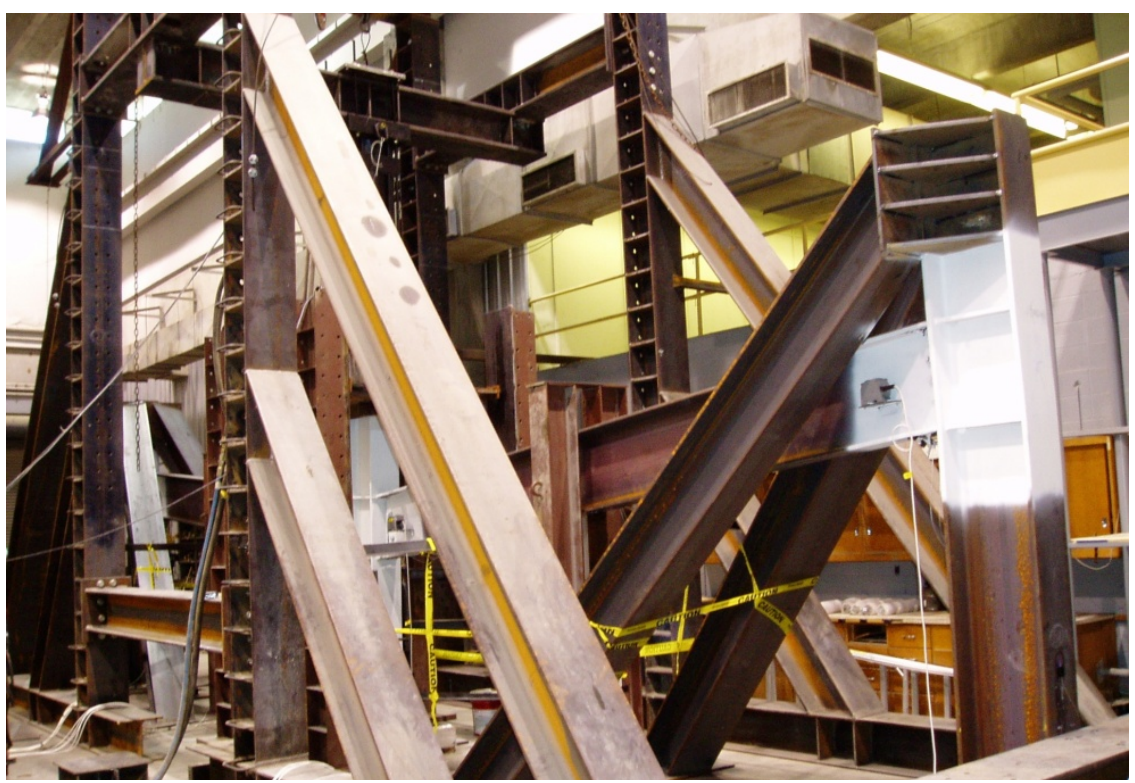

Figure 4-1 Overall view of the WUF-B specimen subjected to large displacements
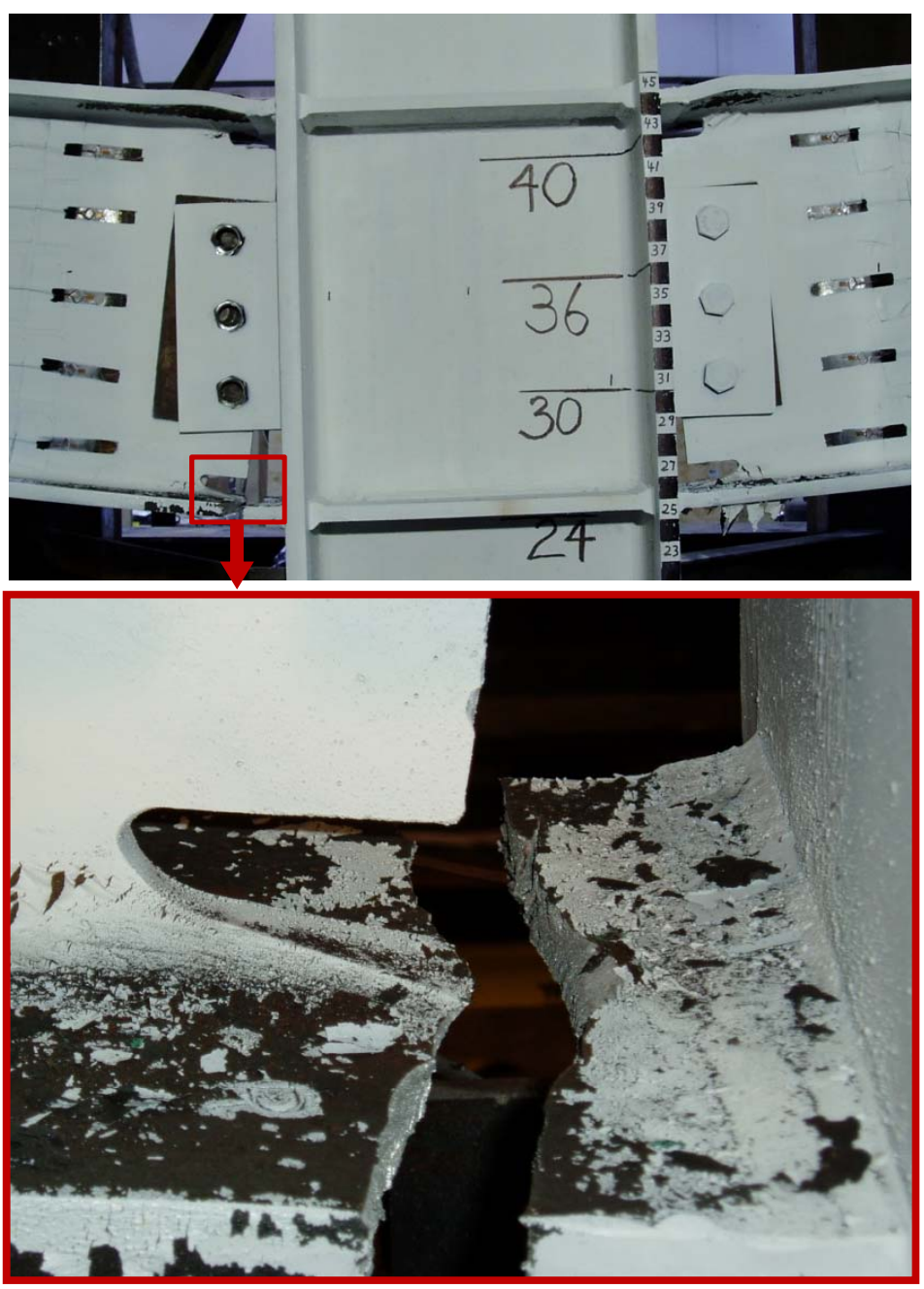

Figure 4-2 Failure mode of the WUF-B specimen 


\subsubsection{Displacement Measurements}

The plots in Figure 4-3 show the vertical load versus vertical displacements at (a) 1/4 span of the beams (D2 and D9), (b) 1/2 span of the beams (D3 and D8), (c) 3/4 span of the beams (D4 and D7), and (d) the center column (D5 and D6). The locations of the displacement transducers were shown in Figure 3-6. As the plots indicate, the specimen was unloaded at a vertical displacement of the center column of about 18 in $(457 \mathrm{~mm})$ to adjust the stroke of the hydraulic ram and was then reloaded again to failure (see Chapter 3). Figure 4-3(d) indicates that the assembly remained in the elastic range up to a vertical displacement of the center column of about 2 in $(50 \mathrm{~mm})$. With increased vertical displacement, the assembly behaved nonlinearly. The specimen failed at a vertical displacement of the center column of about 19.5 in $(495 \mathrm{~mm})$. The pairs of load deformation curves were nearly the same in each of the four plots in Figure 4-3 which indicate that symmetry was largely maintained during the experiment. In subsequent plots, the average of D5 and D6 is used to represent the vertical displacement of the center column.

Figure 4-4 depicts the displacement profile of the beams (D2 through D9) at different load values. The figure shows that at each level of loading, the displacement profile of each beam can be approximated by a straight line, which indicates the formation of plastic hinges at the WUF-B beam-to-column connections.

Figure 4-5 shows the horizontal displacement of the end columns at beam mid-height (D1 and D10) versus the vertical displacement at the center column (average of D5 and D6). In the plot, positive values signify an inward displacement. The figure indicates that displacement transducer D10 showed an initial outward displacement followed by an inward displacement as the behavior became dominated by tensile forces in the beam (catenary behavior). Displacement transducer D1, however, maintained an inward displacement throughout the initial (behavior dominated by flexure) and later (behavior dominated by tensile forces or catenary behavior) portions of the response. This difference seems to violate the symmetric characteristics of the response. The reason for this difference appears to be a slight rigid-body rotation of the specimen at the early stages of loading, possibly due to some slip in one of the connections of a diagonal brace or column end. To adjust the deformations for this effect, the average of the two horizontal displacement measurements (D1 and D10) was calculated and plotted in Figure 4-5 to be representative of the inward displacement of the end columns at beam mid-height. This average will be used for comparison with the computational modeling results in Chapter 5. 
(a)

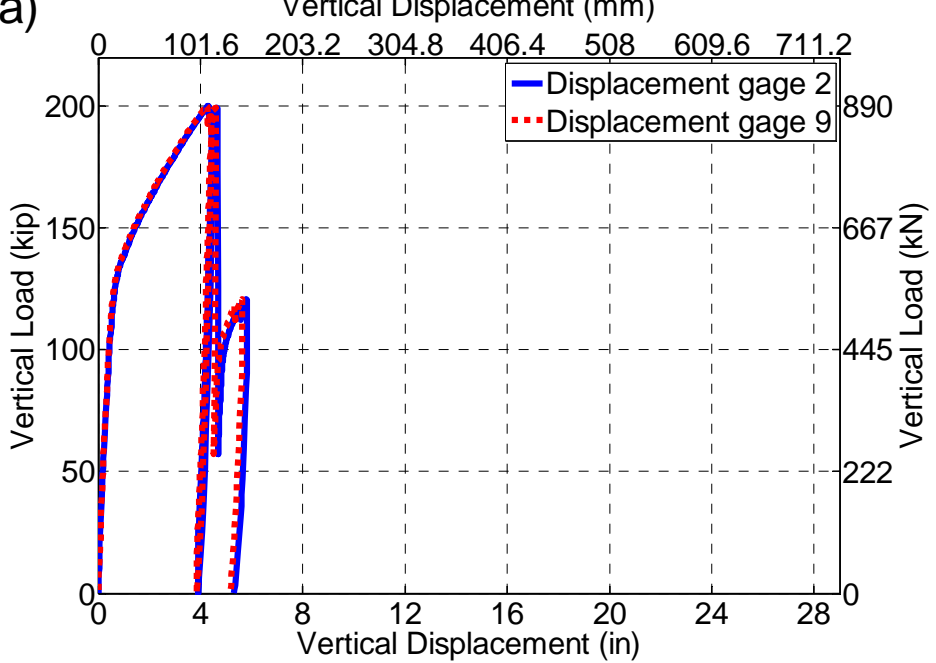

(c)

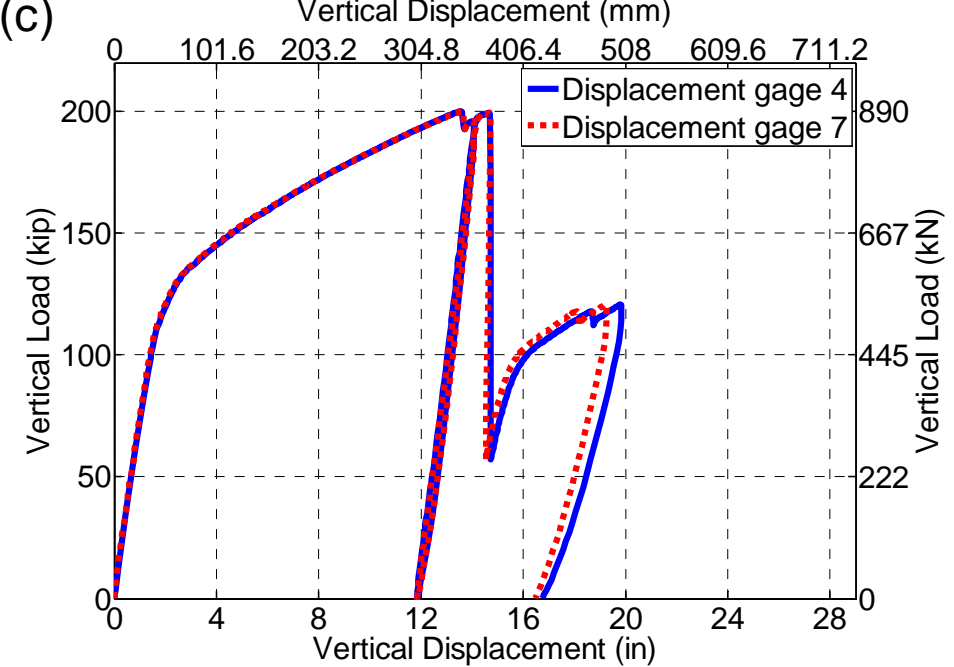

(b) Vertical Displacement $(\mathrm{mm})$

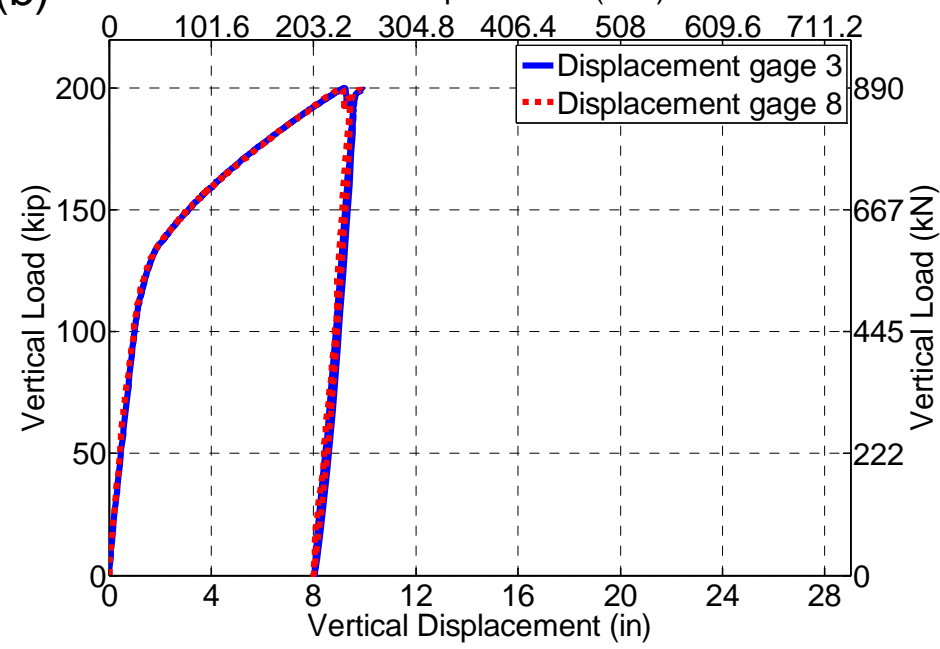

(d)

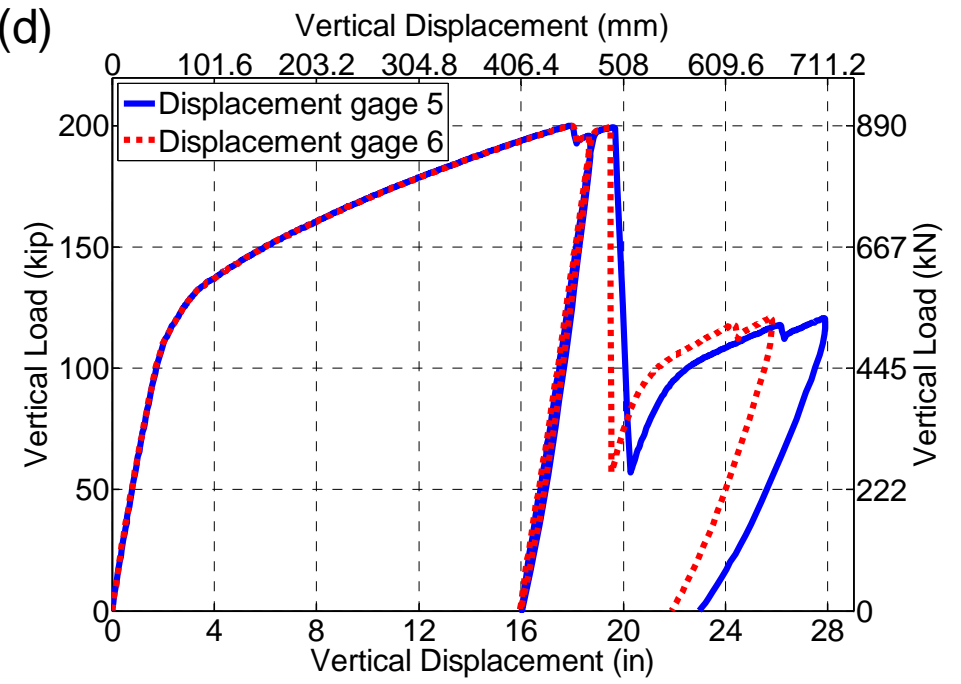

Figure 4-3 Applied vertical load versus vertical displacements at (a) 1/4 span of beams (D2 and D9), (b) 1/2 span of beams (D3 and D8), (c) 3/4 span of beams (D4 and D7), and (d) center column (D5 and D6) for the WUF-B specimen 


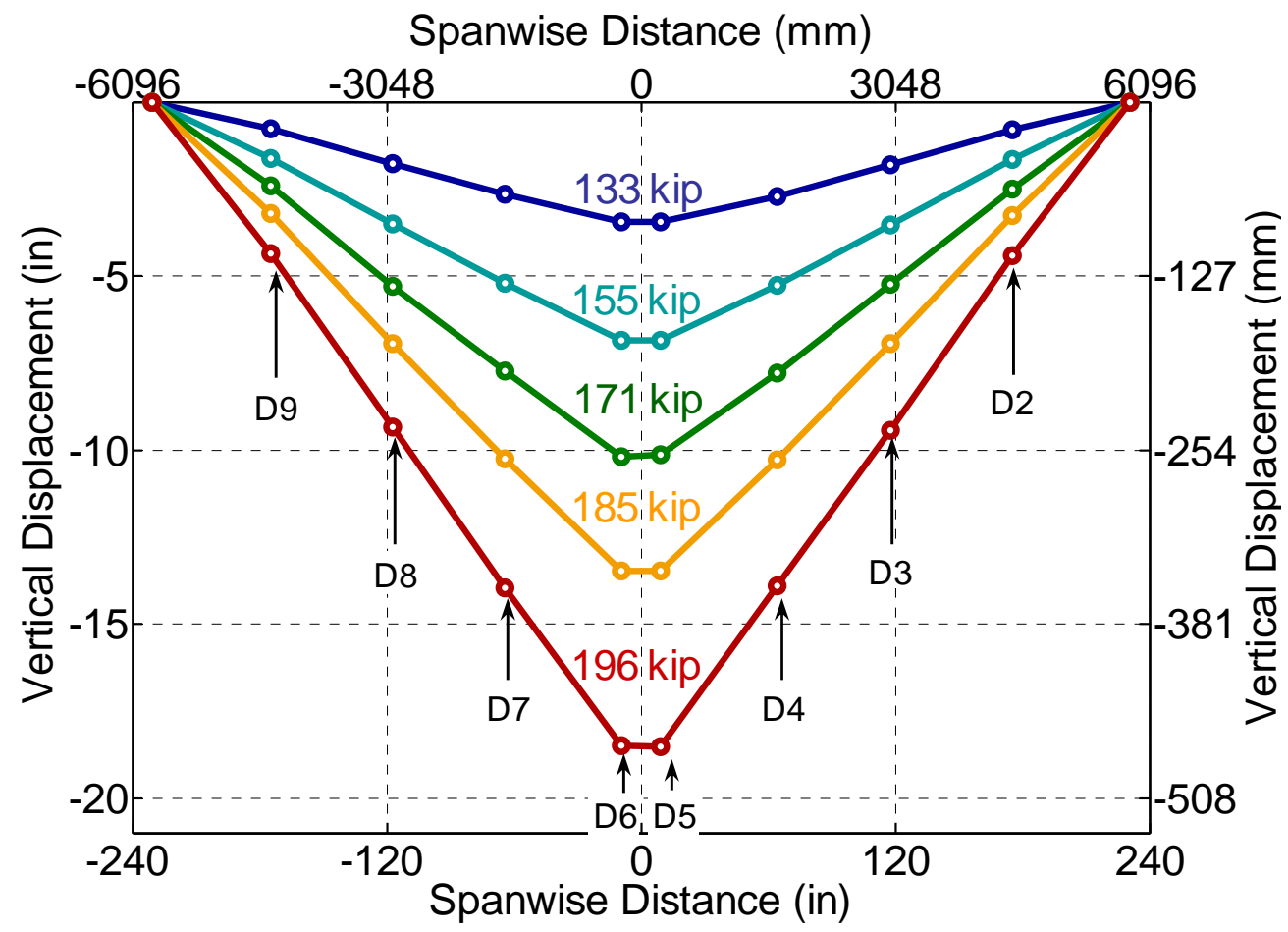

Figure 4-4 Vertical displacement profiles of beams corresponding to indicated vertical loads for the WUF-B specimen (displacements magnified)

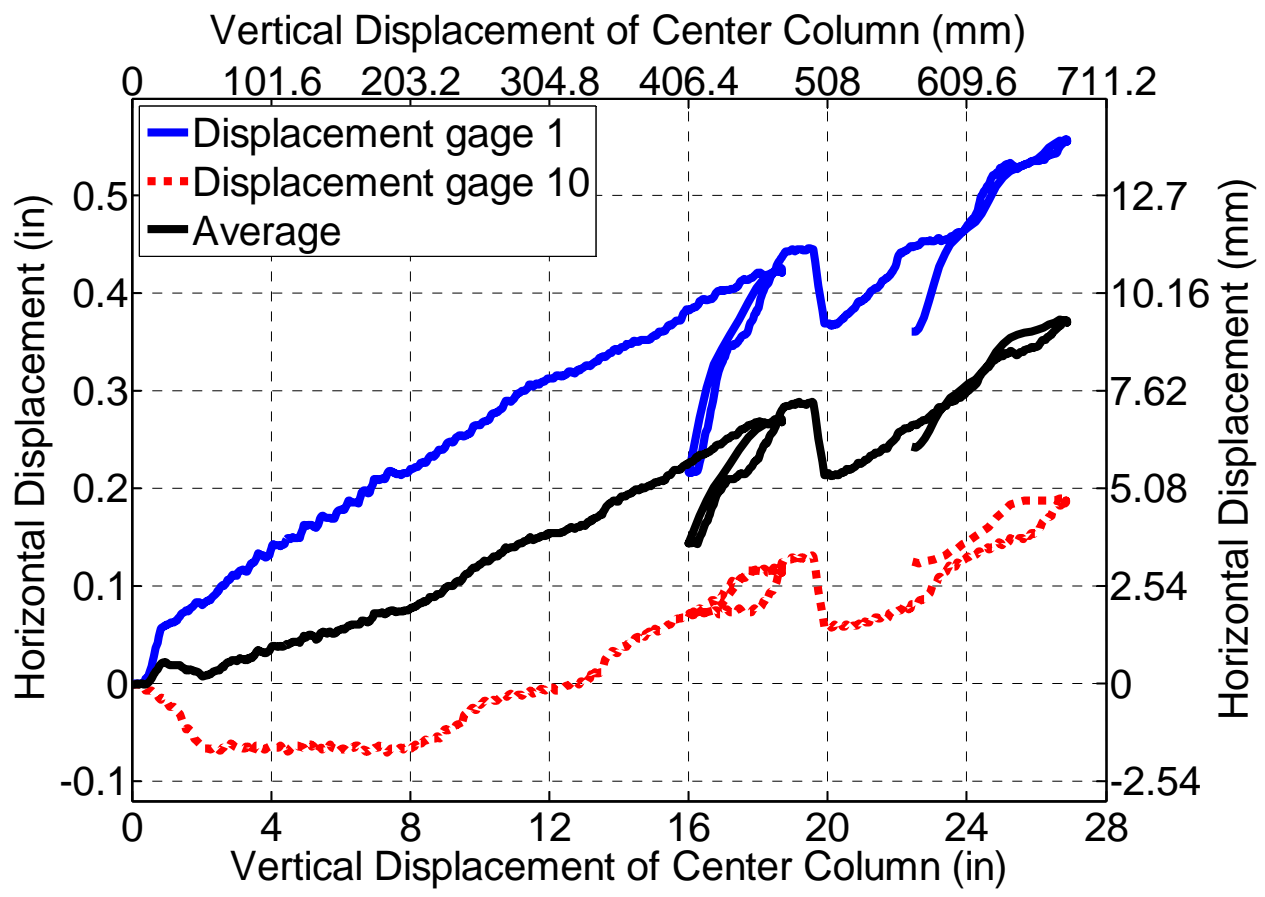

Figure 4-5 Horizontal displacement of end columns at beam mid-height (D1, D10, and their average) versus vertical displacement of center column for the WUF-B specimen 


\subsubsection{Rotation Measurements}

Figure 4-6 shows plots of the vertical load versus the four inclinometer measurements (I1 and I4 for connections to end columns and I2 and I3 for connections to the center column, as shown in Figure 3-6), representing angle of rotation in the vicinity of the WUF-B connections. The plots indicate that the specimen remained in the elastic range up to a rotation of about $0.5^{\circ}(0.01 \mathrm{rad})$ and that the rotation at failure (peak load) was about $4.5^{\circ}(0.088 \mathrm{rad})$. Figure $4-7$ presents the beam angle of rotation versus the vertical displacement of the center column. This figure shows that the rotations were essentially linearly proportional to the vertical displacement of the center column up to the failure of the connection at a displacement of $19.5 \mathrm{in}(495 \mathrm{~mm})$. This is due to the formation of plastic hinges at the beam-to-column connections that allowed rotation of the beam at those locations.
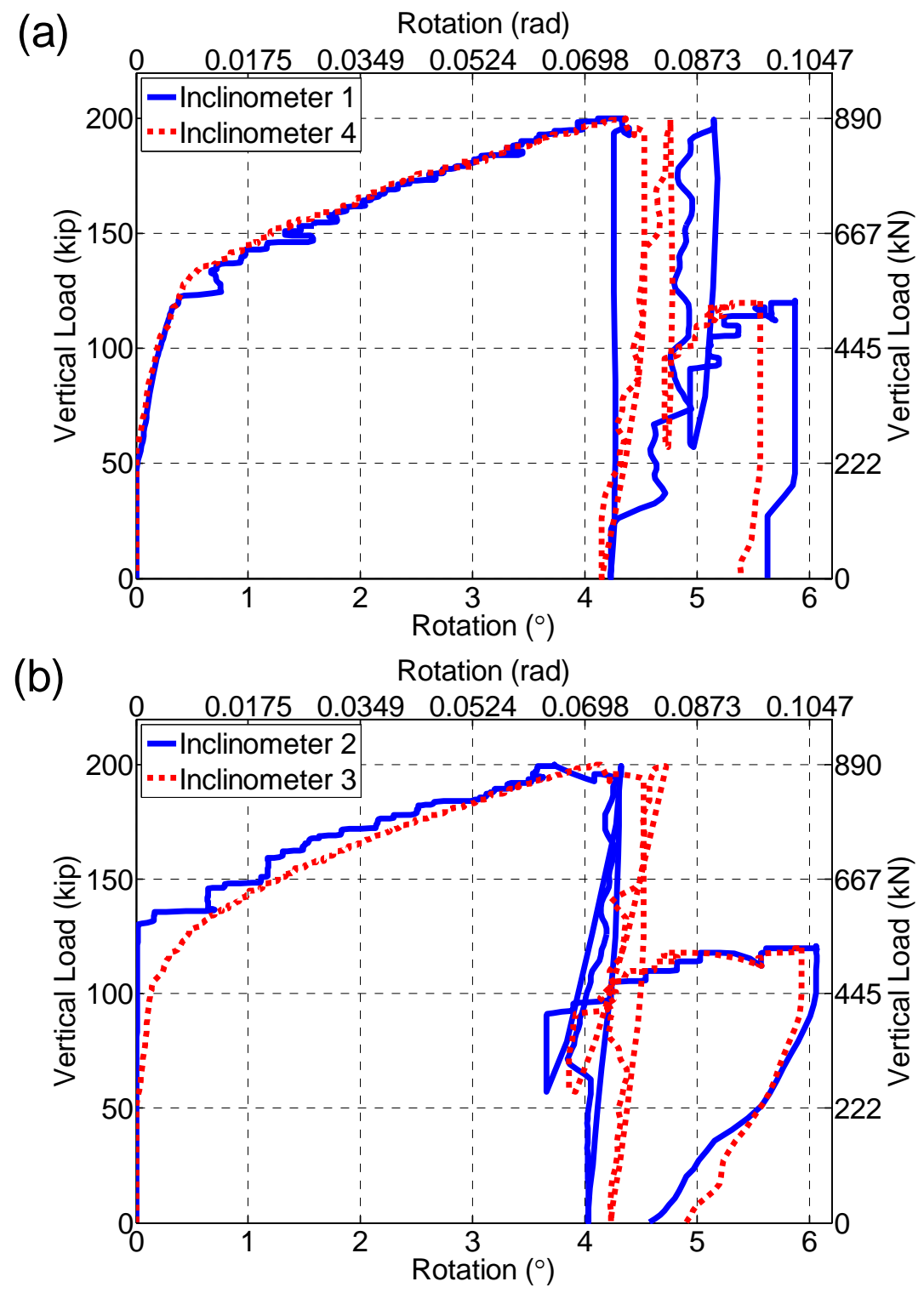

Figure 4-6 Applied vertical load versus angles of rotation at (a) connections to end columns and (b) connections to center column for the WUF-B specimen 
(a)

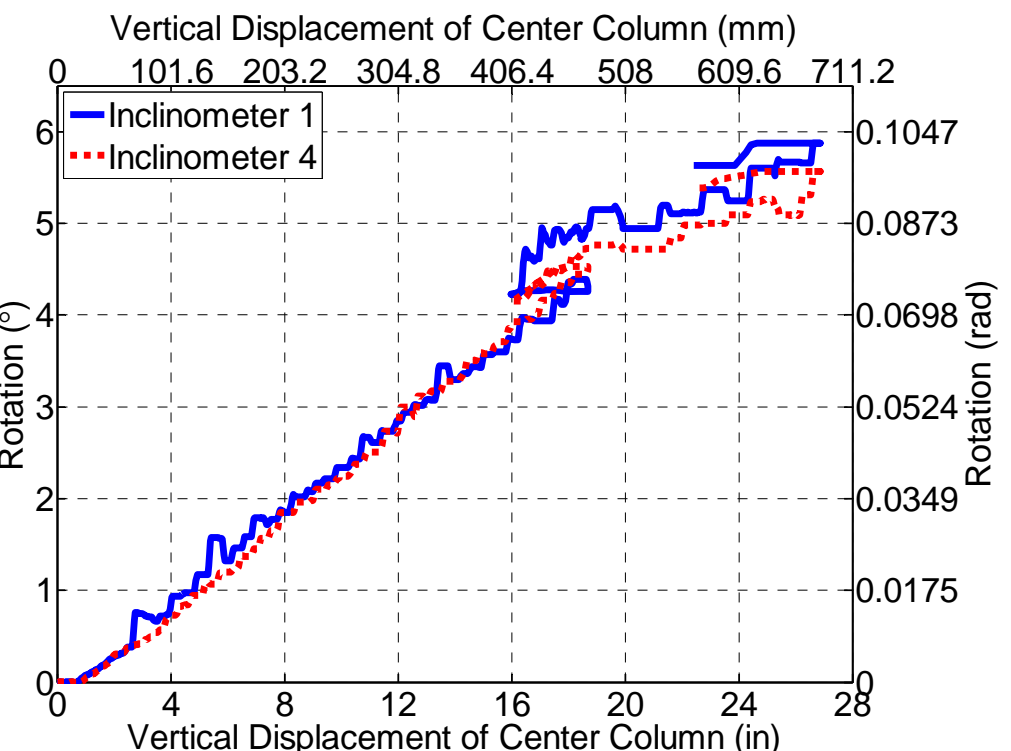

(b)

Vertical Displacement of Center Column ( $\mathrm{mm}$ )

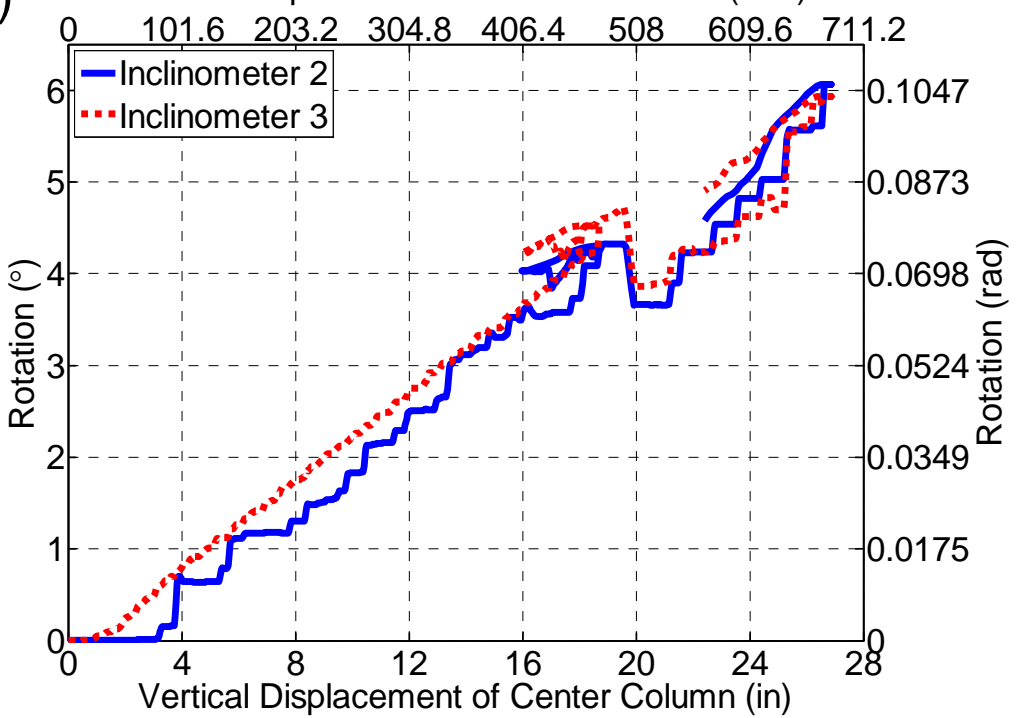

Figure 4-7 Angle of rotation at (a) connections to end columns and (b) connections to center column versus vertical displacement of center column for the WUF-B specimen

\subsubsection{Strain Measurements}

The strain gages were located at eight cross sections, which are labeled in Figure 4-8. Gages at Sections $\mathrm{B} 2$ and $\mathrm{B} 5$ provide information about the strains at mid-span of the beams, which was used to estimate the axial force in the beams. Gages at Sections B1, B3, B4, and B5 provide the strain distribution along the beam height in the vicinity of the connections. Gages at Sections $\mathrm{C} 1$ and $\mathrm{C} 2$ provide information about the strains in the end columns, which was used to estimate the axial force in the end columns. 


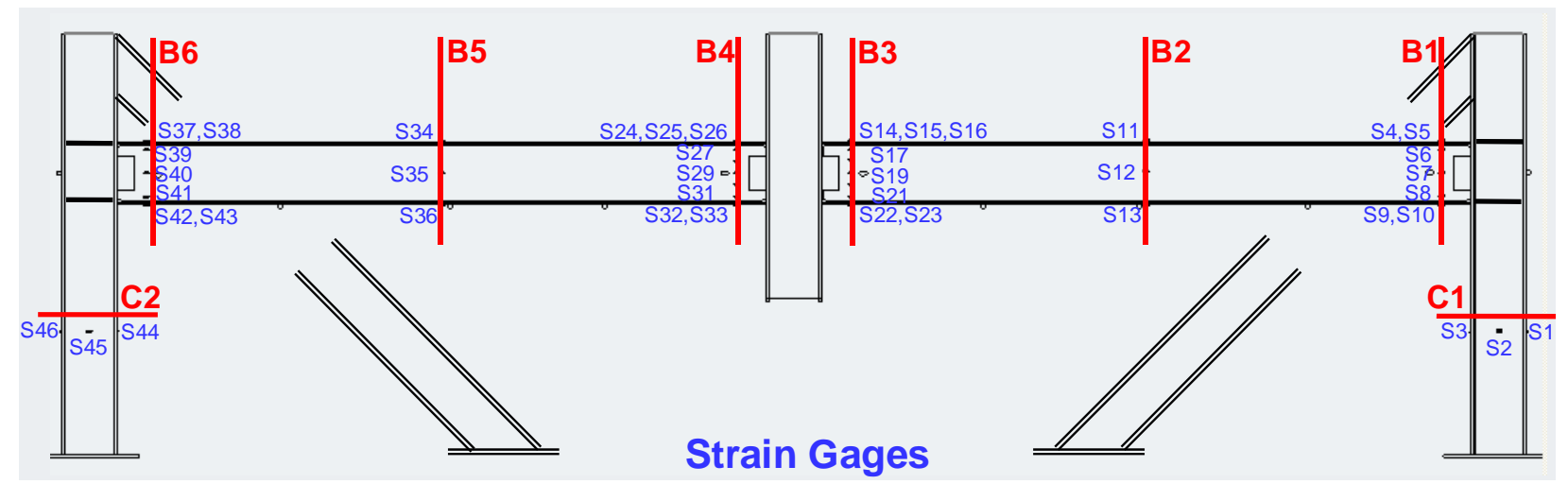

Figure 4-8 Locations of cross sections with strain gages for the WUF-B specimen

Figure 4-9 depicts the strain gage measurements at (a) Section B2 (S11, S12, and S13) and (b) Section B5 (S34, S35, and S36) versus the vertical displacement of the center column. Strain gage S11 malfunctioned during the experiment and did not provide meaningful data. The plots in Figure 4-9 show that all strains at Sections B2 and B5 were significantly less than the nominal yield strain of the steel $\left(0.2 \%\right.$ or $\left.2 \times 10^{-3}\right)$, indicating that at mid-span the beam remained in the elastic range throughout the loading scenario.

From Figure 4-9(b), it can be observed that the beam initially behaved primarily in bending up to a center column displacement of slightly less than 2 in $(51 \mathrm{~mm})$, with the top flange (S34) in compression, the bottom flange in tension (S36), and the neutral axis located approximately at mid-height of the web (S35). At a center column displacement of about 3 in $(76 \mathrm{~mm})$, the beam section at mid-span experienced very small bending moment and axial forces due to the development of negative and positive plastic moments with approximately the same magnitude (associated with the formation of plastic hinges) at the WUF-B connections to the end column and the center column, respectively. Beyond 3 in $(76 \mathrm{~mm})$ of center column displacement, the beam section at mid-span was subjected primarily to axial tension, while the bending moment effects at this cross section continued to be relatively small. The tensile strains in the beam increased with increased center column vertical displacement until the connection at the center column failed. Similar behavior can be observed for Section B2, Figure 4-9 (a), albeit without the strain data for S11.

Figure 4-10 presents the average strains in Section B5, computed as the average of the strain measurement at the top and bottom flanges (B34 and B36, respectively). The figure also shows the average strains in Section B2, estimated as the strain measurement at web mid-height (S12) due to the lack of meaningful data from the strain gage at the top flange (S11). Both average strains are plotted versus the vertical displacement of the center column. The figure shows good agreement between the average strains at the mid-span of each beam. These strains were used to calculate the axial force in the beams. The axial force in the beams versus the vertical displacement of the center column is presented in Figure 4-11. It can be observed that in the early stages of the response, the behavior was dominated by flexure, indicated by the slight compressive axial force in the beams. With increased vertical displacement, tensile axial forces developed in the beams and the behavior was dominated by catenary action. At the time of failure, the axial tension in the beams was slightly greater than $150 \mathrm{kip}(667 \mathrm{kN})$. 

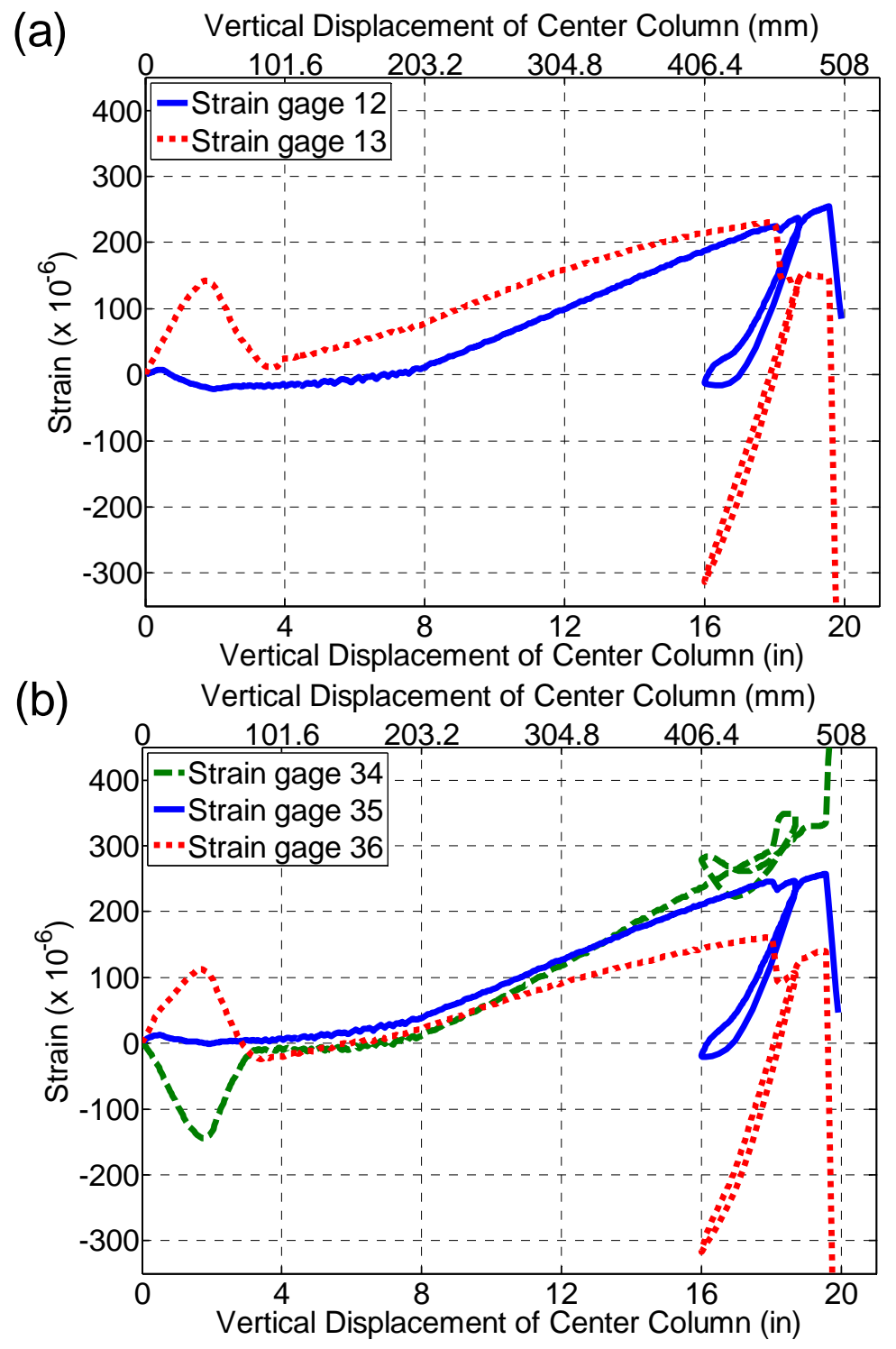

Figure 4-9 Mid-span strain gage measurements at (a) Section B2 and (b) Section B5 versus vertical displacement of center column for the WUF-B specimen 


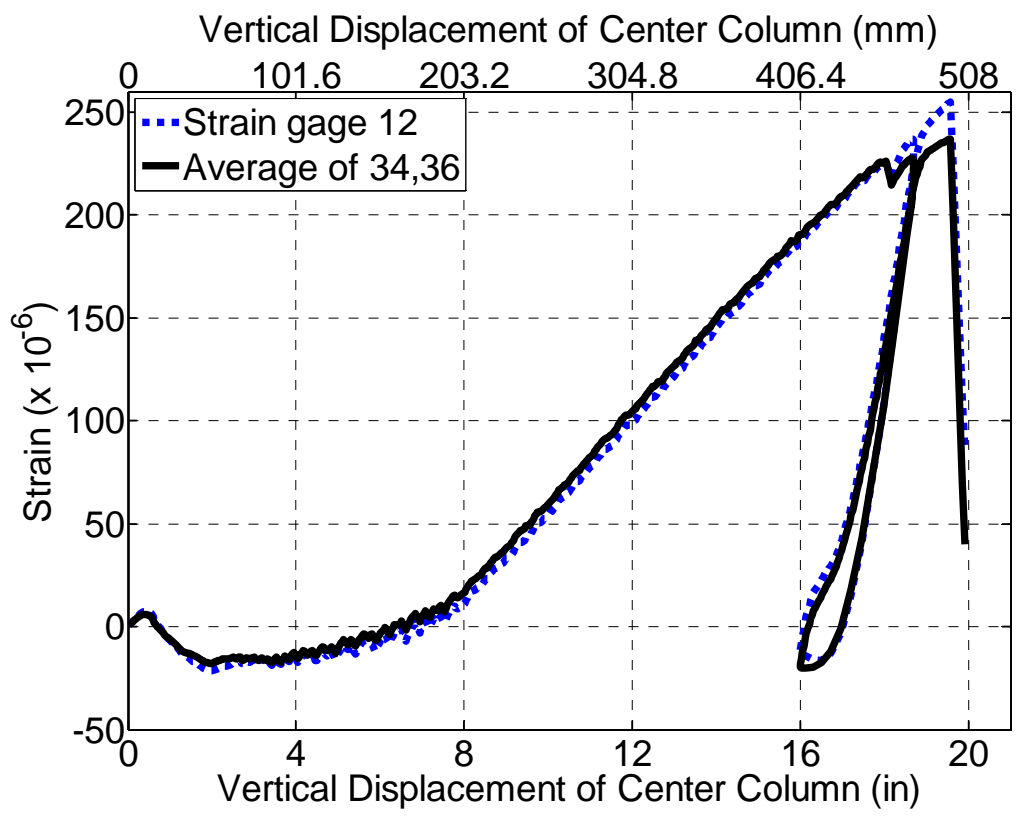

Figure 4-10 Average strains at Sections B2 and B5 versus vertical displacement of center column for the WUF-B specimen

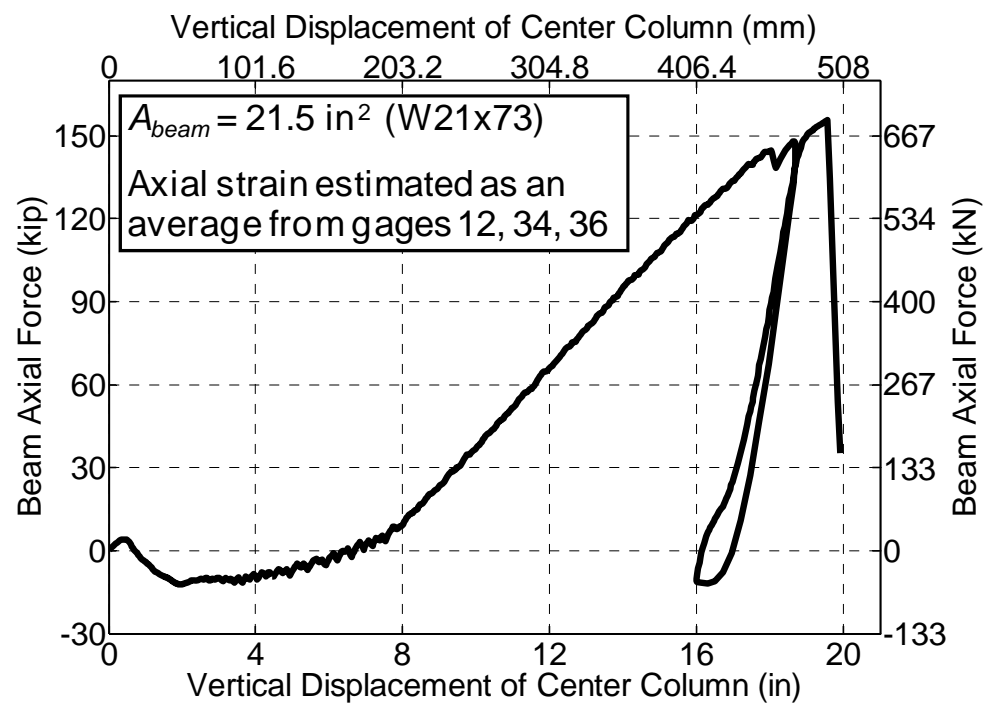

Figure 4-11 Axial force in the beams versus vertical displacement of center column for the WUF-B specimen

Plots of strain gage measurements along Sections B1 and B6 in the vicinity of the WUF-B connections to the end columns are presented in Figure 4-12. Strain distributions correspond to applied vertical loads of $32 \mathrm{kip}, 64 \mathrm{kip}, 100 \mathrm{kip}, 128 \mathrm{kip}$, and $156 \mathrm{kip}(142 \mathrm{kN}, 285 \mathrm{kN}, 445 \mathrm{kN}, 569 \mathrm{kN}$, and $694 \mathrm{kN})$. These loads correspond to center column vertical displacements of 0.5 in, 1.0 in, 2.0 in, 3.0 in, and 7.0 in $(13 \mathrm{~mm}, 25 \mathrm{~mm}, 51 \mathrm{~mm}, 76 \mathrm{~mm}$, and $178 \mathrm{~mm})$. Similar plots are provided in Figure 4-13 for Sections B3 and B4 near the connections to the center column. The plots in both figures indicate that in the initial stages of loading, the beam and its end connections behaved elastically and the response was primarily 
flexural (the neutral axis was slightly shifted to the tensile side, indicating slight compressive forces). With increased loading (increased vertical displacement of center column), the neutral axis shifted toward the compression side due to the presence of axial tensile loads. At vertical loads above $128 \mathrm{kip}(569 \mathrm{kN})$, the strain distributions clearly deviated from linearity, signifying plastic behavior.

(a)

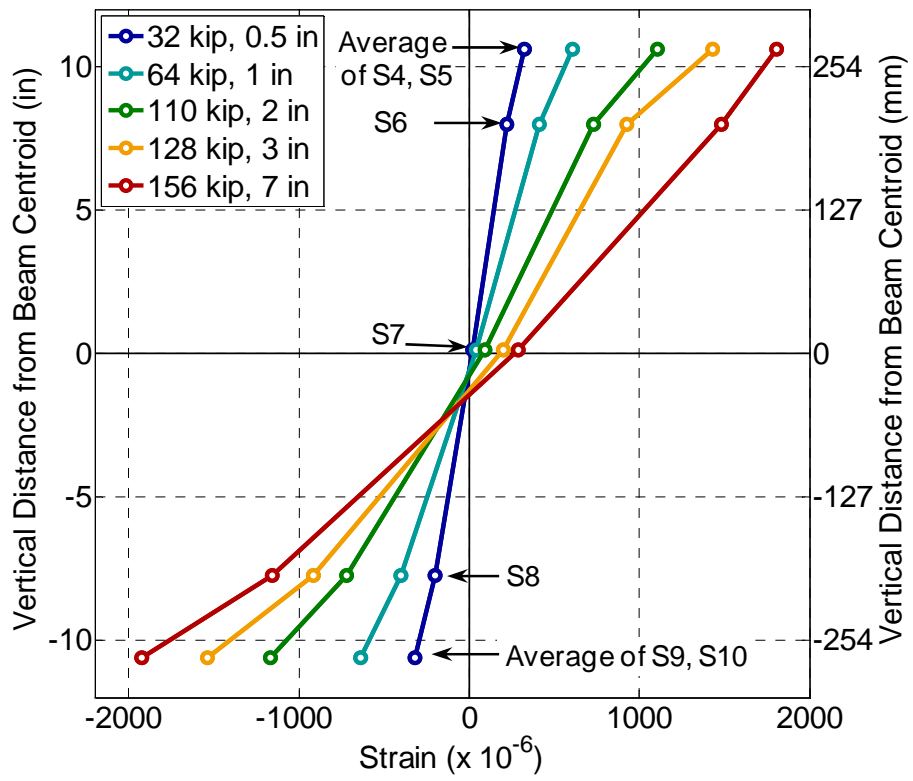

(b)

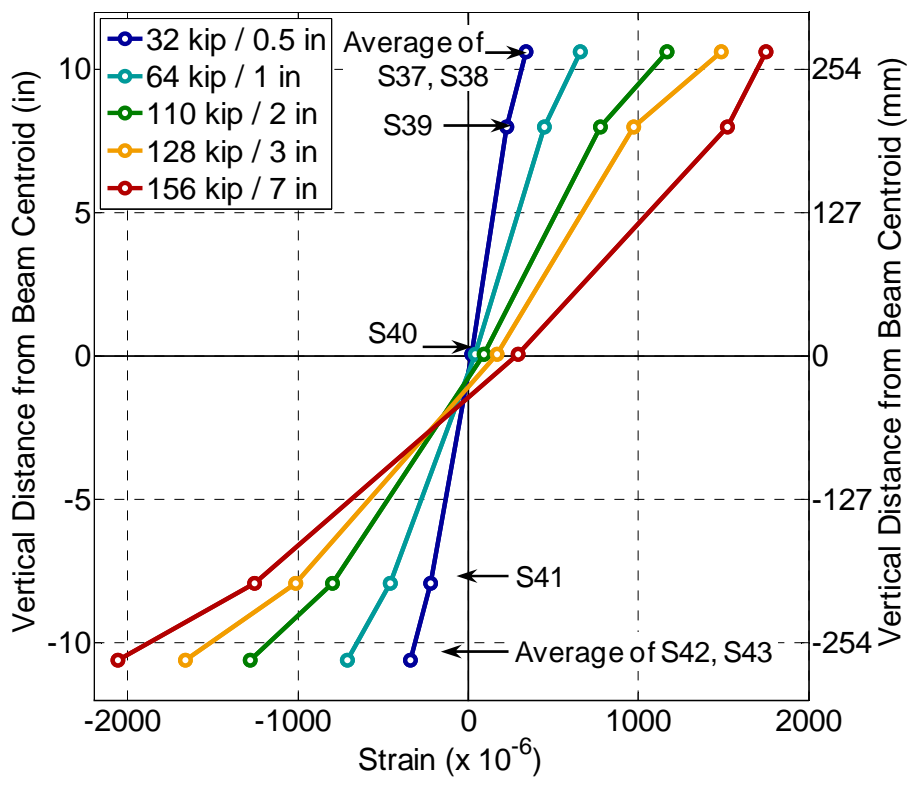

Figure 4-12 Strain distributions along the depth of the beam at (a) Section B1 and (b) Section B6 near the connections to the end columns for the WUF-B specimen 
(a)

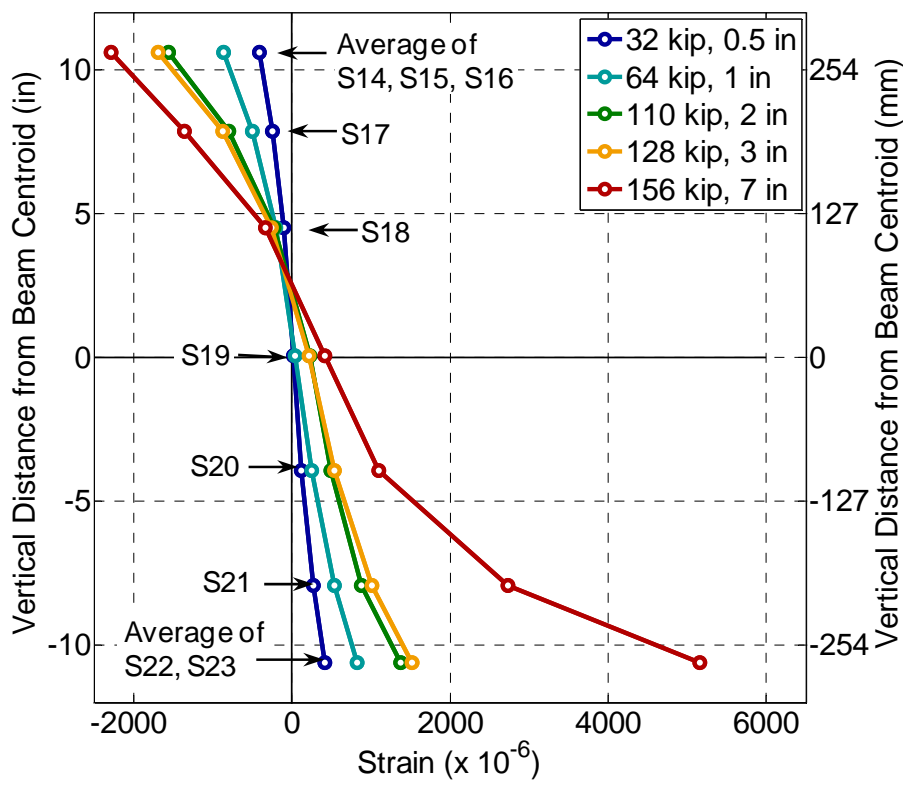

(b)

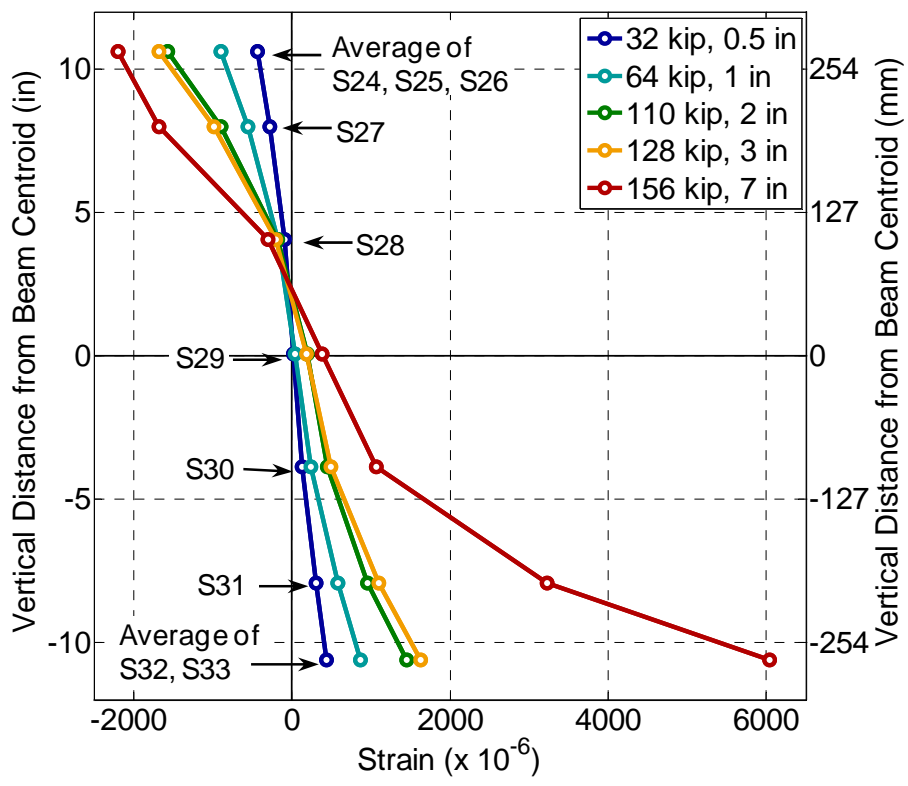

Figure 4-13 Strain distributions along the depth of the beam at (a) Section B3 and (b) Section B4 near the connections to the center column for the WUF-B specimen

Figure 4-14 depicts the strain gage measurements at Sections C1 (S1, S2, and S3) and C2 (S44, S45, and S46) on the end columns below the beams versus the vertical displacement of the center column. The figure indicates that the end columns at this level were subjected to axial forces in addition to bending. The figure shows that all strains at these sections were significantly less than the yield strain of the steel (about $2 \times 10^{-3}$ ), indicating that the columns remained elastic. Plotted in Figure 4-14 is the average strain in the end columns. The average strain was used to calculate the axial force in the end columns. The axial force in the end columns versus the vertical displacement of the center column is presented in Figure 4-15, where it can be observed that at the early stages of the response, the end columns were in compression. With increased vertical displacement and applied load, large compressive forces developed in the diagonal braces, and as a result, axial tension developed in the end columns. 


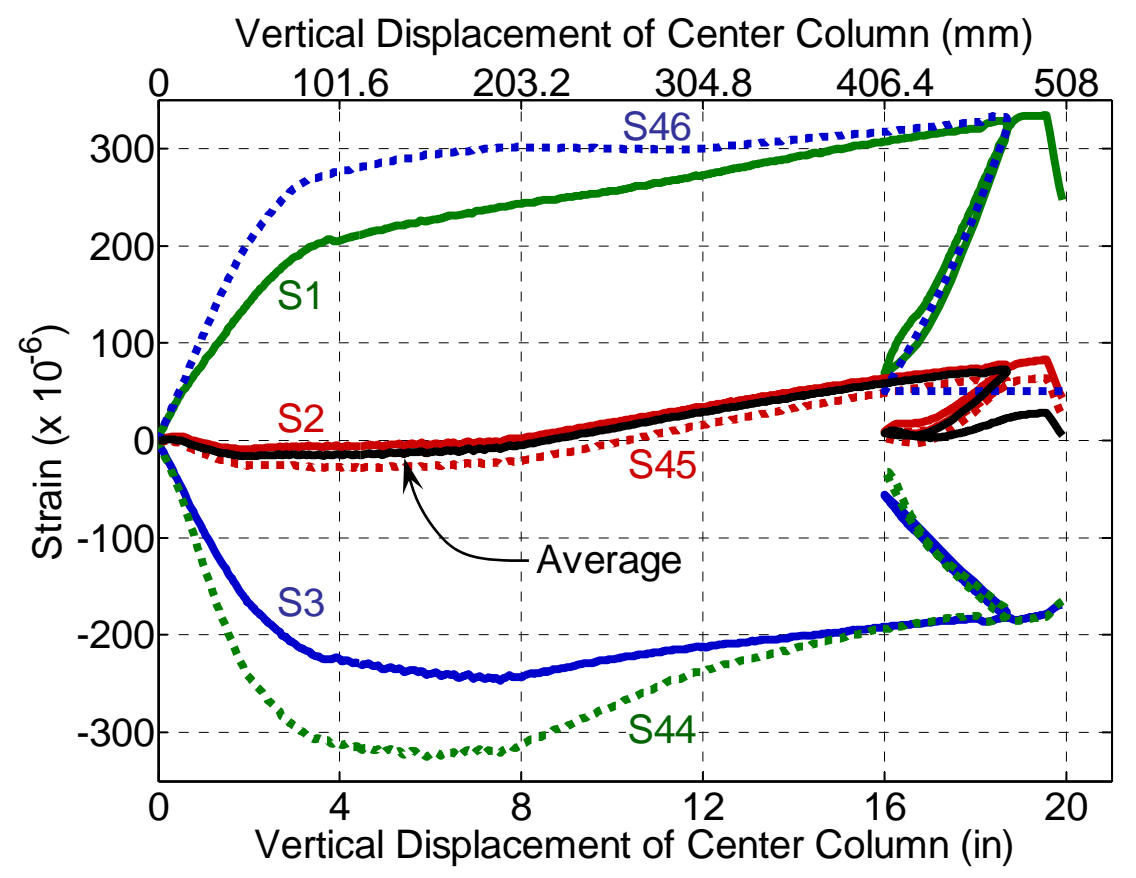

Figure 4-14 Strain gage measurements at Sections C1 and C2, along with their average, versus vertical displacement at center column for the WUF-B specimen

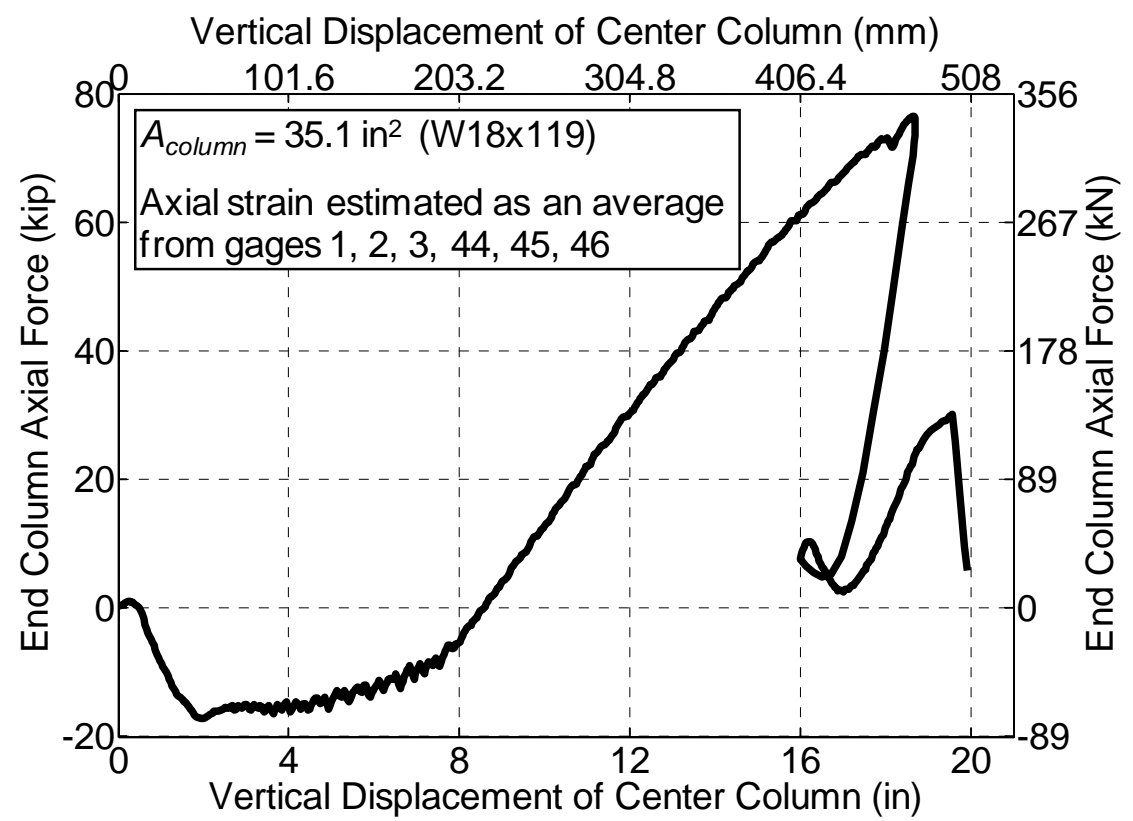

Figure 4-15 Axial forces in the end columns versus vertical displacement of center column for the WUF-B specimen

\subsection{RBS SPECIMEN}




\subsubsection{Observed Behavior and Failure Modes}

Under monotonic vertical displacement of the center column, the RBS specimen (see Figure 4-16) experienced even larger deflections and rotations than the WUF-B specimen before failure occurred. In this test, the RBS specimen failed at a vertical displacement of the center column of about 33.5 in $(851 \mathrm{~mm})$, with a corresponding to a beam chord rotation of about $0.140 \mathrm{rad}$, obtained by dividing the center column displacement at failure by the centerline-to-centerline beam span of 240.0 in $(6096 \mathrm{~mm})$. At that displacement, the applied vertical load was about $400 \mathrm{kip}(1780 \mathrm{kN})$. The failure was characterized by the fracture of the bottom flange in the middle of the reduced section of one of the connections near the center column. As shown in Figure 4-17, the fracture propagated through the web until the specimen could no longer carry the applied load.

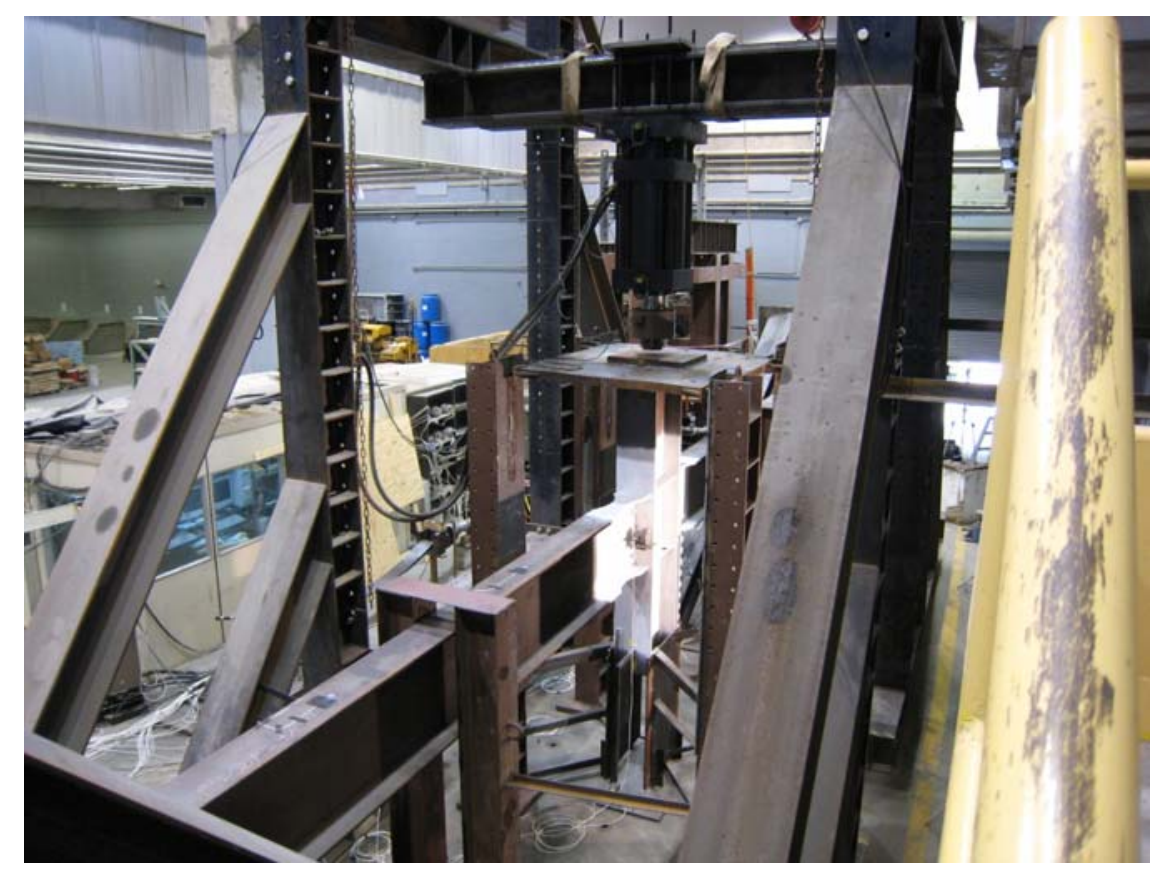

Figure 4-16 Overall view of the RBS test specimen 

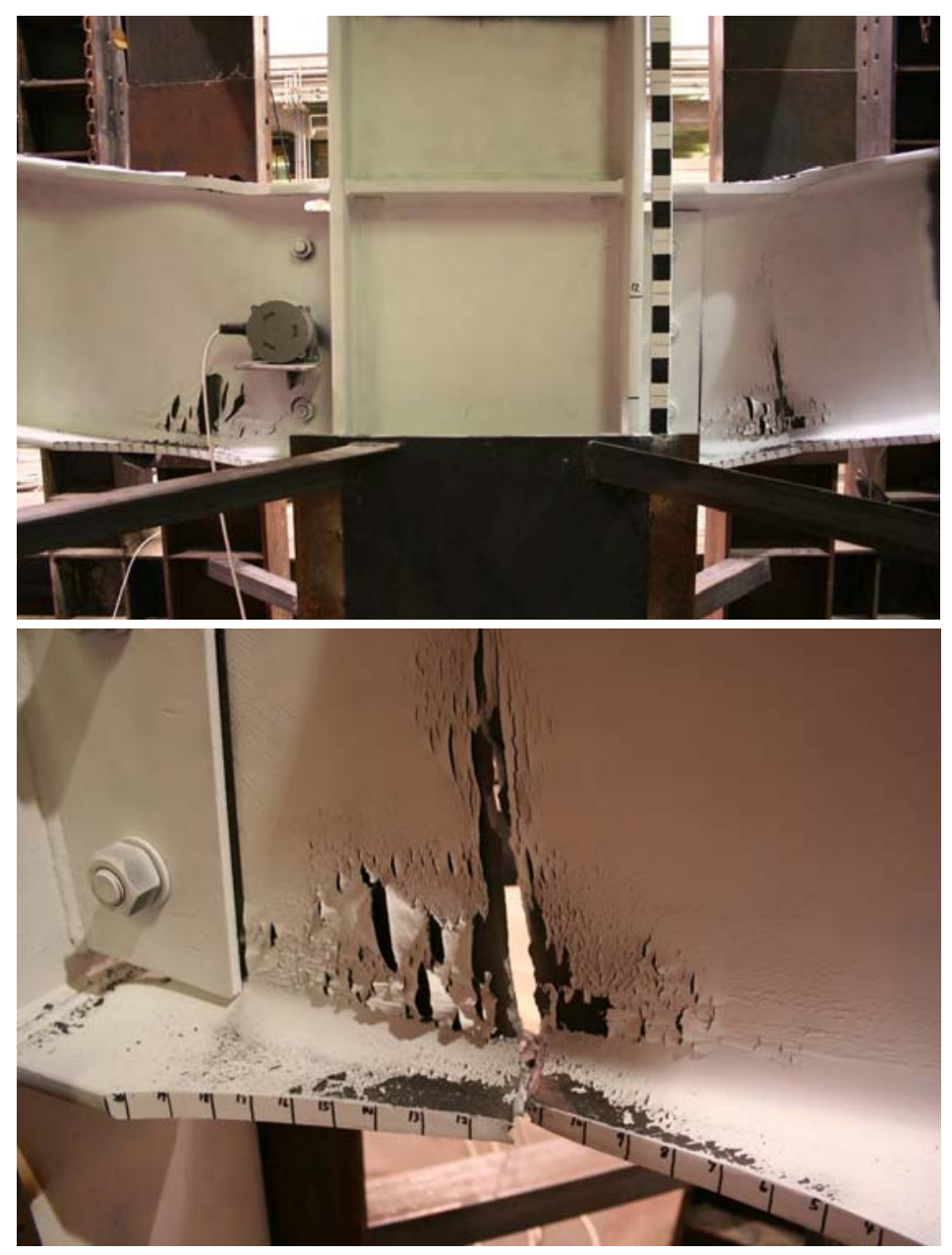

Figure 4-17 Failure mode of the RBS specimen

\subsubsection{Displacement Measurements}

The plots in Figure 4-18 show the vertical load versus vertical displacements at (a) 1/3 span of the beams (D3 and D8), (b) 2/3 span of the beams (D4 and D7), and (c) the center column (D5 and D6). The locations of the displacement transducers were shown previously in Figure 3-7. As the plots indicate, the specimen was unloaded twice at vertical displacements of the center column of about 17 in (432 $\mathrm{mm})$ and 32 in $(813 \mathrm{~mm})$ to adjust the stroke of the hydraulic ram, and then the specimen was loaded again to failure. Figure 4-18(c) indicates that the assembly remained in the elastic range up to a vertical displacement of the center column of about 2 in $(50 \mathrm{~mm})$. With increased vertical displacement, the assembly behaved nonlinearly until it failed at a vertical displacement of the center column of about 33.5 in $(838 \mathrm{~mm})$. The corresponding peak vertical load was about $400 \mathrm{kip}(1780 \mathrm{kN})$. The pairs of nearly identical load deformation curves in each of the three plots in Figure 4-18 indicate that symmetry was largely maintained during the experiment. In subsequent plots, the average of D5 and D6 is used to represent the vertical displacement of the center column. 
(a)

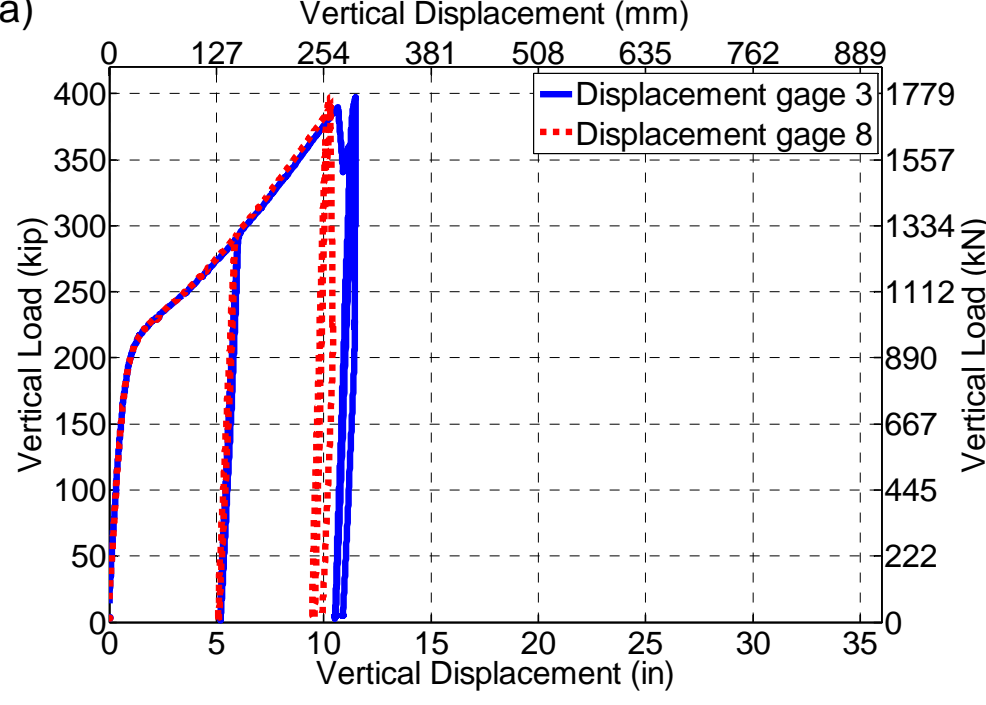

(b)

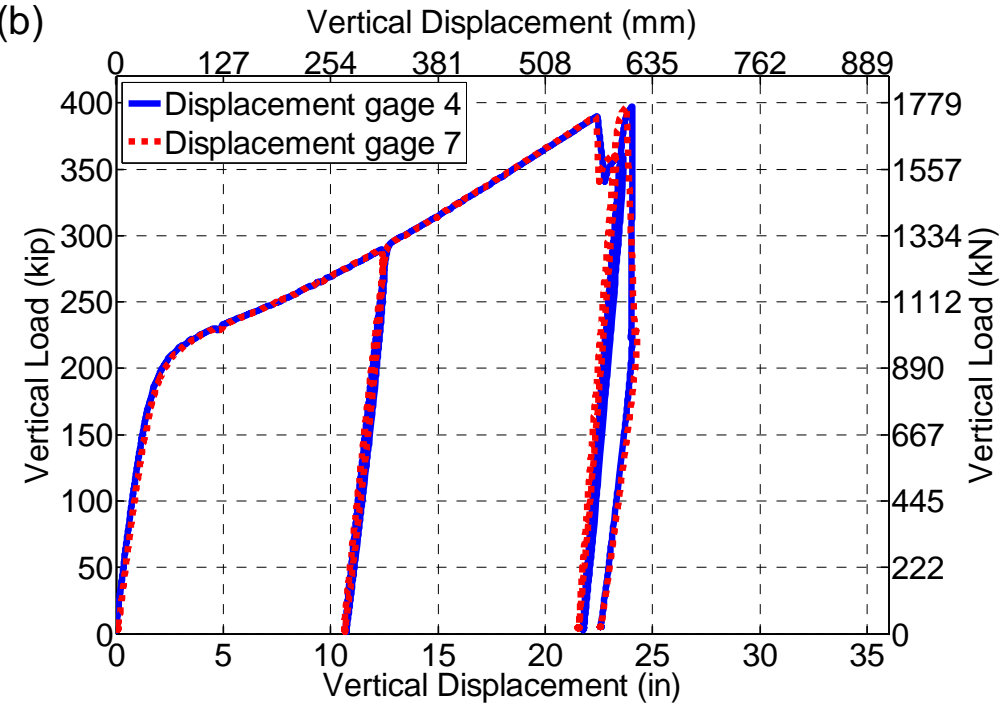

(c)

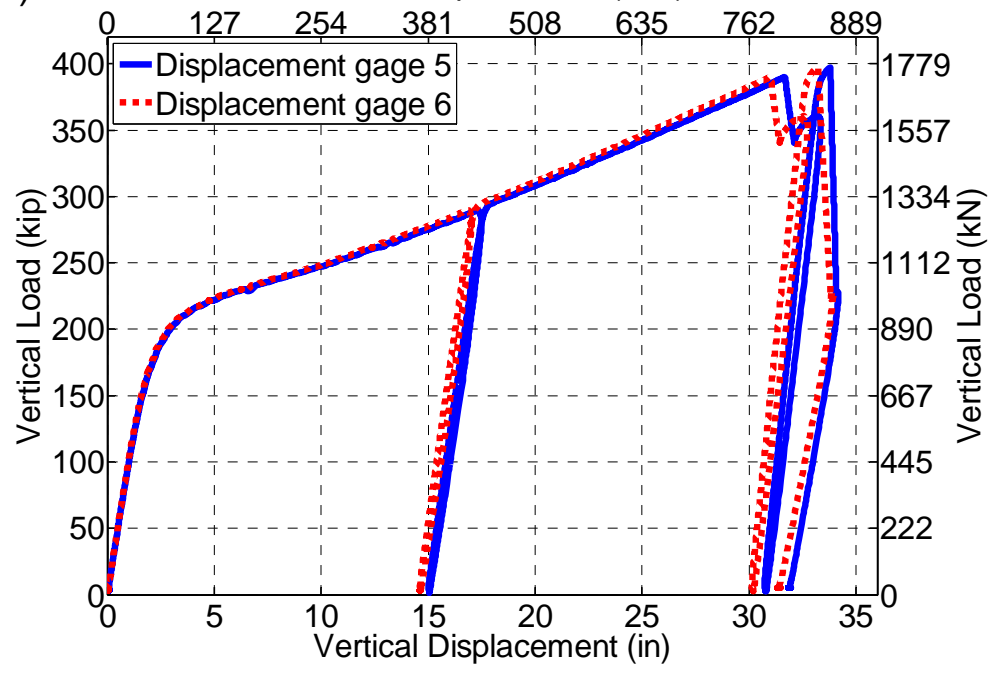

Figure 4-18 Applied vertical load versus vertical displacements at (a) 1/3 span of beams (D3 and D8), (b) 2/3 span of beams (D4 and D7), and (c) center column (D5 and D6) for the RBS specimen 
Figure 4-19 shows the displacement profile of the beam (D3 through D8) at different load values. In the figure, dotted lines are used to connect the measured deflections since straight lines do not accurately represent the deflected shape of the beams due to the presence of kinks at the reduced sections, where plastic hinges formed. Notice also that the small differences between the displacement measurements on each side of the center column indicate a slight rigid body rotation of the test specimen.

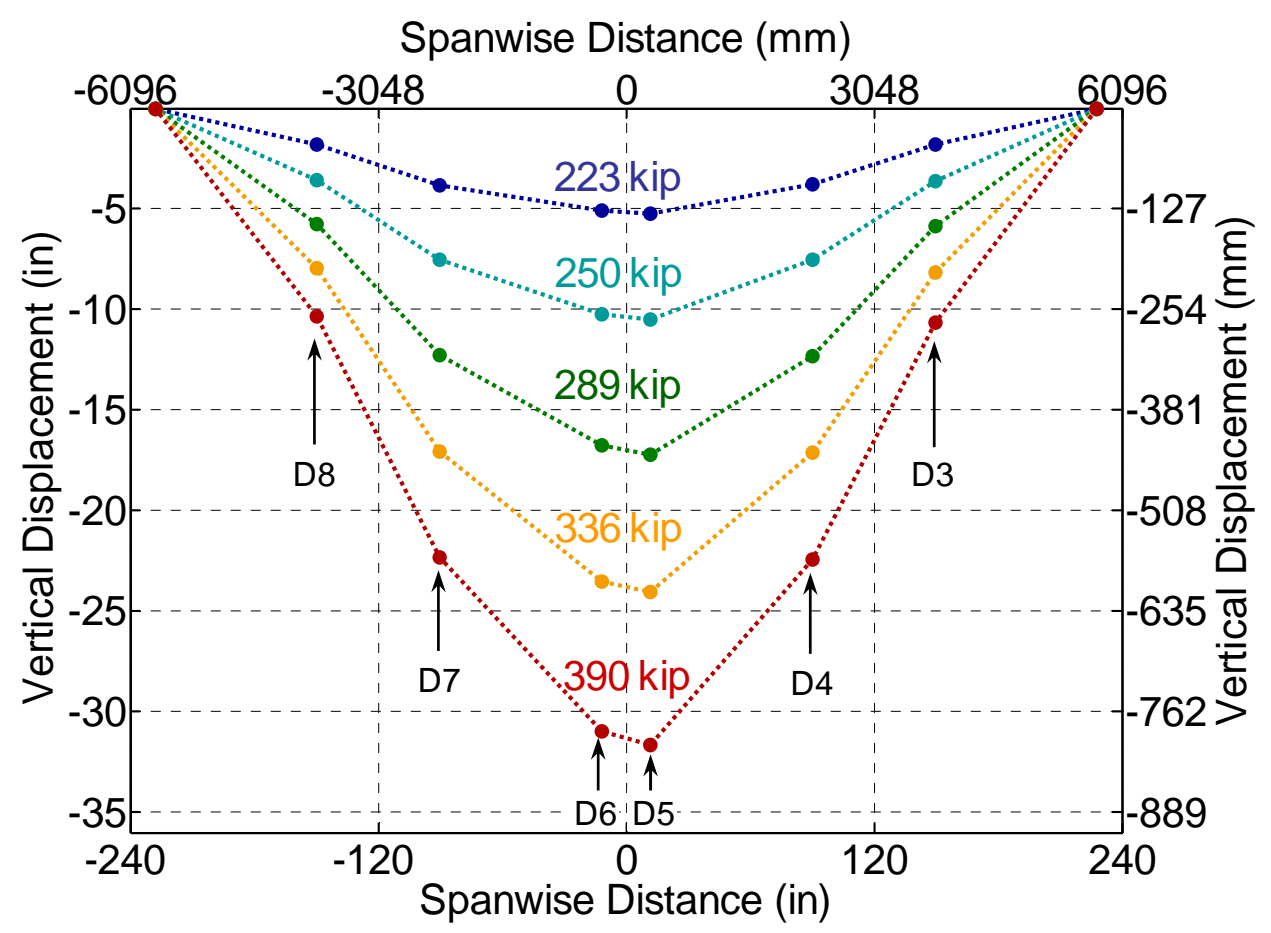

Figure 4-19 Vertical displacement profiles of beams corresponding to indicaged vertical loads for the RBS specimen (displacements magnified)

Figure 4-20 shows the horizontal displacement of the end columns at (a) the column tops (D1 and D10) and (b) the beam mid-height (D2 and D9) versus the vertical displacement of the center column (average of D5 and D6). In the plots, positive values signify an inward displacement. The plots indicate that the end columns maintained an inward, and largely symmetric, displacement throughout the response. The average of the horizontal displacements at the beam mid-height and at the column tops were calculated and plotted in Figure 4-20 as representative of the inward displacement of the end columns. These averages will be used for comparison with the computational modeling results in Chapter 5 . 
(a)

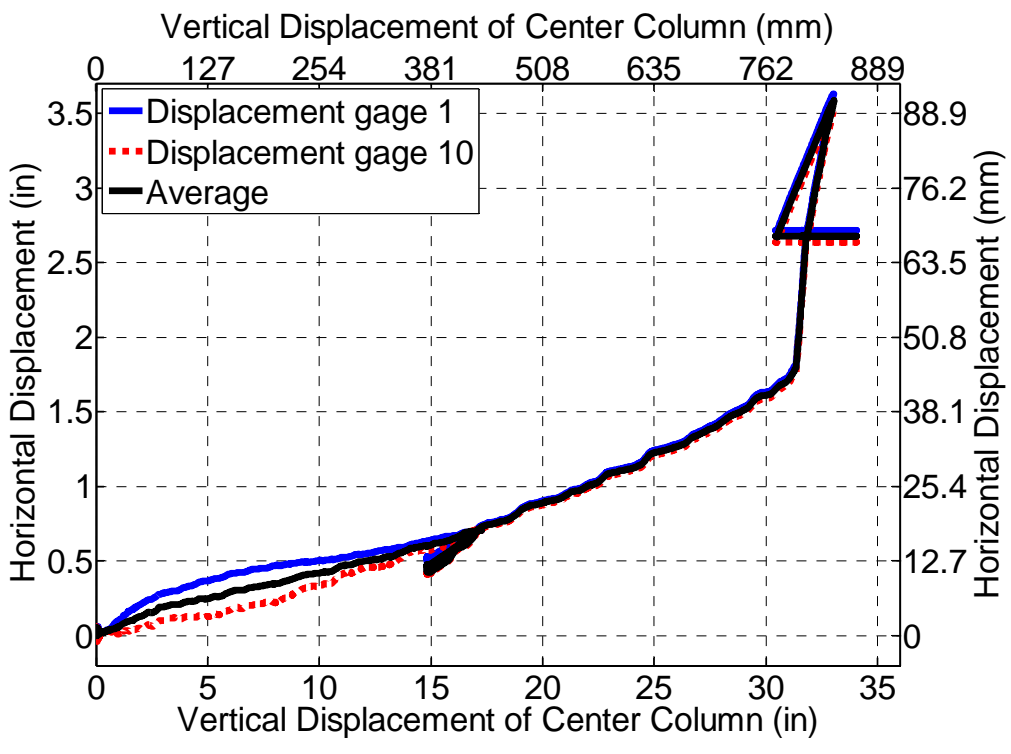

(b)

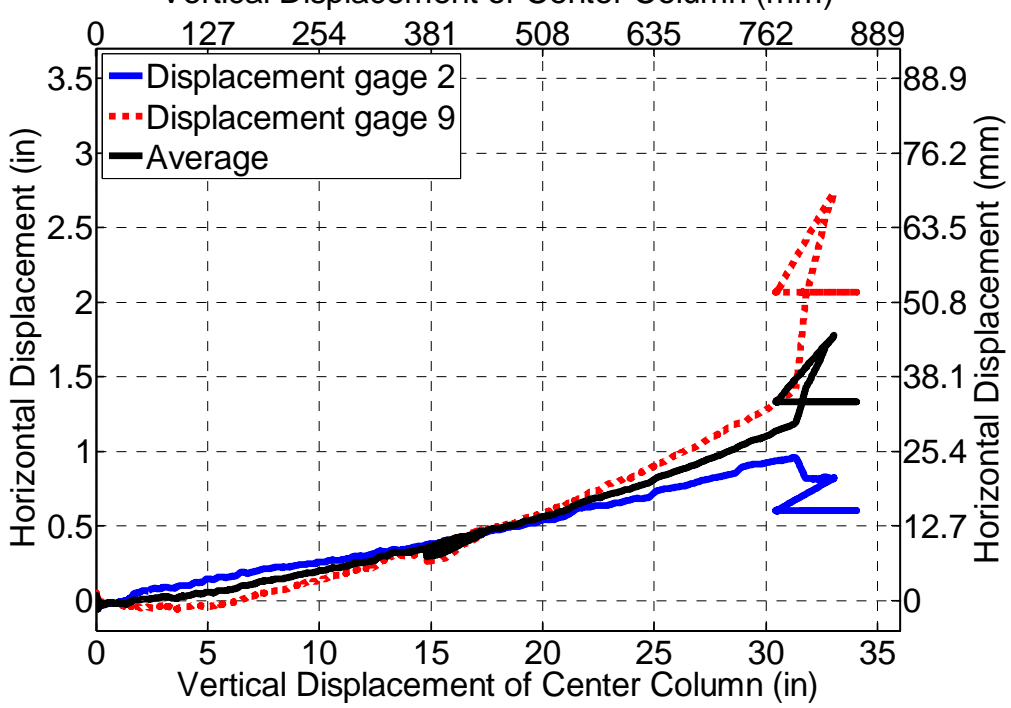

Figure 4-20 Horizontal displacements of end columns at (a) column top and (b) beam midheight versus center column displacement for RBS specimen

\subsubsection{Rotation Measurements}

During the experiment, inclinometers I3 and I4 malfunctioned. Plots of the vertical load versus the measurements from inclinometers I1 and I2 (see Figure 3-7), representing angle of rotation at an end column connection and a center column connection, respectively, are shown in Figure 4-21. Note that these rotations do not represent the overall rotation of the beam due to the fact that plastic hinges formed in the middle of the reduced sections, resulting in kinking away from the face of the beam-column interface, where the inclinometers were located. Figure 4-22 presents the angle of rotation versus vertical displacement at the center column. This figure shows that the rotations were essentially linearly proportional to the vertical displacement of the center column up to the failure of the connection at a displacement of 33.5 in $(851 \mathrm{~mm})$. 


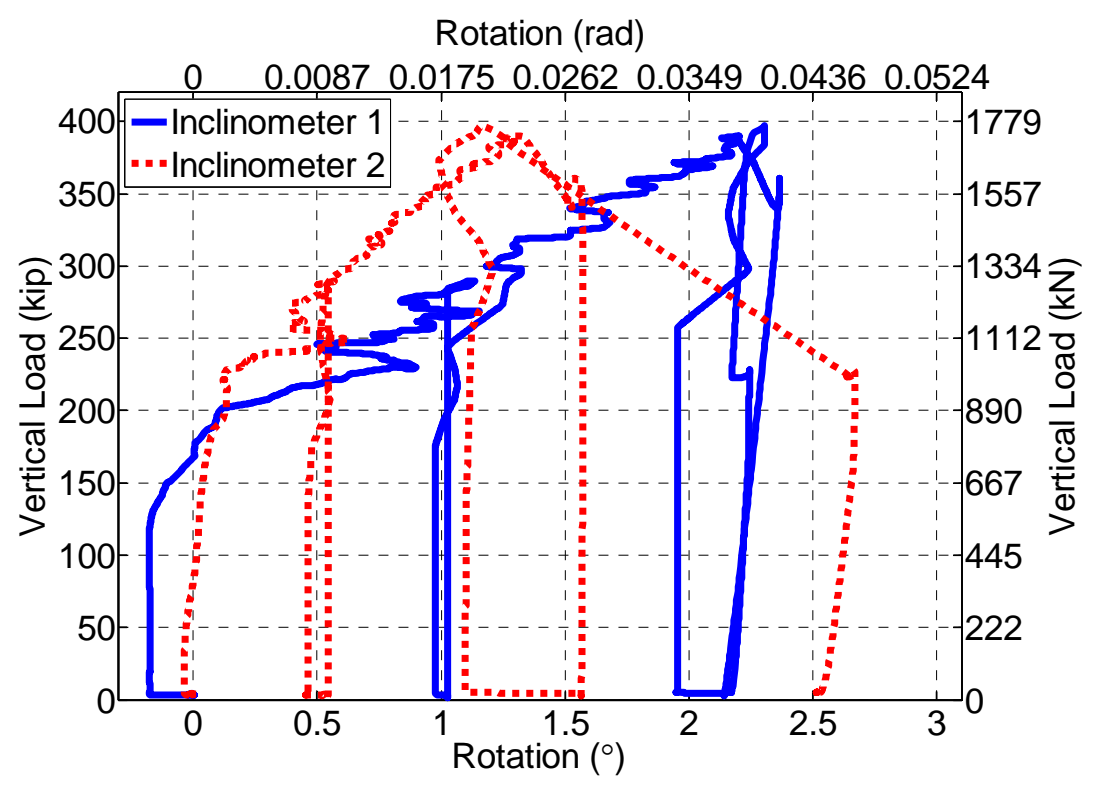

Figure 4-21 Vertical load versus angle of rotation at connections to end and center columns for RBS specimen

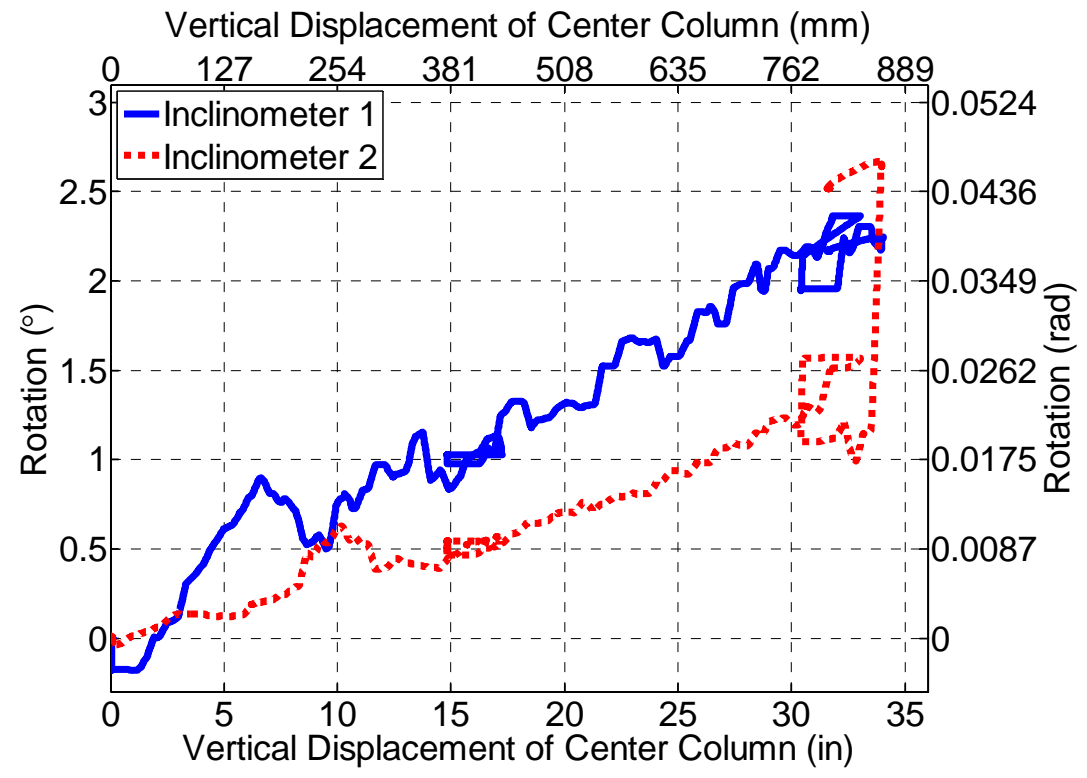

Figure 4-22 Angle of rotation at connections to end column and center column versus center column displacement for RBS specimen 


\subsubsection{Strain Measurements}

The strain gages mounted to the test specimen provided valuable information on the state of strain and stress at multiple locations. The strain gages were located at twelve cross sections, which are labeled in Figure 4-23. Gages at Sections B2, B3, B6, and B7 provide information about the strains in the beams outside of the connection regions and are used to estimate the axial force in the beams. Gages at Sections B1, B4, B5, and B8 provide the strain distribution along the beam height in the vicinity of the reduced sections. Gages at Sections $\mathrm{C} 1$ and $\mathrm{C} 2$ provide information about the strains in the end columns that are used to estimate their axial forces, while gages at Sections W1 and W2 provide information about the strains in the lateral braces that are used to estimate their axial forces.

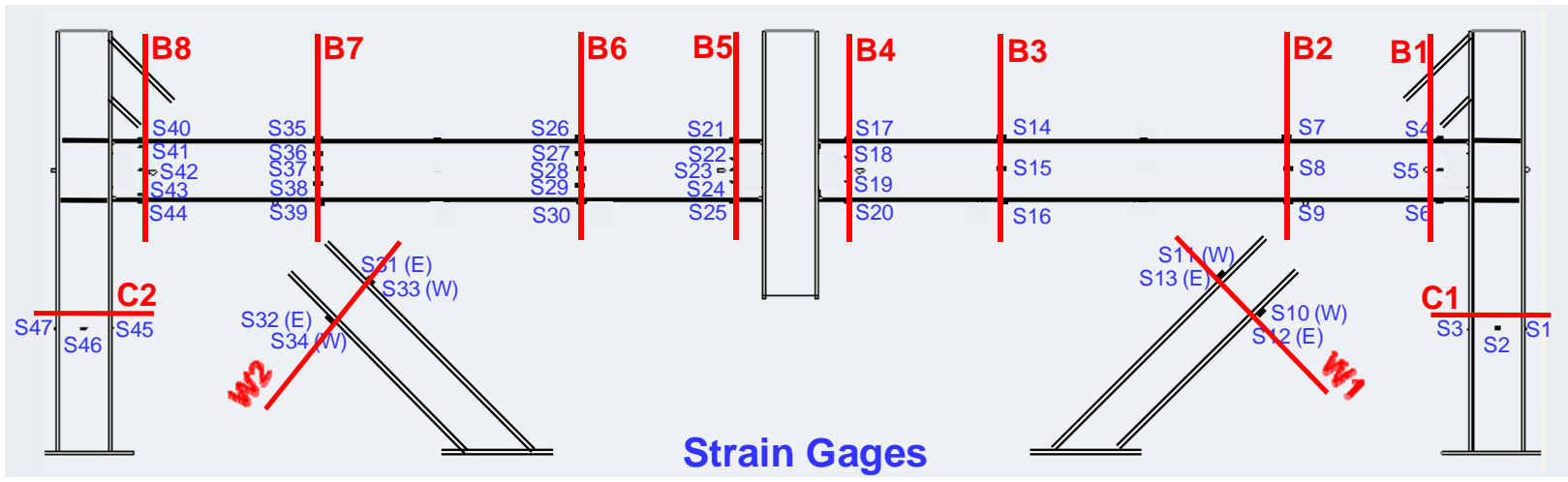

Figure 4-23 Locations of cross sections with strain gages

Figure 4-24 depicts the strain gage measurements at (a) Section B2 (S7, S8, and S9) and (b) Section B7 (S35, S36, S37, S38, and S39) versus the vertical displacement of the center column. This figure shows that all strains at these sections were significantly less than the nominal yield strain of the steel $(0.2 \%$ or $2 \times 10^{-3}$ ), indicating that at these cross sections, outside of the connection regions, the beam remained in the elastic range during the entire response. From Figure 4-24 it can be observed that the beam initially behaved primarily in bending up to a center column displacement of about 3 in (76 $\mathrm{mm}$ ) where the top flanges in these sections were in tension, the bottom flanges were in compression, and the neutral axis was approximately at mid-height of the web. With increased center column displacement, axial tensile forces developed in the beams, as demonstrated by the tensile strains at mid-height of the beams. The tensile strains in the beams increased with increased center column vertical displacement until failure occurred at the reduced beam section. 

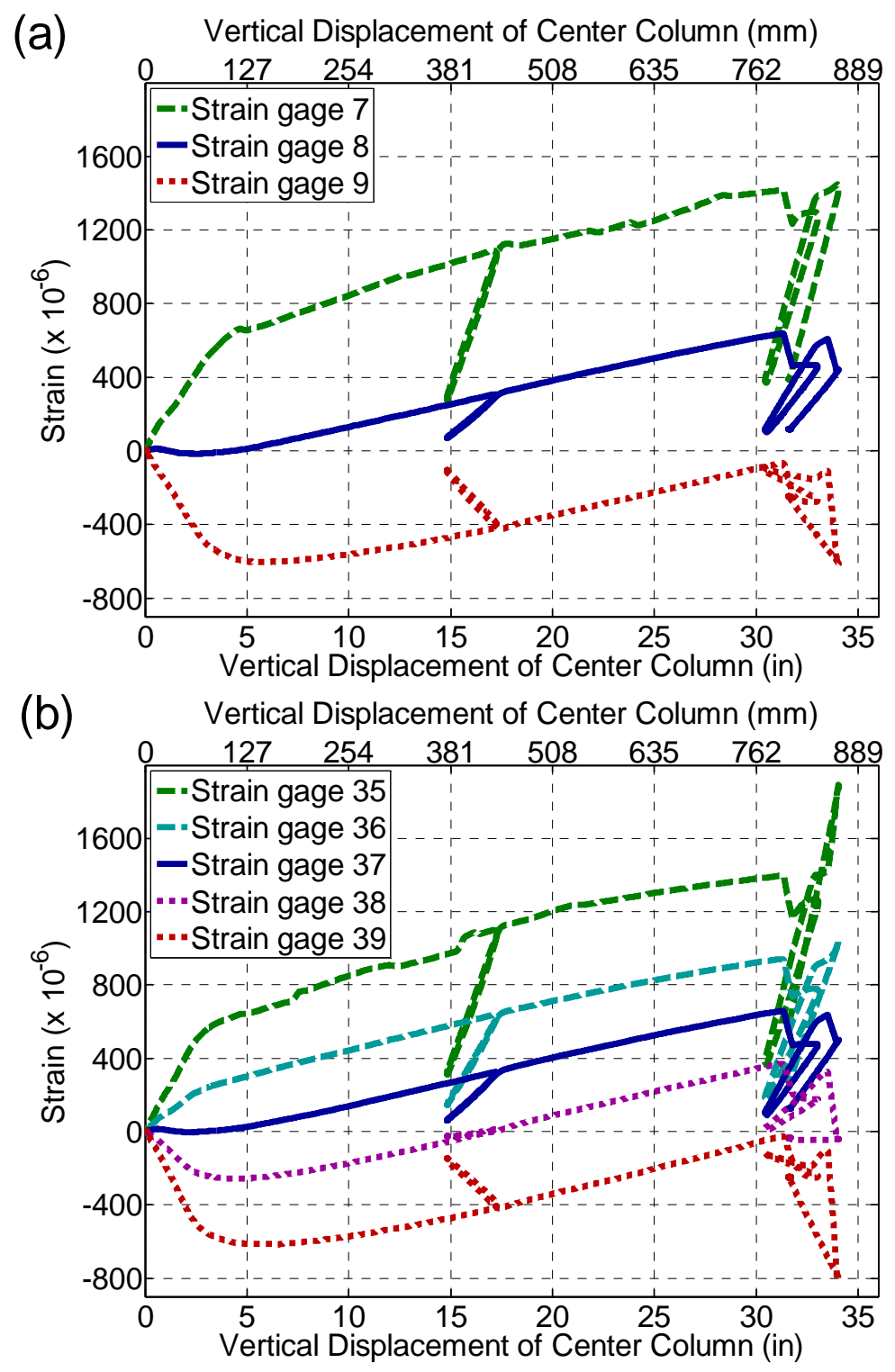

Figure 4-24 Strain versus center column displacement at (a) Section B2 and (b) Section B7 of
RBS specimen

Figure 4-25 presents the average strains in Section B2 and Section B7, plotted against the vertical displacement of the center column. The figure indicates good agreement between the average strains from both sections. These average strains were used to calculate the axial force in the beams. The axial force in the beams versus the vertical displacement of the center column are presented in Figure 4-26, where it can be observed that in the early stages of the response, the behavior was dominated by flexure with minor axial forces in the beams. With increased vertical displacement, tensile axial forces developed in the beams. At the time of failure, the axial tension in the beams was about 550 kip $(2447 \mathrm{kN})$. 


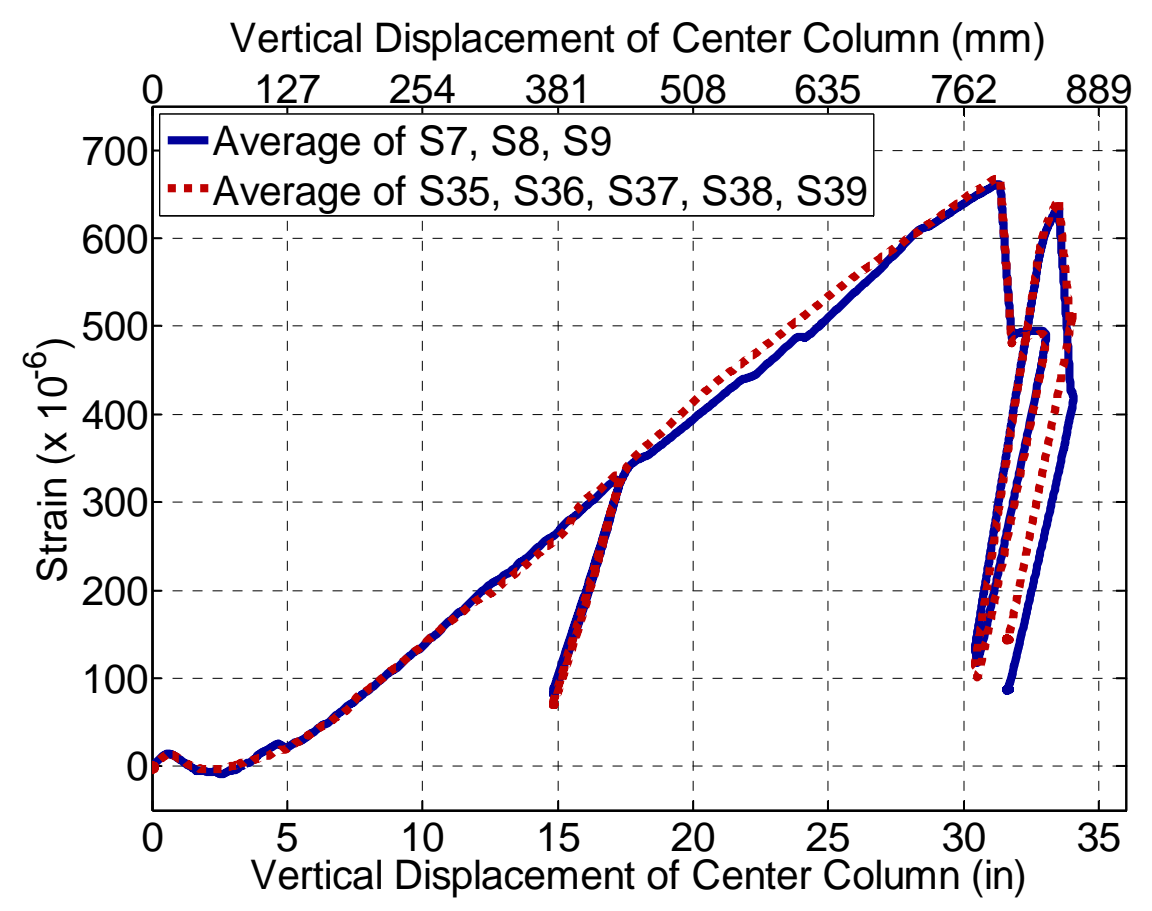

Figure 4-25 Average strains at Sections B2 and B7 versus center column displacement of RBS specimen

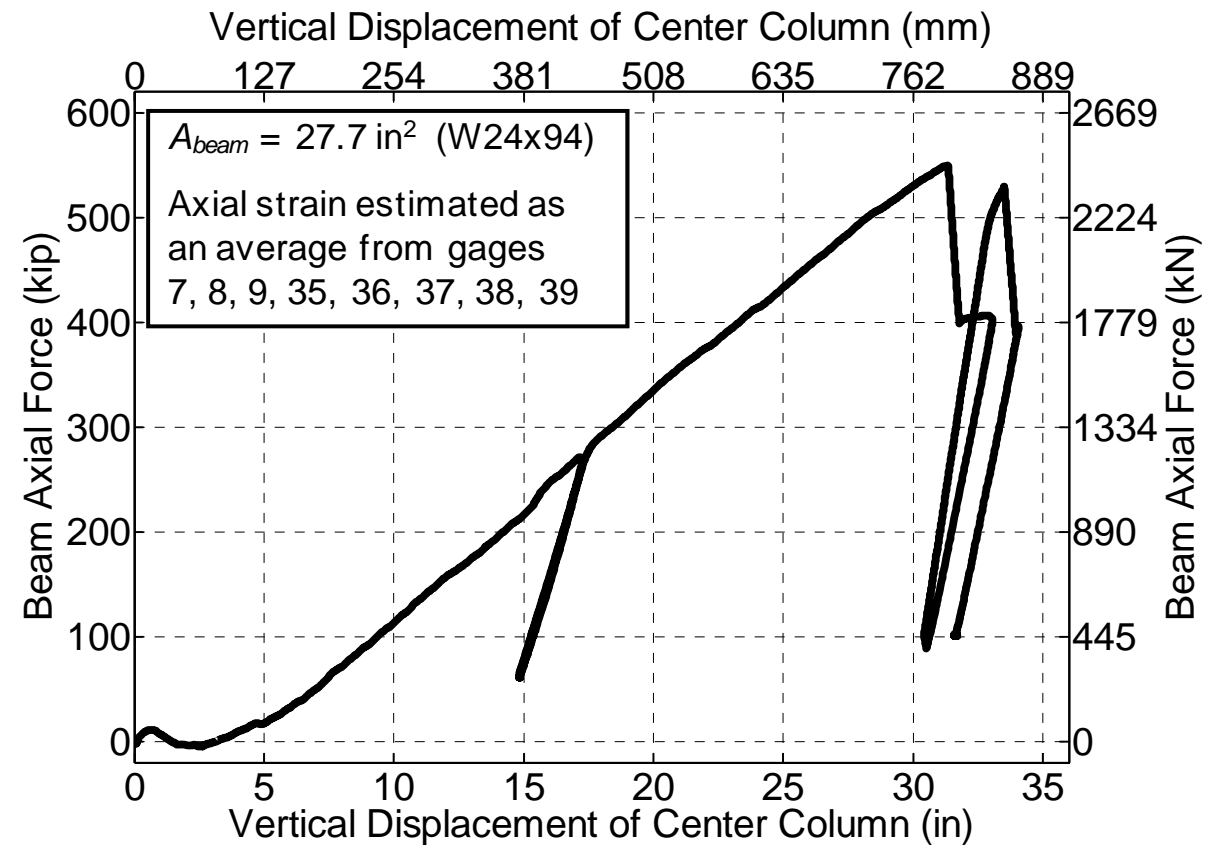

Figure 4-26 Axial force in beams versus center column displacement of RBS specimen 
Plots of strain gage measurements along Sections B1 and B8 in the vicinity of the reduced sections near the end columns are presented in Figure 4-27, corresponding to applied vertical loads of 13 kip, 76 kip, $152 \mathrm{kip}$, and $192 \mathrm{kip}(58 \mathrm{kN}, 338 \mathrm{kN}, 676 \mathrm{kN}$, and $854 \mathrm{kN})$. These loads correspond to center column vertical displacements of $0.13 \mathrm{in}, 0.75 \mathrm{in}, 1.65 \mathrm{in}$, and $2.6 \mathrm{in}(3 \mathrm{~mm}, 19 \mathrm{~mm}, 42 \mathrm{~mm}$, and $66 \mathrm{~mm})$. Similar plots are provided in Figure 4-28 for Sections B4 and B5 at the reduced sections near the center column for applied vertical loads of $22 \mathrm{kip}, 76 \mathrm{kip}, 131 \mathrm{kip}$, and $170 \mathrm{kip}(98 \mathrm{kN}, 338 \mathrm{kN}, 583 \mathrm{kN}$, and $756 \mathrm{kN}$ ), corresponding to center column vertical displacements of 0.22 in, 0.75 in, 1.36 in, and 1.97 in $(6 \mathrm{~mm}, 19 \mathrm{~mm}, 35 \mathrm{~mm}$, and $50 \mathrm{~mm})$. Note that these strains are plotted for selected applied loads and displacements up to the onset of yielding for the specified cross sections. Since these strain distributions describe the response at the early stages of loading (prior to significant yielding and catenary behavior), the plots in both figures indicate that the beams behaved essentially elastically for the selected load range.

Figure 4-29 shows the strain gage measurements outside of the connection regions, along (a) Sections B2 and B7 and (b) Sections B3 and B6. Strain distributions are shown corresponding to applied vertical loads of $100 \mathrm{kip}, 225 \mathrm{kip}, 275 \mathrm{kip}$, and $375 \mathrm{kip}(445 \mathrm{kN}, 1001 \mathrm{kN}, 1223 \mathrm{kN}$, and $1668 \mathrm{kN}$ ), which correspond to center column vertical displacements of $1.0 \mathrm{in}, 5.0 \mathrm{in}, 15.0 \mathrm{in}$, and $30.0 \mathrm{in}(25 \mathrm{~mm}$, $128 \mathrm{~mm}, 383 \mathrm{~mm}$, and $765 \mathrm{~mm}$ ). The plots in this figure indicate that in the initial stages of loading, the beam behaved elastically and the response was primarily flexural (the neutral axis was always at midheight of beam web). With increased loading (and vertical displacement of the center column), the neutral axis shifted toward the compression side due to the presence of axial tensile loads. At a vertical load of about $375 \mathrm{kip}(1668 \mathrm{kN})$, the strain distributions at Sections B3 and B6 deviated from linearity, signifying the onset of yielding, while the strain distributions at Sections B2 and B7 remained linear, signifying elastic behavior.

Figure 4-30 depicts the strain gage measurements at Sections C1 (S1, S2, and S3) and C2 (S45, S46, and S47) on the end columns, below the beams, versus the vertical displacement of the center column. The figure indicates that the end columns at this level were subjected to axial force in addition to bending. The figure shows that all strains at these sections were significantly less than the nominal yield strain of the steel $\left(0.2 \%\right.$ or $\left.2 \times 10^{-3}\right)$, indicating that the columns remained in the elastic range throughout the test. Plotted in Figure 4-30 is the average strain in the end columns. The average strain was used to calculate the axial force in the end columns. The axial force in the end columns versus the vertical displacement of the center column is presented in Figure 4-31, where it can be observed that in the early stages of the response, the end columns were in compression. With increased vertical displacement and applied load, large compressive forces developed in the diagonal braces (see Figure 4-33), and as a result, axial tension developed in the end columns. 
(a)

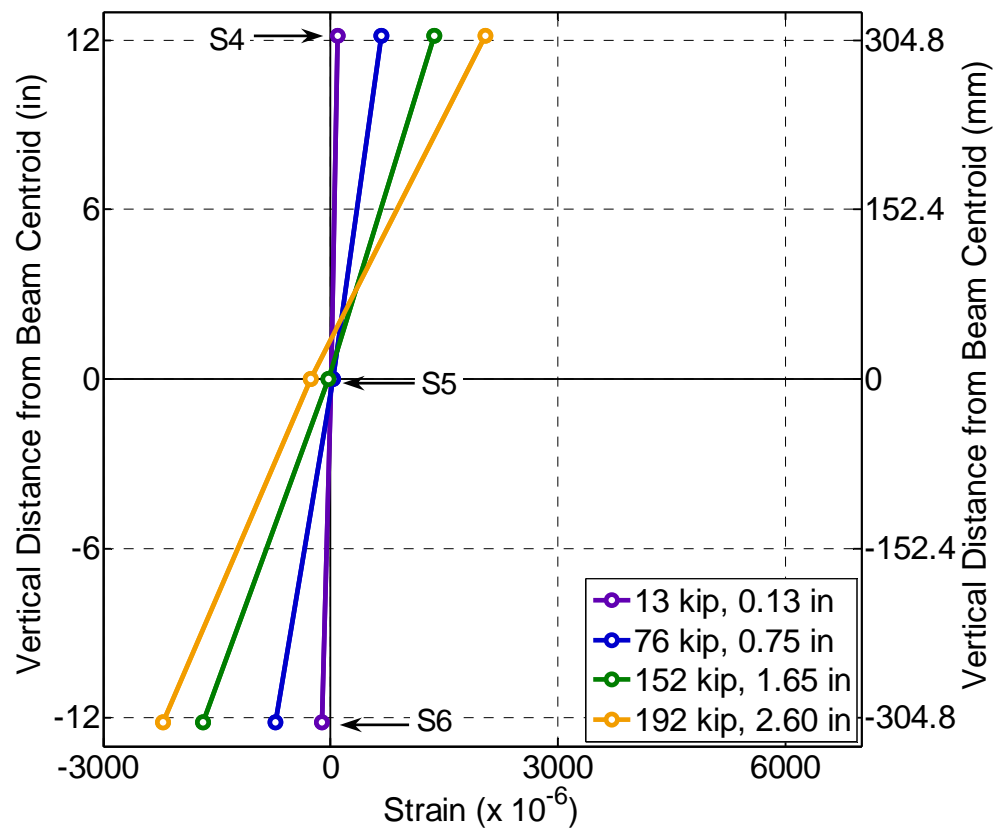

(b)

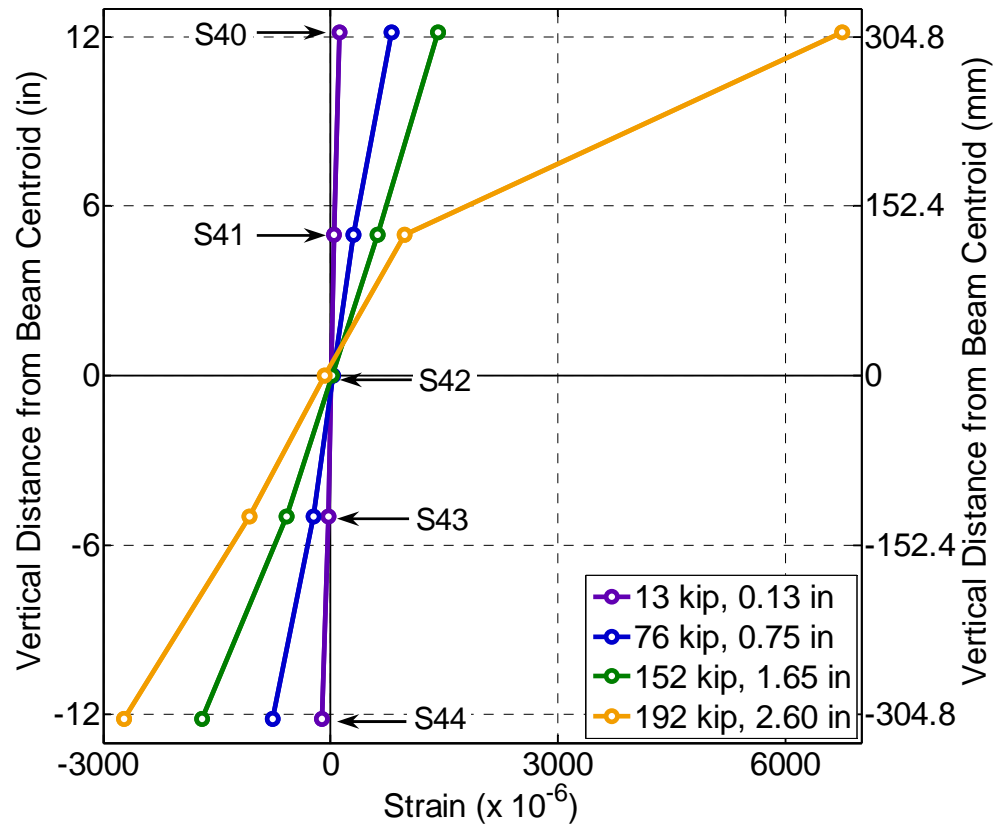

Figure 4-27 Strain distributions along the depth of beam at (a) Section B1 and (b) Section B8 near the connections to the end columns of RBS specimen 
(a)

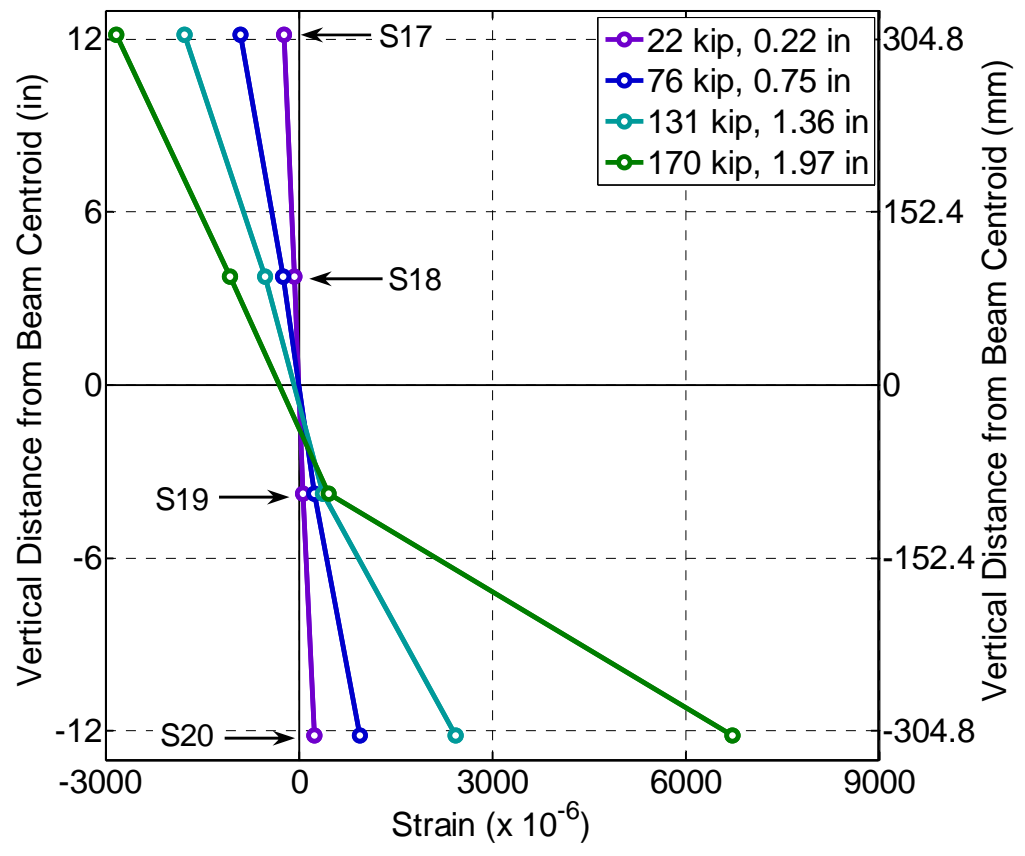

(b)

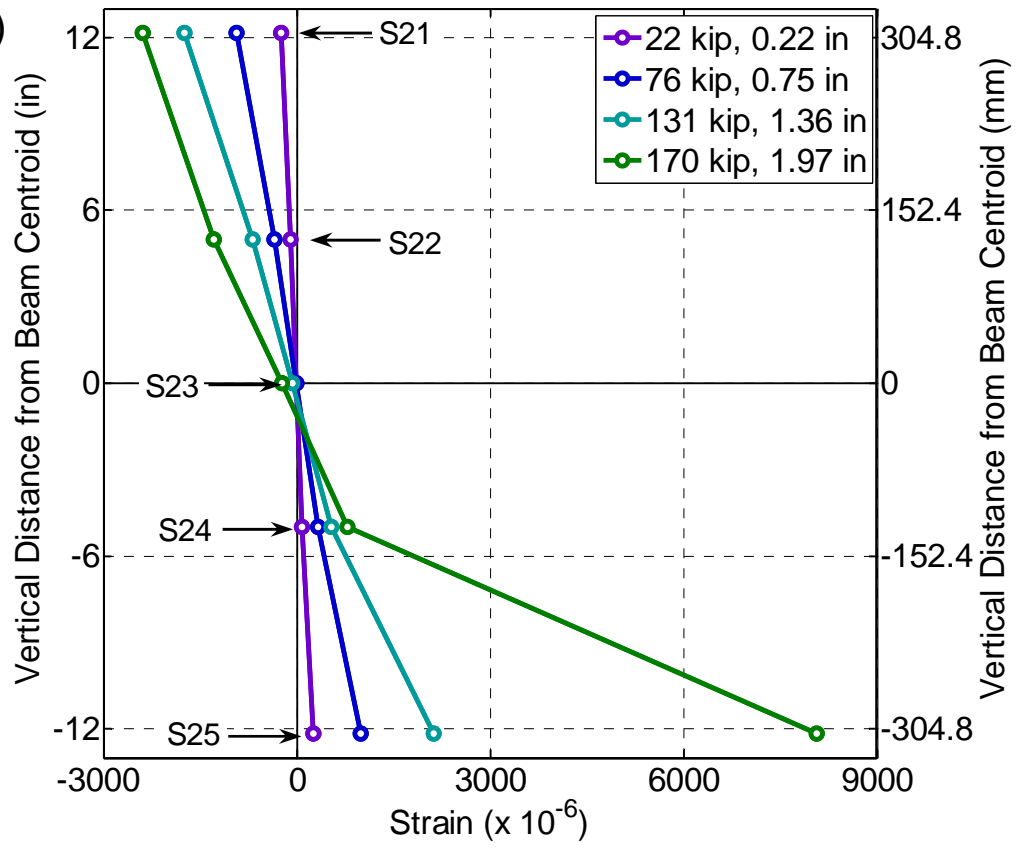

Figure 4-28 Strain distributions along the depth of beam at (a) Section B4 and (b) Section B5 near the connections to the center column of RBS specimen 
(a)
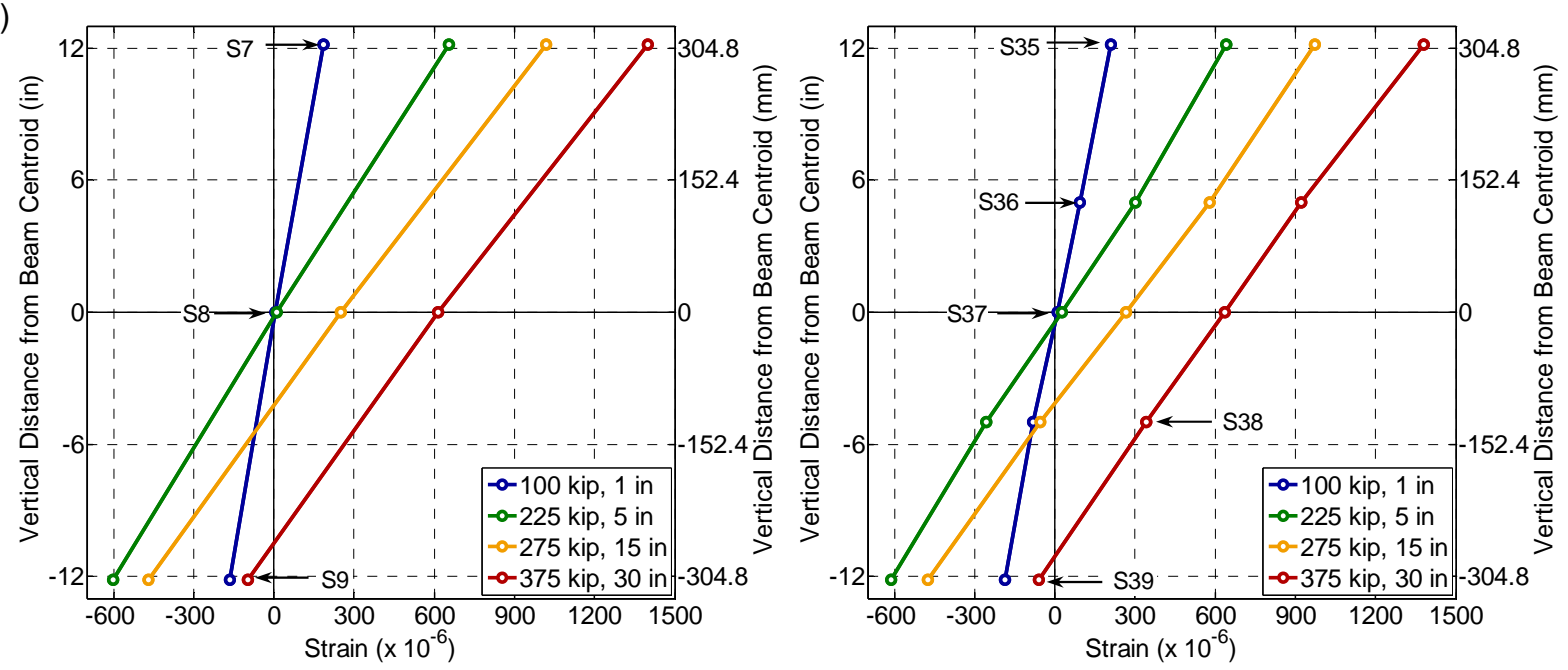

(b)
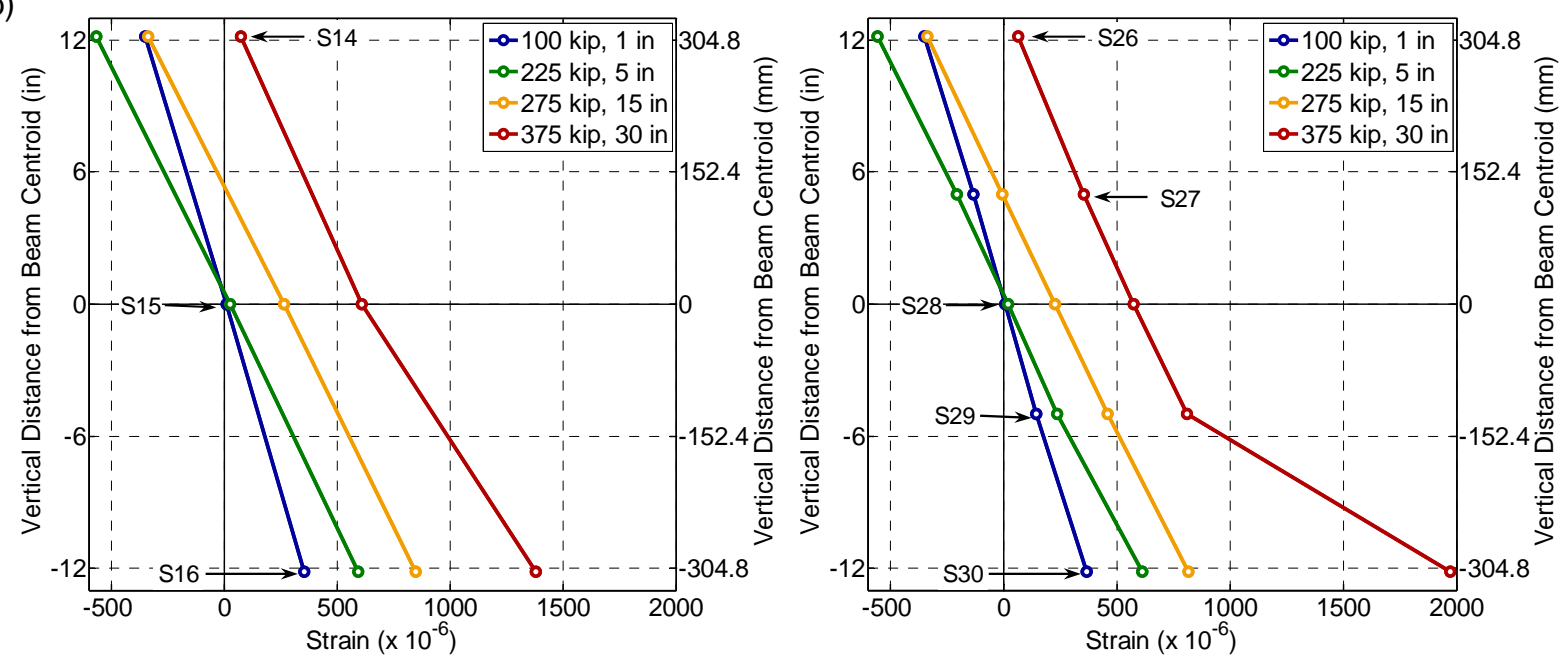

Figure 4-29 Strain distributions along the depth of beam at (a) Sections B2 and B7, and (b) Sections B3 and B6 of RBS specimen 


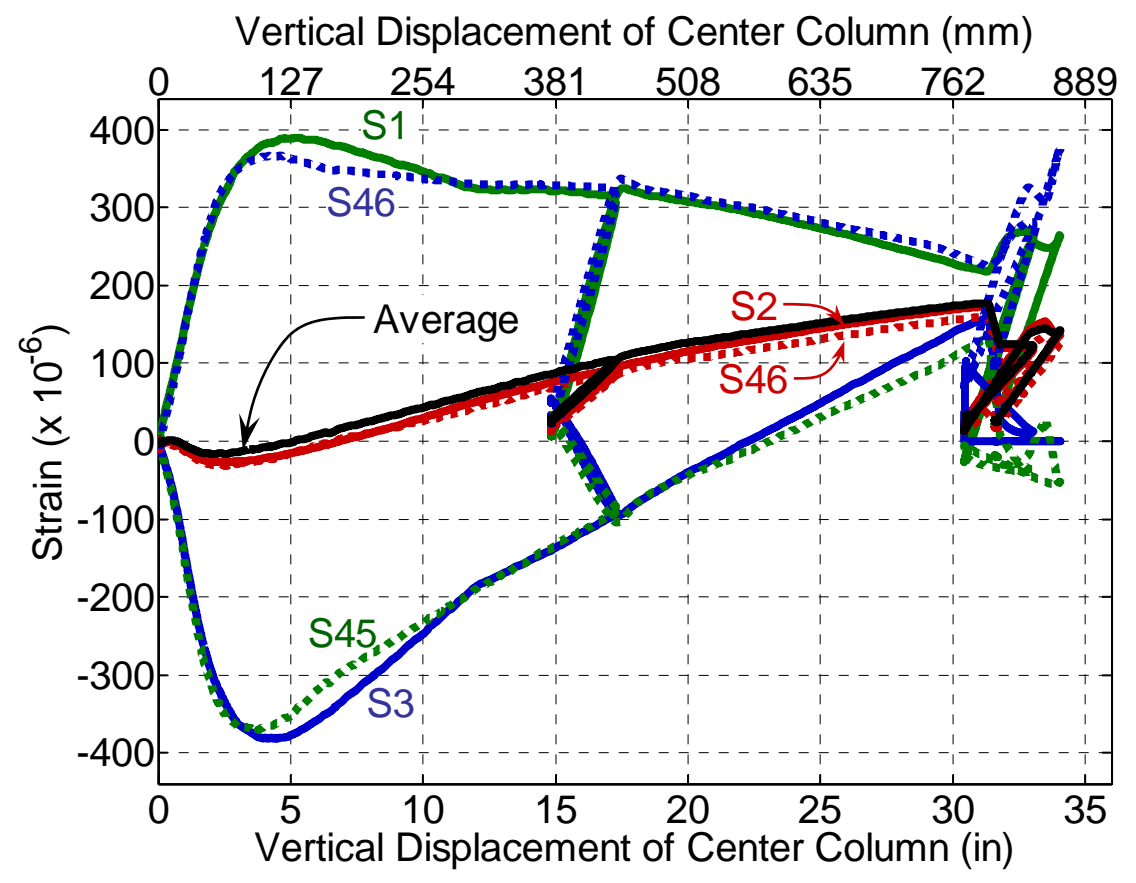

Figure 4-30 Strain measurements at Sections C1 and C2, along with their average, versus center column displacement of RBS specimen

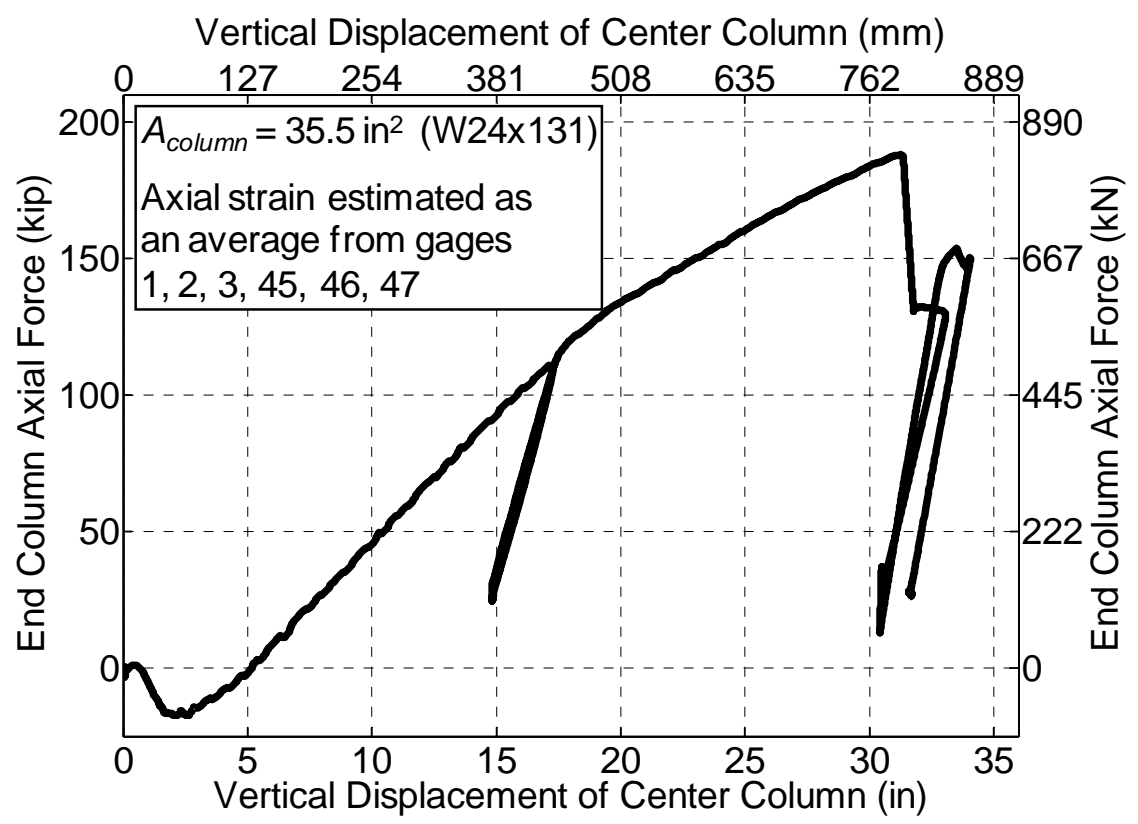

Figure 4-31 Axial force in end columns versus center column displacement of RBS specimen 
Figure 4-32 depicts the strain gage measurements at Section W1 (S10 and S11 for the east brace and S12 and S13 for the west brace) and Section W2 (S31 and S32 for the east brace and S33 and S34 for the west brace) on the diagonal braces versus the vertical displacement at the center column. The figure indicates that each brace was subjected to both axial force and bending. The figure shows that all strains at these sections were significantly less than the nominal yield strain of the steel $\left(0.2 \%\right.$ or $\left.2 \times 10^{-3}\right)$, indicating that the braces remained in the elastic range throughout the test. The average strain plotted in Figure 4-32 is the average of all the eight strain measurements. This average strain was used to calculate the axial force in each diagonal brace. The axial force in the diagonal braces versus the vertical displacement of the center column is presented in Figure 4-33, where it can be observed that the diagonal braces were always in compression during the response.

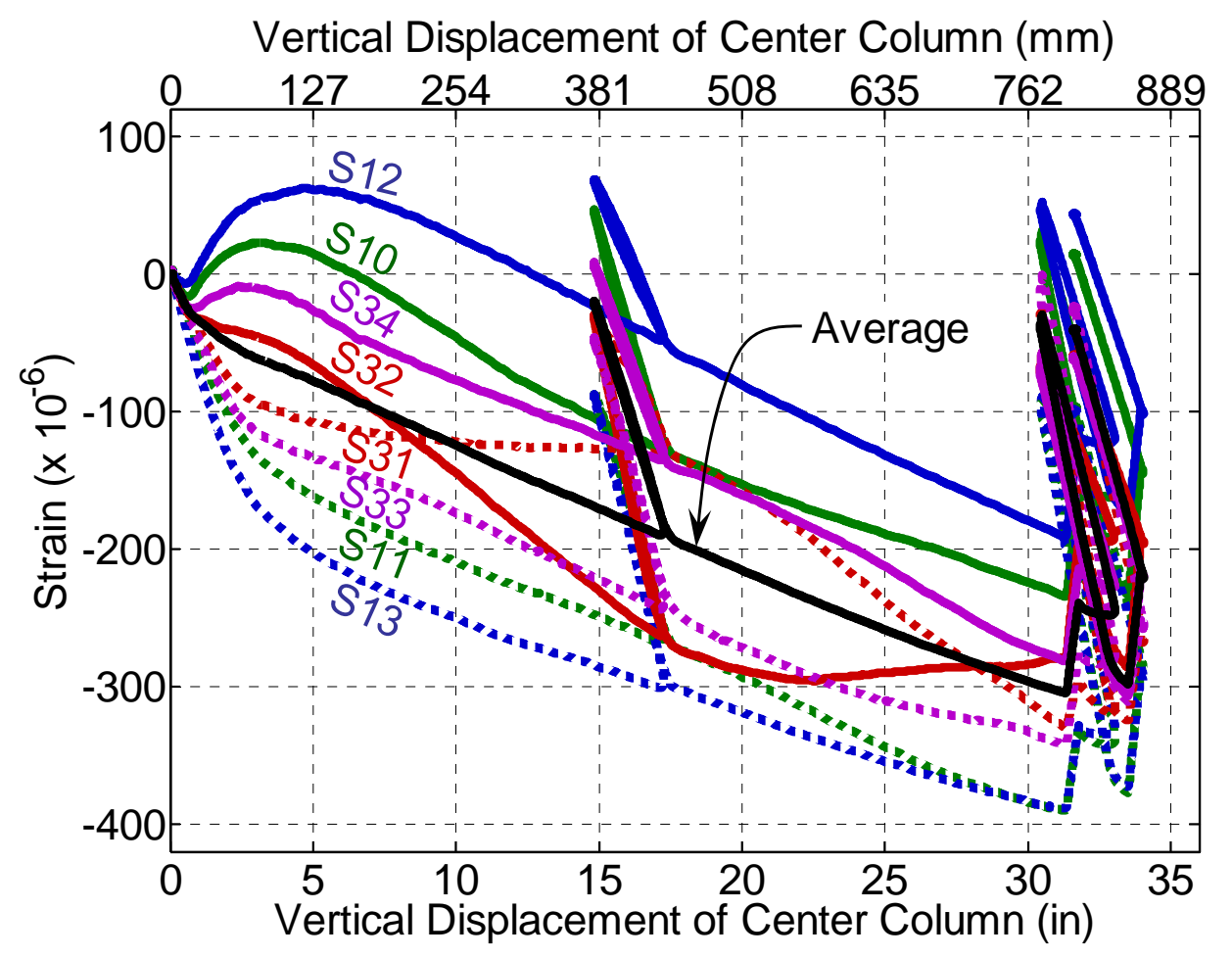

Figure 4-32 Strain measurements at Sections W1 and W2, along with their average, versus center column displacement of RBS specimen 


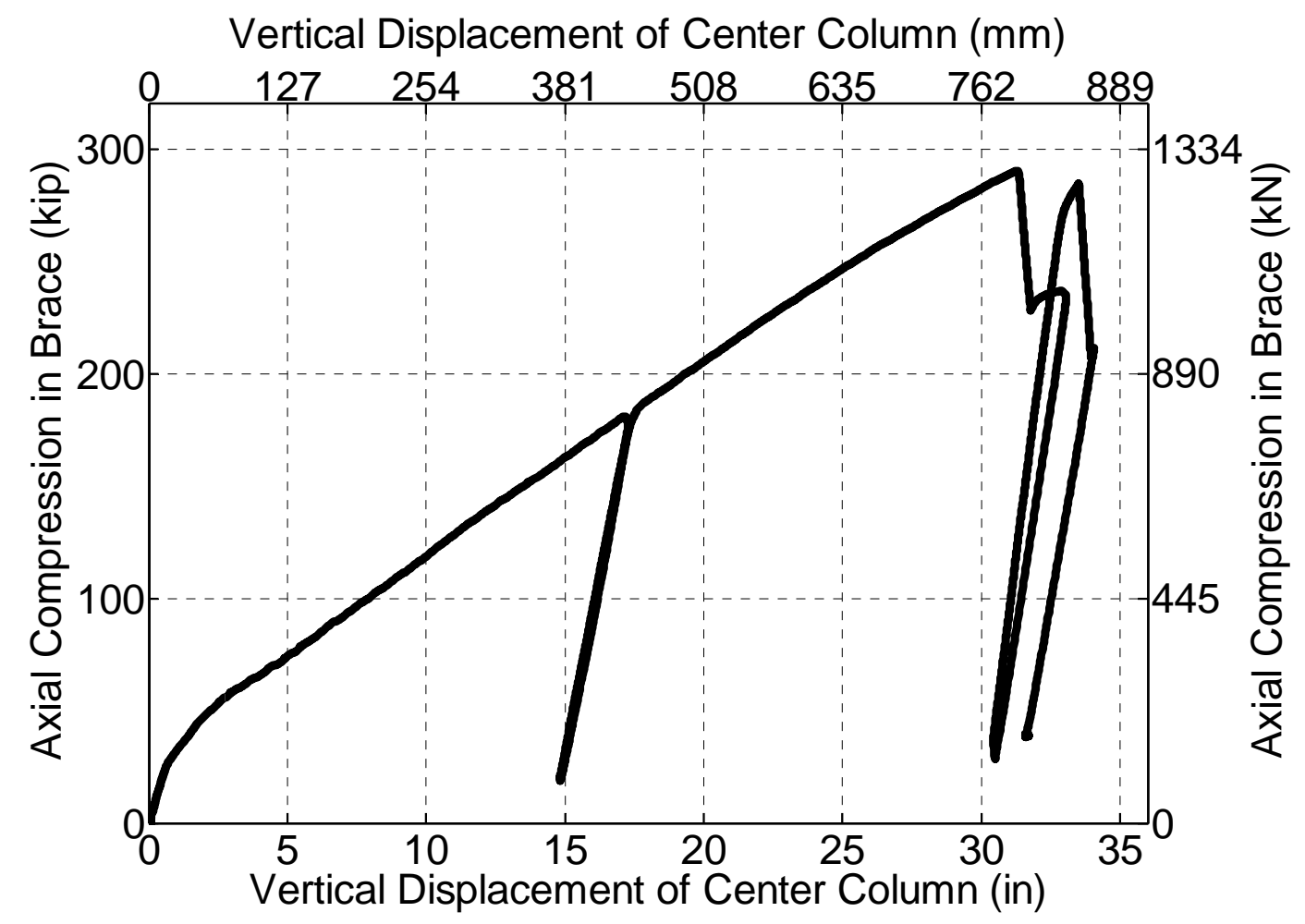

Figure 4-33 Axial compressive force in each diagonal brace versus center column displacement of RBS specimen

\subsection{DISCUSSION OF TEST RESULTS}

This chapter presented the experimental performance of beam-column assemblies with two types of moment resisting connections under vertical column displacement. The connections considered include (1) a welded unreinforced flange-bolted web (WUF-B) connection and (2) a reduced beam section (RBS) connection. The experimental results included the observed behavior and failure modes, along with response measurements from the displacement transducers, inclinometers, strain gages, and load cell.

For both the WUF-B and RBS test specimens, the beam-column assembly initially remained in the elastic range at small displacements of the center column. In that early stage of the response, the behavior was dominated by flexure. With increased vertical displacement, yielding occurred at the beam-to-column connections, and axial tension developed in the beams, indicating catenary behavior. The axial tension in the beams increased until the connections could no longer sustain the combined bending and axial stresses, and the beam-column assemblies failed.

The failure of the WUF-B test specimen was characterized by the following sequence: (1) local buckling of the top flanges of the beams near the center column, (2) successive shear failure of the lowest and middle bolts connecting the beam web to a shear tab at the center column, and (3) fracture of the bottom flange near the weld access hole immediately thereafter. The failure of the RBS test specimen was 
characterized by the fracture of the bottom flange in the reduced section of a connection near the center column. The fracture propagated through the web until the vertical load-carrying capacity was lost.

Table 4-1 summarizes the rotation capacities based on the tests conducted in this study and on prior seismic test data (see Chapter 2). As the table indicates, the rotations at peak load based on the experimental results in this study were about $0.081 \mathrm{rad}$ for the WUF-B connections, obtained by dividing the center column displacement at failure of $19.5 \mathrm{in}(495 \mathrm{~mm})$ by the centerline-to-centerline beam span of 240.0 in $(6096 \mathrm{~mm})$, and $0.140 \mathrm{rad}$ for the RBS connection, obtained by dividing the center column displacement at failure of $33.5 \mathrm{in}(851 \mathrm{~mm})$ by the centerline-to-centerline beam span of $240.0 \mathrm{in}$ $(6096 \mathrm{~mm})$. The rotational capacities of these connections based on seismic testing data are approximately $0.047 \mathrm{rad}$ for the WUF-B connection, based on Equation (2.1), and 0.073 rad for the RBS connection, based on Equation (2.3). These results show that the rotational capacities of these connections under monotonic column displacement are about twice as large as those based on seismic test data. Contributors to this difference may include: (1) cyclic loading leads to significant degradation in the strength and stiffness of the connection, while no such degradation is expected under monotonic loading, and (2) the applied loads are resisted by different mechanisms in the two cases, with the connection in pure flexure for seismic loading but subjected to combined flexure and tension under vertical column displacement.

Table 4-1. Comparison of rotation capacities of WUF-B and RBS connections based on seismic data and monotonic column displacement

\begin{tabular}{|c|c|c|}
\hline \multirow{2}{*}{$\begin{array}{c}\text { Connection } \\
\text { Type }\end{array}$} & $\begin{array}{c}|c| \\
\text { Seismic Data } \\
\text { (FEMA 350) }\end{array}$ & $\begin{array}{c}\text { Monotonic Loading } \\
\text { (This Study) }\end{array}$ \\
\cline { 2 - 3 } & 0.047 & 0.081 \\
\hline WUF-B & 0.073 & 0.140 \\
\hline RBS & \multicolumn{2}{|c}{} \\
\hline
\end{tabular}

\subsection{REFERENCES}

FEMA (2000). Recommended seismic design criteria for new steel moment-frame buildings, FEMA 350, SAC Joint Venture and Federal Emergency Management Agency, Washington, D.C. 


\section{Chapter 5 \\ Computational Modeling and ANALYSis Of TeSt Specimens}

\section{$5.1 \quad$ INTRODUCTION}

This chapter presents a computational investigation of the response of steel beam-column assemblies with moment resisting connections under the monotonic loading conditions expected in column removal scenarios, in which connections are subjected to combined bending and tension. The objectives of the analyses are to: (1) develop validated, detailed models of the assemblies, including the moment connections that mimic the behavior and failure modes of the test specimens, (2) develop reduced models of the connections that can be used in future studies to conduct three-dimensional system-level analyses of structures for assessment of their disproportionate collapse vulnerability, and (3) gain insight into the behavior and failure modes of the moment resisting connections, including the capacity of the connections to carry tensile forces that develop in the beams.

The finite element analyses presented in this study are conducted using explicit time integration in LSDYNA (Hallquist, 2007), a general-purpose finite element software package. The analyses account for both geometrical and material nonlinearities, including element failure and erosion. In all analyses the center stub column is pushed down under displacement control until failure occurs. Displacements are increased at a slow rate to ensure a static response (no dynamic amplification), similar to the test loading. Comparisons between the analysis results of the detailed and reduced models and the experimental results are presented to validate the models developed herein.

Section 5.2 provides an overview of the material models used in the analyses. Sections 5.3 and 5.4 provide details on the model development and the analysis results for the WUF-B specimen and the RBS specimen, respectively. Section 5.5 presents a summary and discussion of the analysis results.

\section{$5.2 \quad$ MATERIAL MODELS}

\subsubsection{Steel Sections and Plates}

Various material models are available in LS-DYNA that can capture the nonlinear behavior and failure of the steel components. The primary material model used in the analyses presented in this study was a piecewise linear plasticity model (material model 24 in LS-DYNA; Hallquist, 2007). In this model, an effective stress versus effective plastic strain curve is specified, along with a plastic strain to failure. Once the failure strain is reached, the element is eroded, simulating fracture of the steel.

For the various types of steel used in the test specimens, the material model parameters were developed based on engineering stress-strain curves obtained from coupon tensile tests for all steel sections and plates (see Chapter 3). The coupon tensile tests applied the ASTM 370 test standard (ASTM Designation A 370-03a 2003). For both the WUF-B and RBS specimens, the coupon tests provided data for beam webs, beam flanges, column webs, column flanges, shear tabs, continuity plates, and any doubler plates. 
For the solid and shell elements used in the detailed models, the approach to developing the material model parameters for each steel type was as follows:

- $\quad$ The engineering stress-strain curve was converted to a true stress vs. plastic strain curve. The true stress $\sigma_{T}$ is based on the load divided by the actual cross sectional area of the sample and is equal to the engineering stress $\sigma_{\text {eng }}$ multiplied by a term to correct for the change in cross section:

$$
\sigma_{T}=\sigma_{\text {eng }}(1+e)
$$

where $e$ is the engineering strain. Prior to the onset of localization (necking), the natural or true strain $\varepsilon_{T}$ is defined as

$$
\varepsilon_{T}=\ln (1+e)
$$

The plastic strain is then obtained as $\varepsilon_{p}=\varepsilon_{T}-\sigma_{T} / E$, where $E$ is the elastic modulus and $\sigma_{T} / E$ represents the elastic strain.

- Since for each steel type, a number of coupon tests were conducted, the converted true stressstrain curves were averaged. The averaged true stress-strain curve was then extrapolated beyond the point of necking onset.

- Iterative finite element analyses of the tensile test were carried out, and the failure strain $\varepsilon_{f}$ and the extrapolation of the true stress-strain curve were adjusted until quantitative agreement of the measured and calculated engineering stress-strain behavior in the softening region beyond the maximum stress was reached. Due to the dependence of strain to failure on mesh size, the finite element models were developed, using the same mesh type (shell or solid element) and size as those used in the various models of the test specimens for each steel type.

This approach ensured that the measured nonlinear material behavior up to failure was accurately captured in the material model. In addition, the simulation of the material testing provided a validation that the material model parameters were defined accurately and that the model could reproduce the measured response for the test conditions.

For the beam elements used in the reduced models, Eqs. (5.1) and (5.2) do not apply for large strains, because the beam model does not account for changes in cross-sectional area. Rather than using Eq. (5.1), the engineering stress values were input directly in the beam material models. The corresponding plastic strain values were adjusted so that the engineering stress-strain curves obtained computationally from uniaxial tension matched those obtained experimentally. Values of the failure strain $\varepsilon_{f}$ for a particular beam element size were determined such that the extension at fracture was consistent with the results of a detailed solid or shell element model with a corresponding gage length.

Figure 5-1 shows examples of detailed finite element models of a coupon sample obtained from the flanges of the W21x73 beam section used in the WUF-B specimen. For modeling the beam flanges in the WUF-B specimen, the detailed solid/shell element model (see Section 5.3.1) used two different mesh types: (1) a solid element mesh with element size of approximately 0.18 in (4.6 mm), typical of that used in the vicinity of the connections, and (2) a shell element mesh with element size of approximately 0.75 in $(19 \mathrm{~mm})$, typical of that used away from the connections. These mesh types and sizes were used in the modeling of the coupons as shown in Figure 5-1. Figure 5-2 shows the true stress-true strain curves used as input for the beam flange steel for the solid, shell, and beam element models. As is evident in the figure, coarser meshes entail the use of smaller values of the failure strain $\varepsilon_{f}$ to achieve consistent results. 
Note that the true stress vs. plastic strain curve used for the shell elements is extrapolated horizontally beyond the point of necking onset, while the curve used for the solid elements is extrapolated tangentially. Figure 5-3 presents the measured engineering stress-strain curve from the coupon test samples along with the analysis results of the solid and shell element models of the coupons. Strain values in the figure correspond to a gage length of 2 in $(51 \mathrm{~mm})$, and results from the beam element model are not included, as they correspond to a longer gage length. The comparison between the measured and calculated stressstrain behavior indicates that the material models capture the constitutive relationships for the steel of the beam flange with reasonable accuracy. The process shown here was repeated for all coupon tests to develop the constitutive material models for beam webs and flanges, column webs and flanges, shear tabs, continuity plates, and doubler plates corresponding to the various element types and sizes considered in the finite element models. For the reduced models, in which wide flange sections were represented by beam elements, material models were based on stress-strain data from the flanges, rather than the webs.

(a)

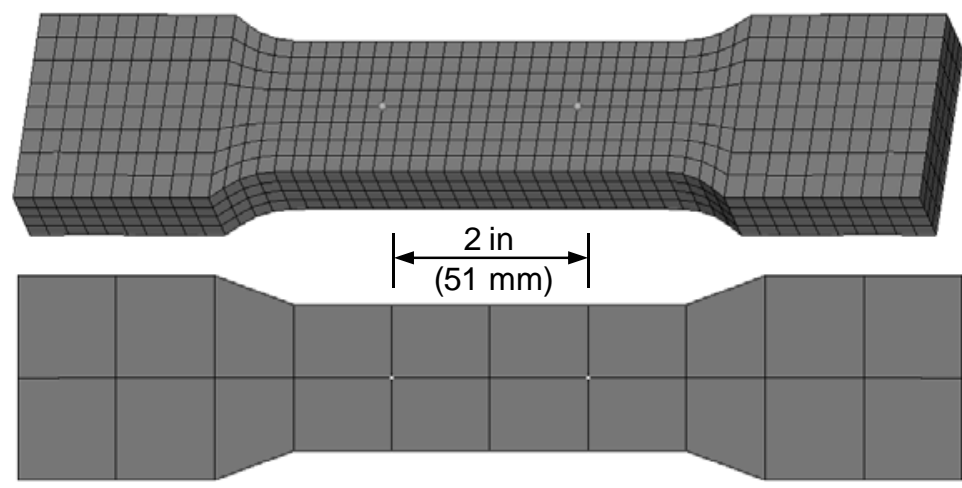

Figure 5-1 Example finite element models of ASTM 370 coupon tensile samples: (a) solid element model with 0.18 in $(4.6 \mathrm{~mm})$ element size; (b) shell element model with 0.75 in $(19 \mathrm{~mm})$ element size

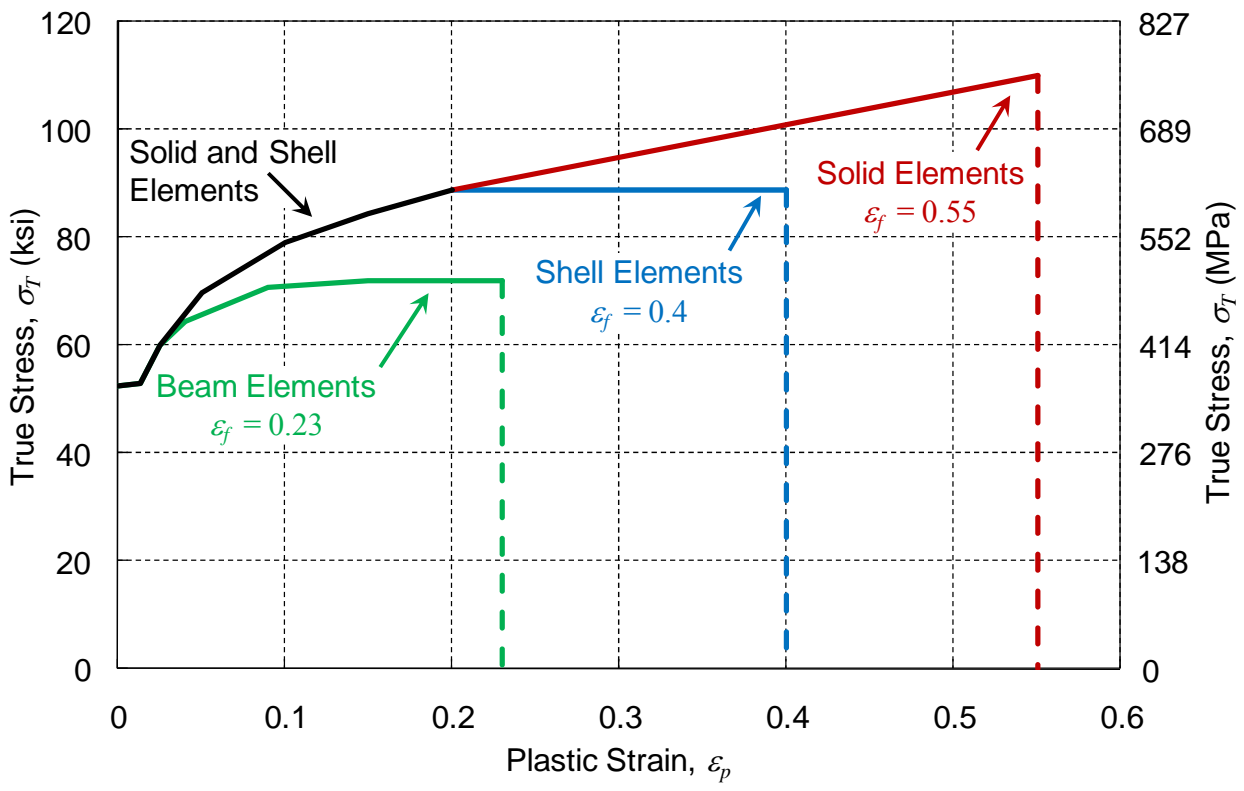

Figure 5-2 True stress-strain curves for the solid, shell, and beam elements used in modeling the beam flanges of the WUF-B specimen 


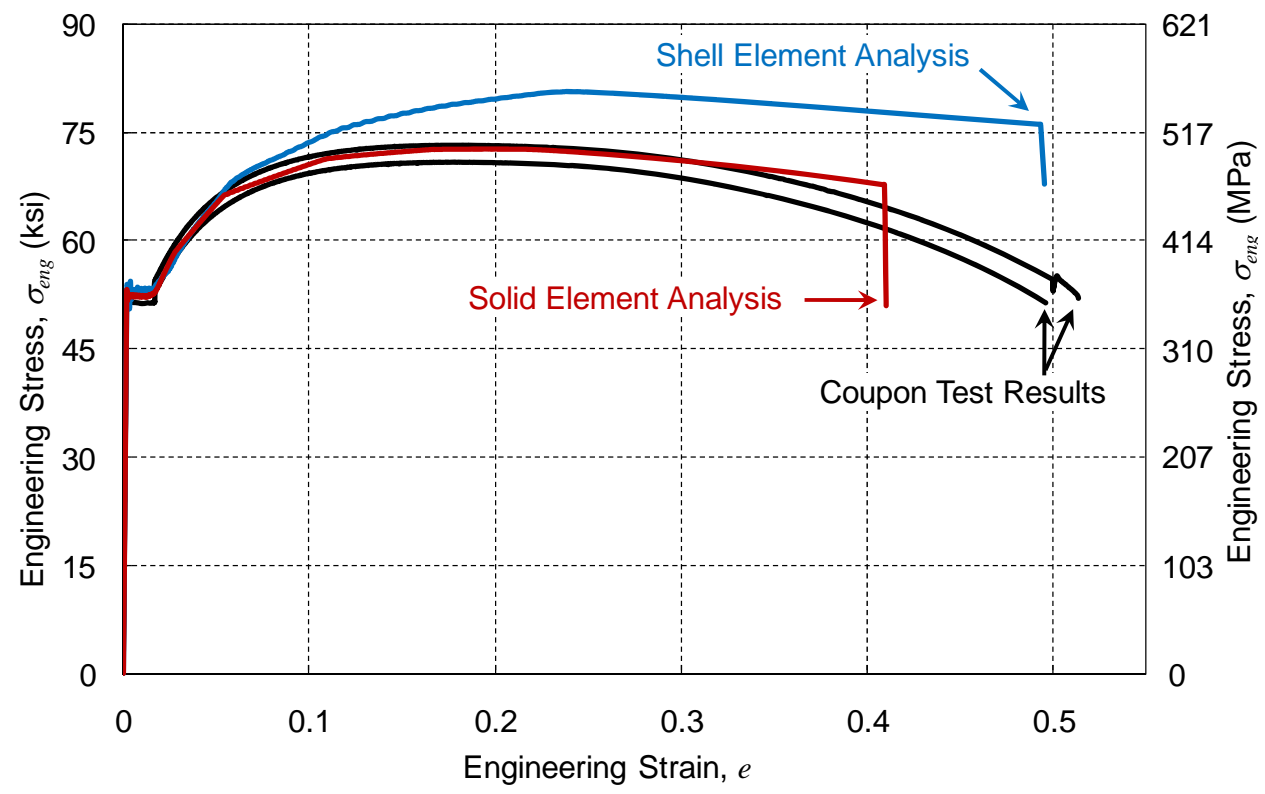

Figure 5-3 Engineering stress-strain curves obtained from coupon tests and from the analysis using solid and shell elements for modeling the beam flanges of the WUF-B specimen

\subsubsection{High Strength Bolts}

The bolts connecting the shear tabs to the beam webs in the WUF-B specimen were 1 in $(25.4 \mathrm{~mm})$ diameter ASTM A490 high strength bolts. Data in the open literature (Kulak et al., 1987) were used to calibrate the stress-strain relationships for the bolt material. The bolt material was represented by a piecewise linear plasticity model (material model 24 in LS-DYNA; Hallquist, 2007), which was used for the steel sections and plates. The true stress-strain relationship for the bolt material used in this model is shown in Figure 5-4.

The approach taken to develop the stress-strain relationship for the bolt material shown in Figure 5-4 was to develop a solid element model of the bolt for a double shear test and calibrate the resulting shear loaddeformation curve against experimental data reported in Kulak et al. (1987). The finite element mesh used to model the bolt was identical to that used in the detailed solid/shell element model of the WUF-B specimen (see Section 5.3.1). The model of the double shear bolt test is shown in Figure 5-5 and the deformed shape and failed bolt are shown in Figure 5-6. Due to symmetry, only one half of test sample with appropriate boundary conditions was considered in the analysis. Figure 5-7 shows the calculated load-deformation curve along with the experimental data from Kulak et al. (1987). Note that the load values reported in Figure 5-7 are for single shear (double shear divided by two). For the calculated shear load-deformation curve, the deformations reported are those for the bolt only (between the bolt head and shank), whereas the data from Kulak includes the test jig deformations. That may explain the difference in elastic stiffness between the measured and calculated responses. Overall, the agreement between the measured and calculated responses was good. In the reduced model of the WUF-B specimen (Section 5.3.2), spring elements were used to model the shear behavior of the bolts. 


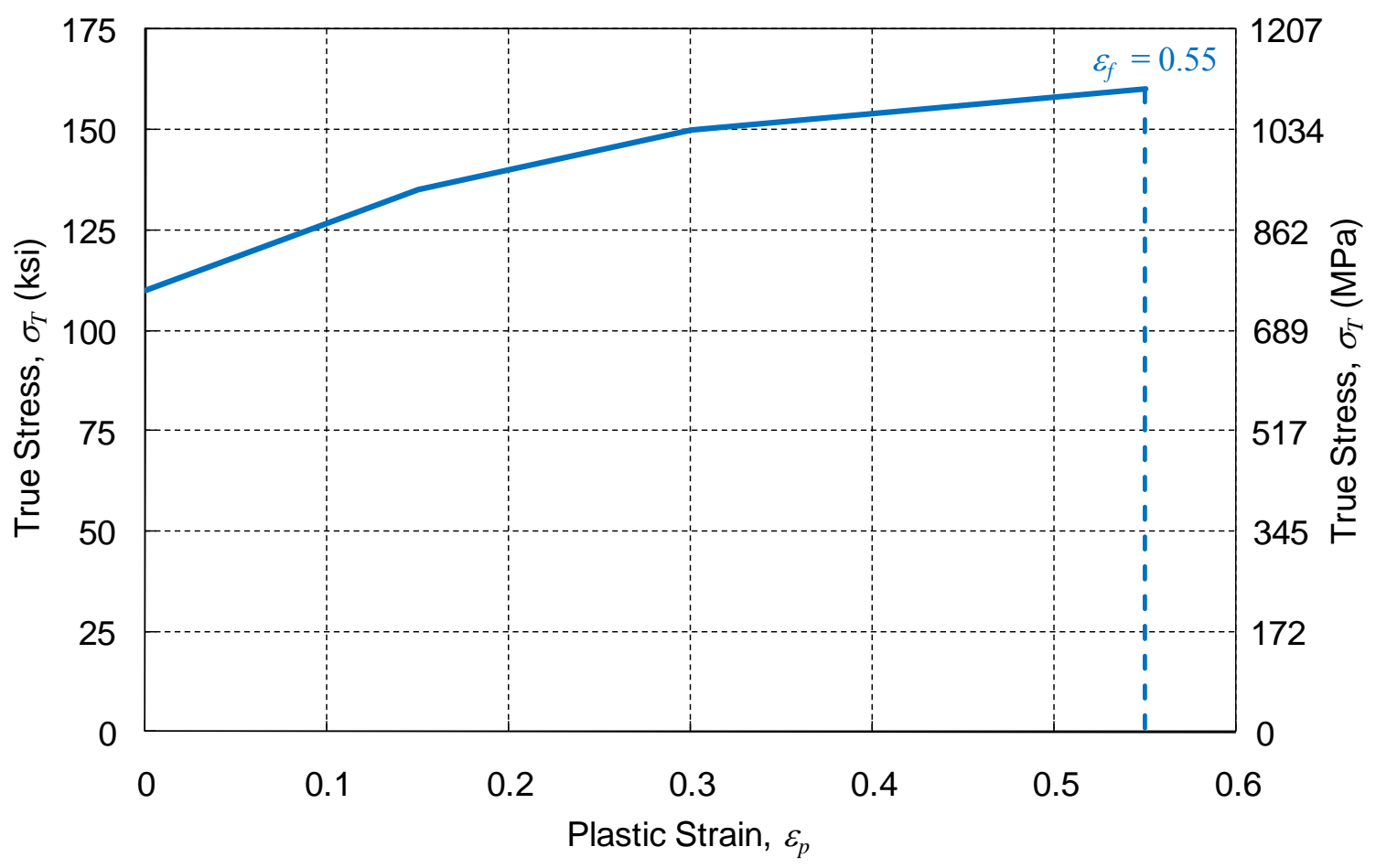

Figure 5-4 True stress-strain curve for the solid elements used in modeling the bolts of the WUF-B specimen

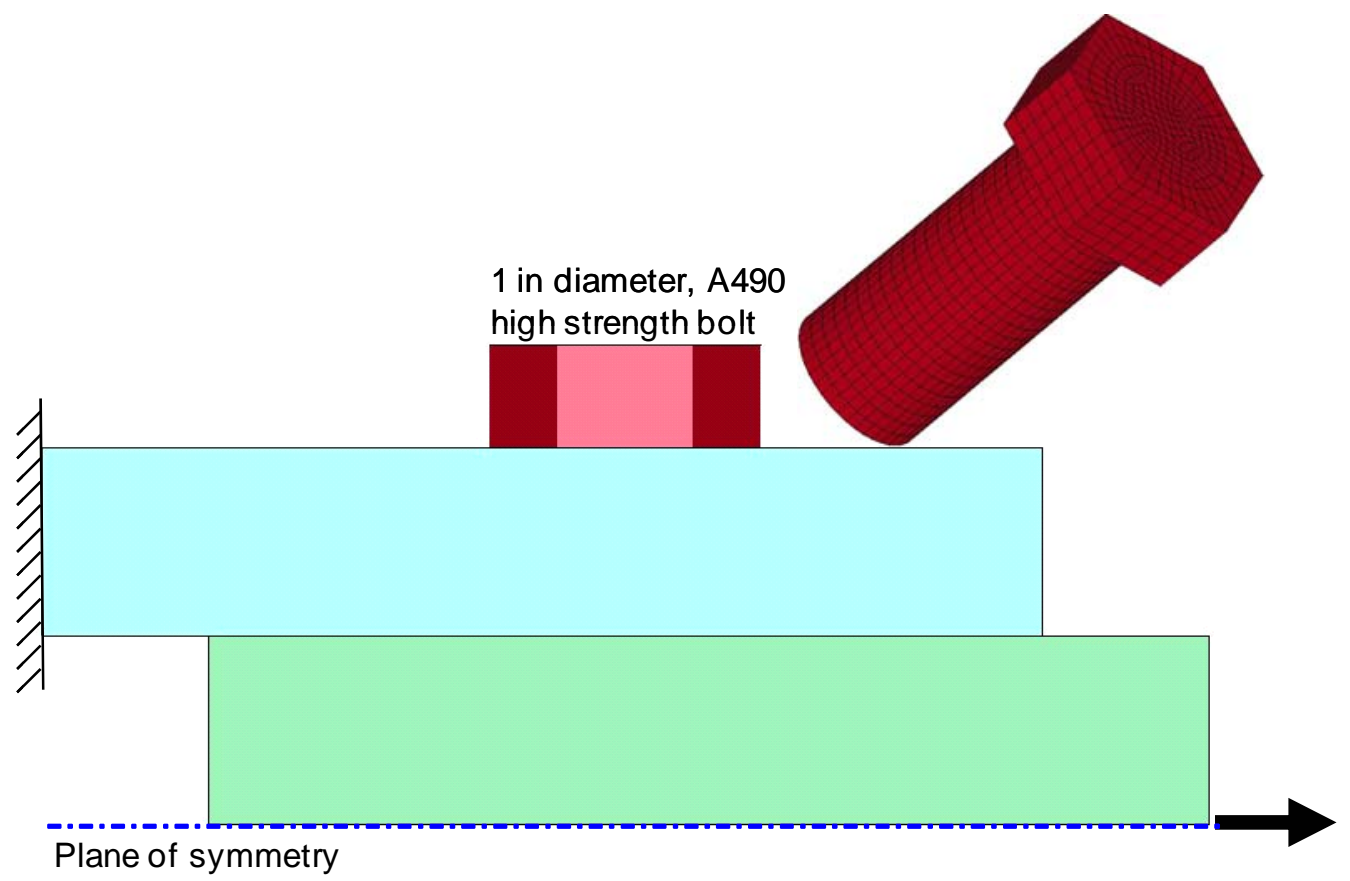

Figure 5-5 Finite element model of a bolt double shear test 


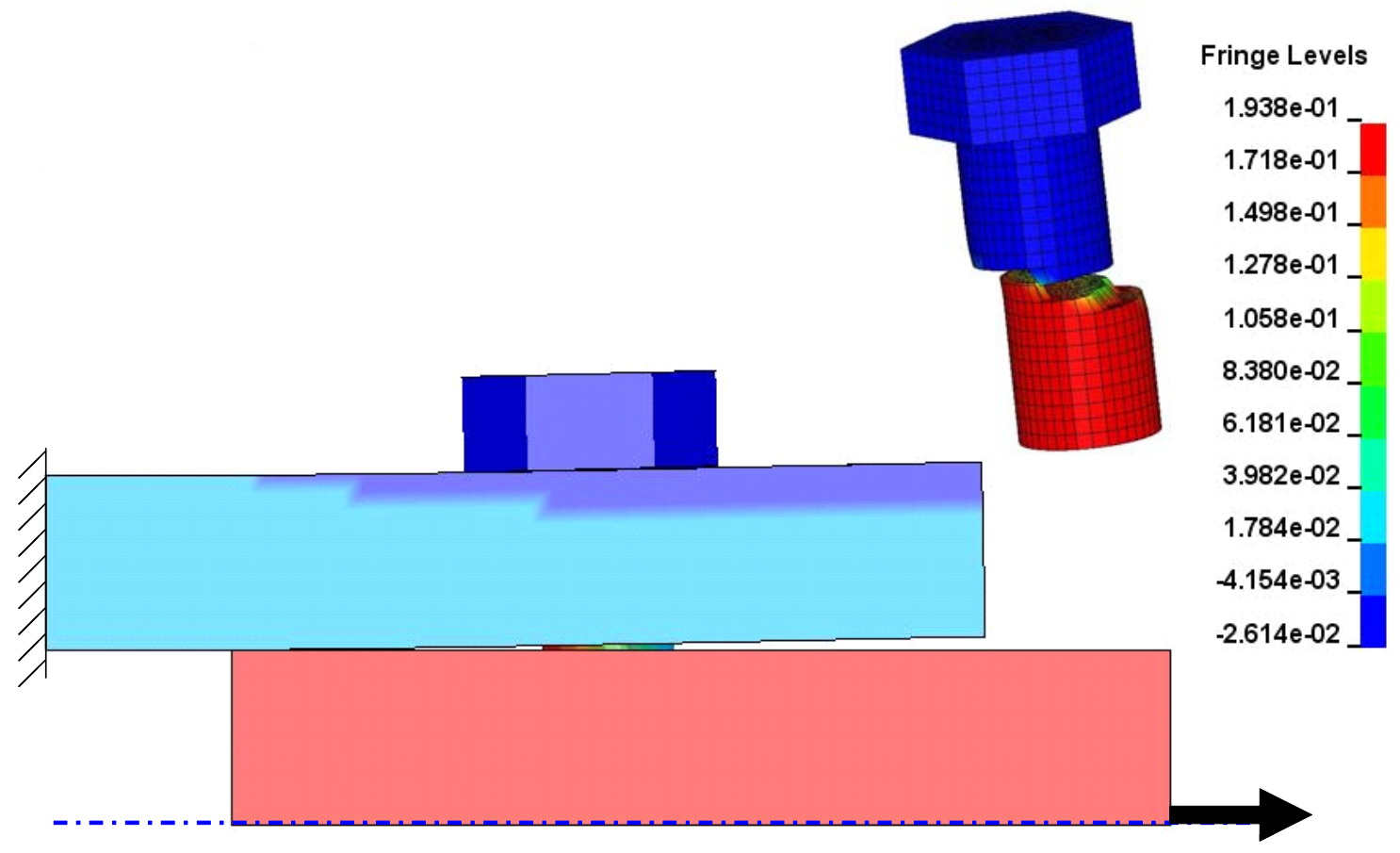

Figure 5-6 Response of the bolt double shear model

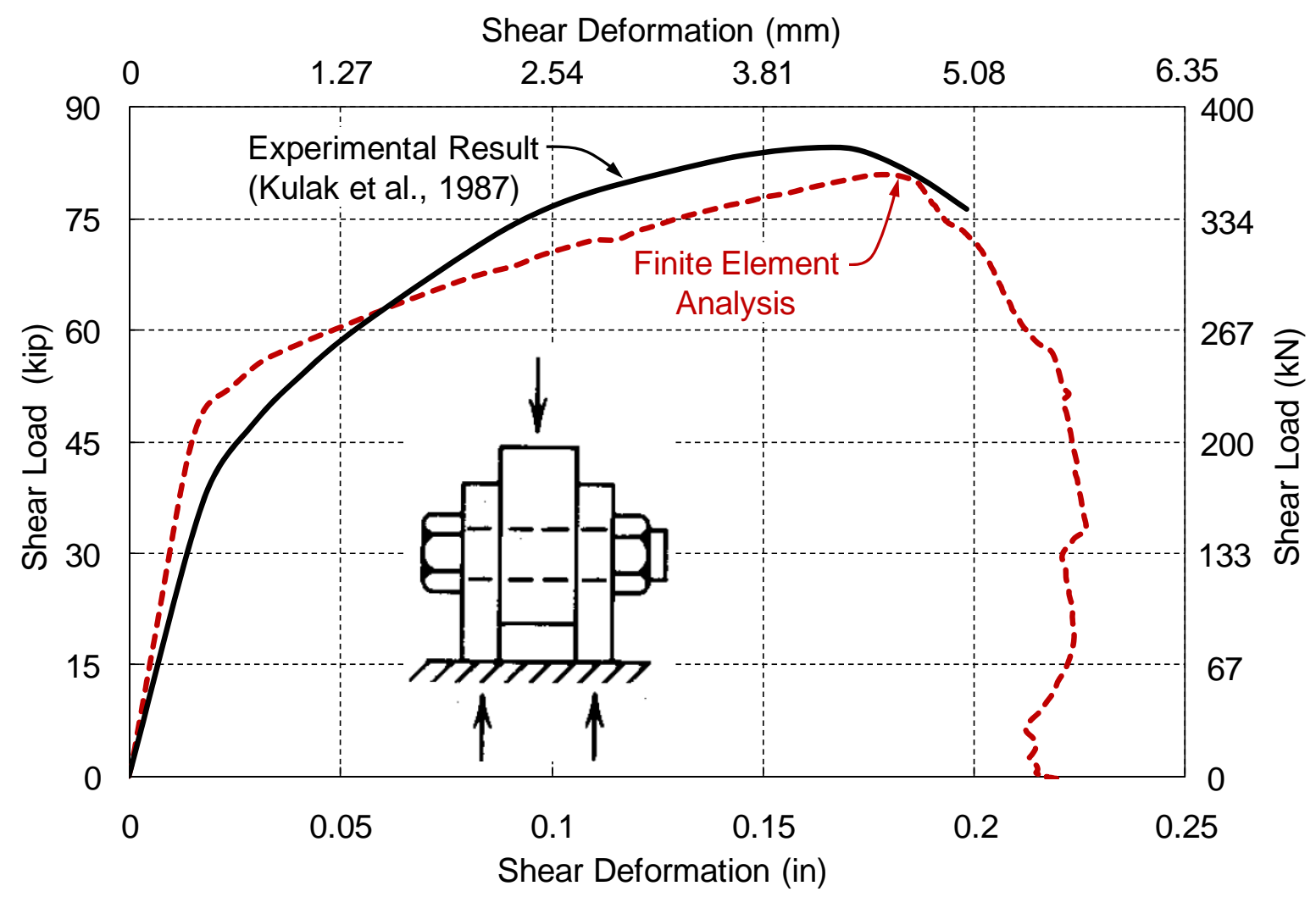

Figure 5-7 Measured and calculated shear load-deformation curves for 1 in, A490 bolt 


\subsubsection{Diagonal Braces}

In the experimental setup for both specimens (see Chapter 3), two diagonal braces were rigidly attached to the top of each end column to simulate the bracing effect provided by the upper floors in a multi-story building. Since the details of the brace and its connections were not of primary importance to the computational effort, these diagonal braces were represented as an arrangement of spring elements in all models. The spring elements accounted for various sources of nonlinearity that might include the brace response and the end connections behavior (plasticity, slip, etc). The load-deformation characteristics of these springs, for each specimen, were estimated as follows:

- The axial force in each brace was estimated based on:

o RBS specimen: the strain gage measurements on the braces (see Figure 4-33)

0 WUF-B specimen: force equilibrium considering the axial force in the end columns (see Figure 4-15) and the applied vertical load (strain measurements on the braces were unavailable for this specimen)

- The axial displacement (or shortening) of each brace, calculated as the component (along the axis of the brace) of the lateral displacement of the end column at mid-depth of the brace, was estimated based on:

o RBS specimen: interpolation of the measured horizontal displacements of the end columns at (a) column top and (b) beam mid-height (see Figure 4-20)

o WUF-B specimen: measured horizontal displacements of the end columns at mid-height of the beam (see Figure 4-5), from which displacements at mid-depth of the brace were estimated based on analyses using the reduced model (see Section 5.3.2) with the loaddisplacement curve for the braces updated iteratively until convergence was achieved (displacement measurements at the top of the end columns were unavailable for this test).

Figure 5-8 shows the load-deformation curves for each diagonal brace for both specimens based on the methodology outlined above. Nonlinear behavior of the braces is evident, most likely associated with yielding and slippage where the braces were connected to the strong floor of the testing facility.

\subsection{WUF-B FINITE ELEMENT MODELS}

Two finite element models of the WUF-B specimen were developed to study the response characteristics of the specimen and to compare the calculated response with that measured during the test. The first was a detailed model of the specimen with approximately 300000 solid and shell elements, while the second was a reduced model with about 150 beam and spring elements. The following sections provide descriptions of the models and the analysis results. 


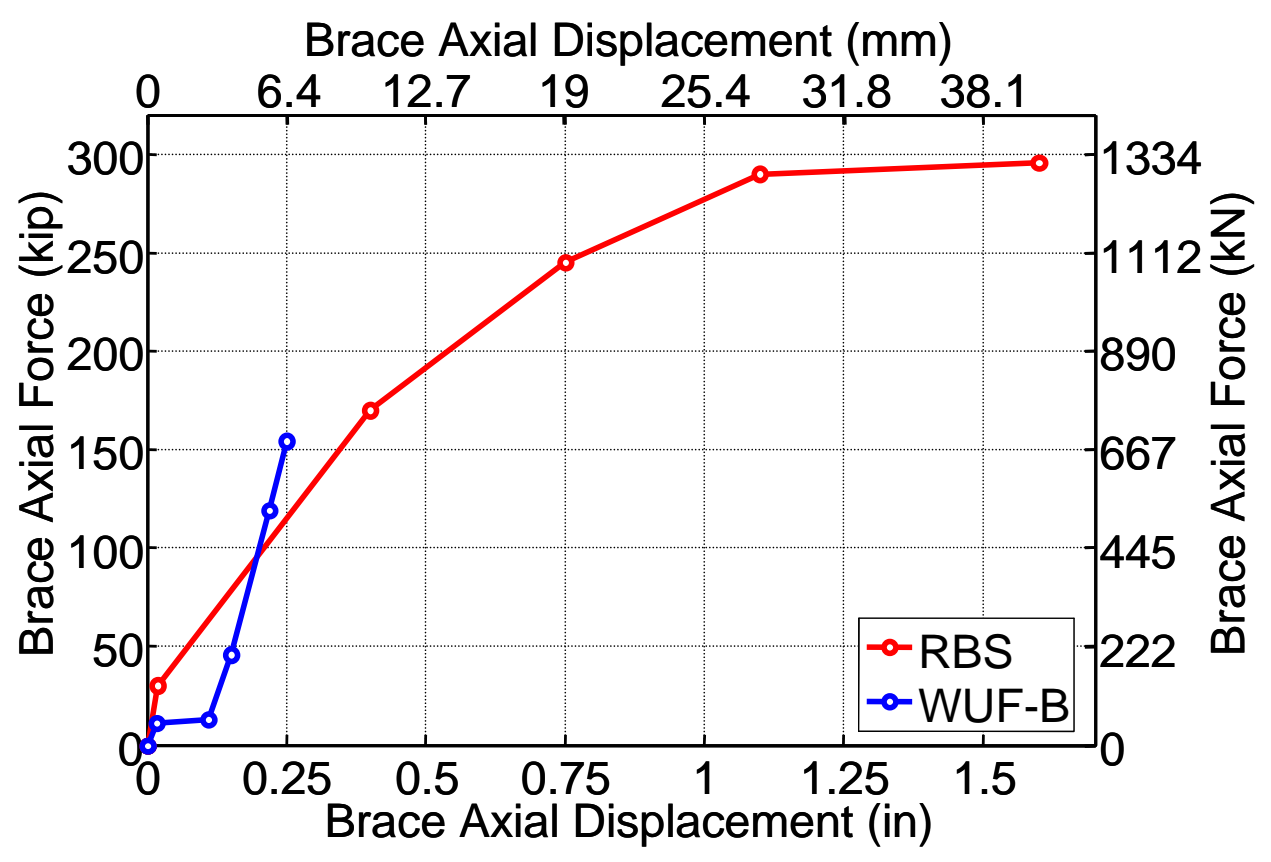

Figure 5-8 Axial load-displacement curve for diagonal braces for the WUF-B and RBS specimens

\subsubsection{Detailed (Solid/Shell Element) Model}

An overview of the detailed model used in the analysis of the WUF-B specimen is shown in Figure 5-9. Due to symmetry, only one half of the beam-column assembly with appropriate boundary conditions was modeled. The detailed model consisted of finely meshed solid (brick) elements representing the beams, columns, continuity plates, shear tabs, bolts, and welds in the vicinity of the connection. The details of the connection model are shown in Figure 5-10. Four layers of solid elements were used for all beam and shear tab plates and welds, which resulted in an element size in the range of 0.11 in to 0.19 in $(2.8 \mathrm{~mm}$ to $4.8 \mathrm{~mm}$ ). Two to four layers of solid elements were used for all column and continuity plates, which resulted in an element size in the range of 0.22 in to 0.53 in $(5.6 \mathrm{~mm}$ to $13.5 \mathrm{~mm})$. Solid elements with a minimum dimension of 0.07 in $(1.8 \mathrm{~mm})$ were used for the bolts. Contact with friction was defined between the bolts, shear tabs, and beam web to model the transfer of forces through the bolted connection. Contact was also defined between the shear tab and beam web to ensure that the beam web did not penetrate the shear tab, or vice versa. Hand calculations showed that the stresses in the fillet weld connecting the shear tab to the column flange were low compared to their strength. As a result, the shear tab was modeled as rigidly connected to the column flange.

Away from the connection zones, the beam and columns were modeled with shell elements (see Figure 59 and Figure 5-10). Appropriate constraints were imposed at the interface between the shell and solid elements to ensure that nodes on the solid elements remained in the same direction as the fiber of the shell elements. Spring elements were used to model the diagonal braces at the top of the end columns (see Section 5.2.3). All nodes were fixed at the bases of the end columns. Similar to the test configuration, out-of-plane lateral displacements of the beam flanges were constrained at mid-span. 
The steel materials for the beams, columns, and connection components, including the bolts, were modeled using a piecewise linear plasticity model as described in Section 5.2. Elements were eroded when a pre-specified strain-to-failure $\varepsilon_{f}$ was reached, signifying fracture of the steel.

The deflected shape of the WUF-B specimen based on this analysis is shown in Figure 5-11. During the response, the beam-column assembly responded initially in a purely flexural mode before catenary behavior developed. The beam remained essentially elastic except for sections in the vicinity of the connections next to the center and end columns where significant yielding was observed. The failure mode of the connection in the analysis, shown in Figure 5-12, was very similar to that observed in the experiment, shown previously in Figure 4-2. The lowermost bolt connecting the beam web to the shear tab at the center column failed in shear at a vertical displacement of the center column of about 17.5 in (445 mm), which was immediately followed by failure of the middle bolt. The bottom flange of the beam near the weld access hole began to fracture at a center column vertical displacement of approximately 19 in $(483 \mathrm{~mm})$. The fracture initiated at the root of the access hole (center of flange) and propagated outward until the bottom flange completely fractured as can be seen in Figure 5-12.

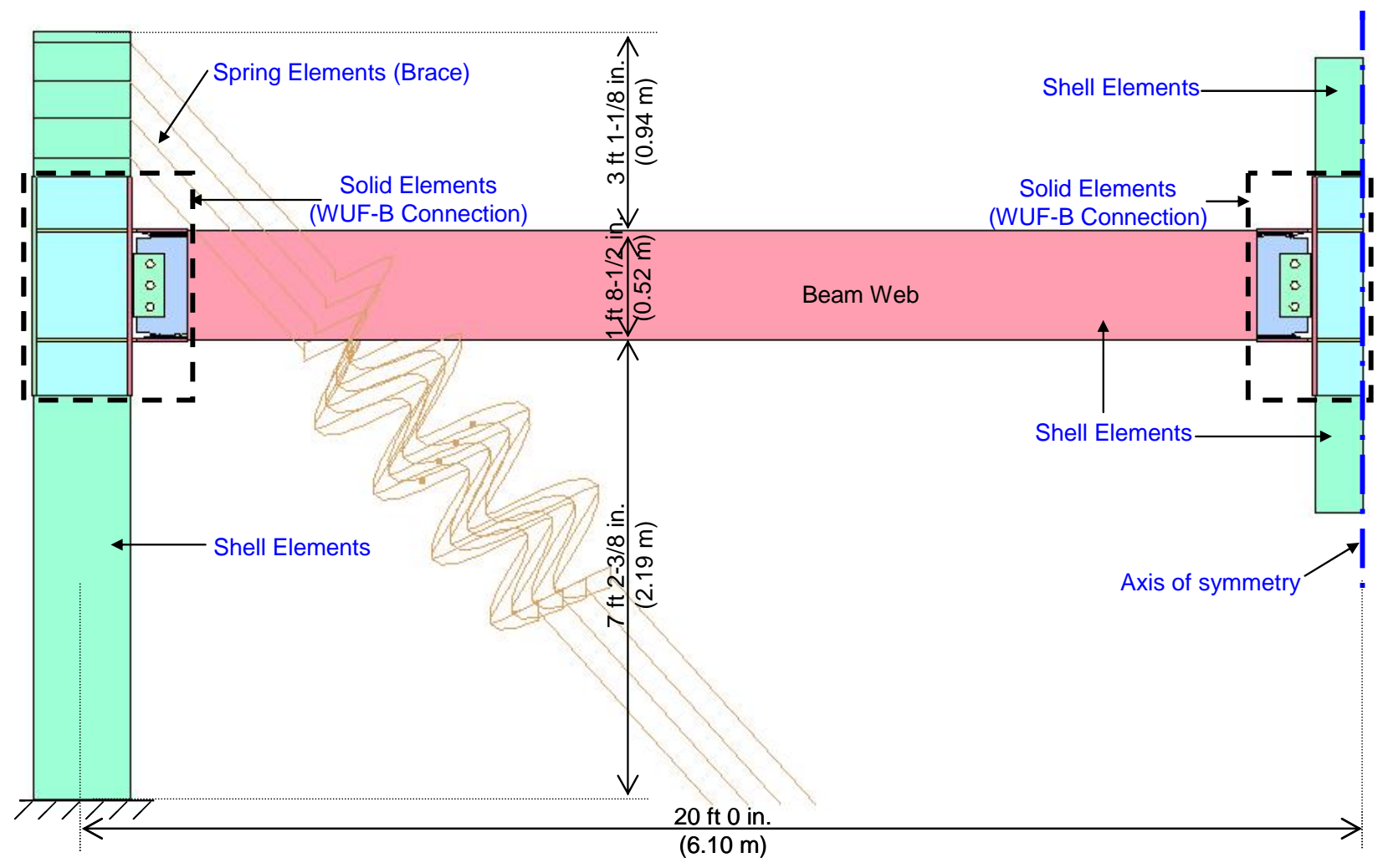

Figure 5-9 Overview of the detailed model of the WUF-B specimen 


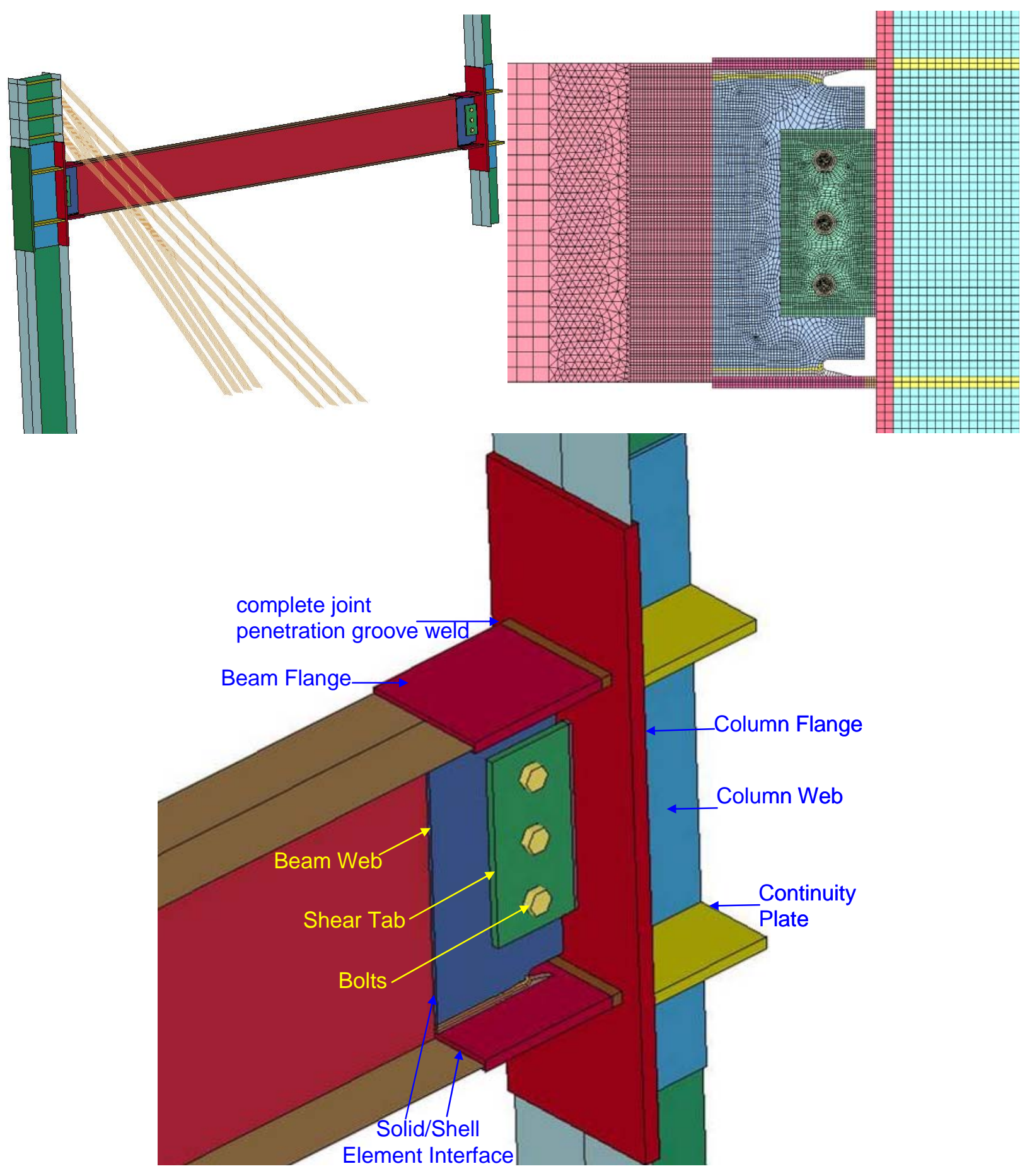

Figure 5-10 Detailed views of the WUF-B connection in the detailed model of the WUF-B specimen 


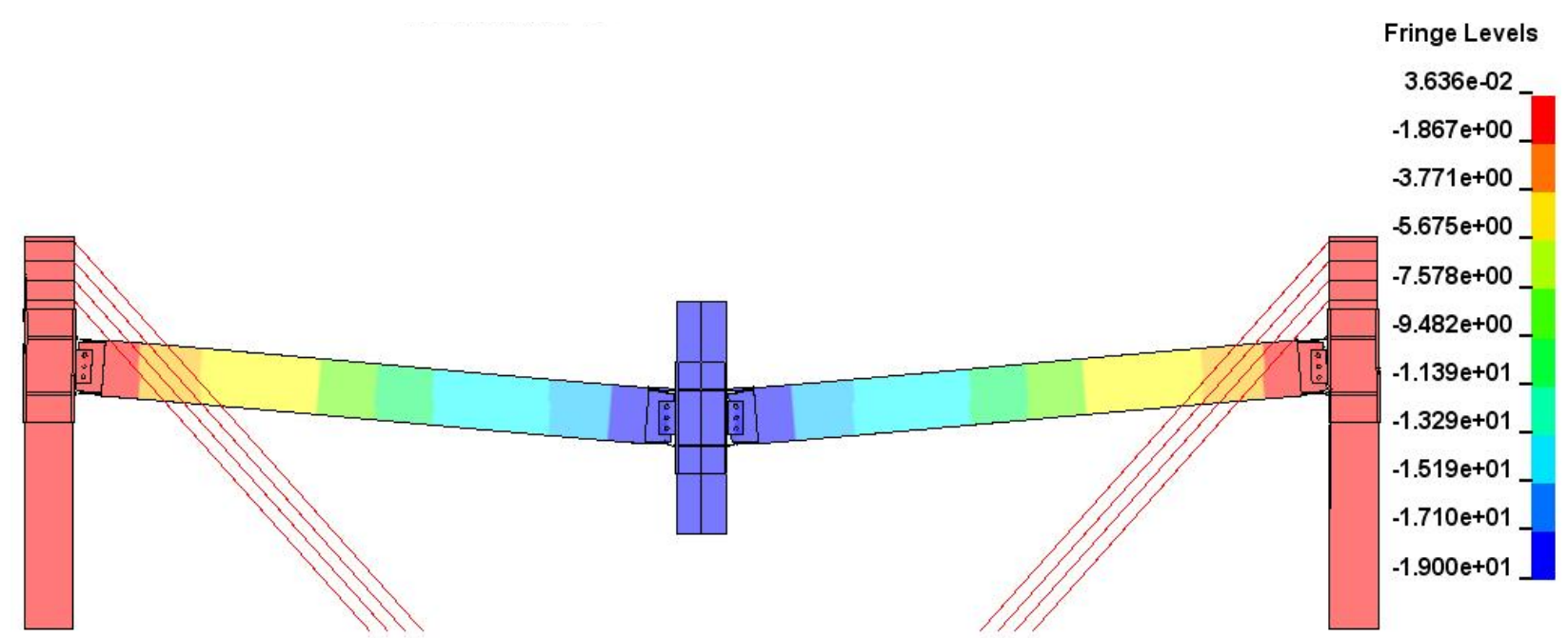

Figure 5-11 Deflected shape of WUF-B detailed model at a center column vertical displacement of 19 in (483 mm). Contours represent vertical displacements in inches.
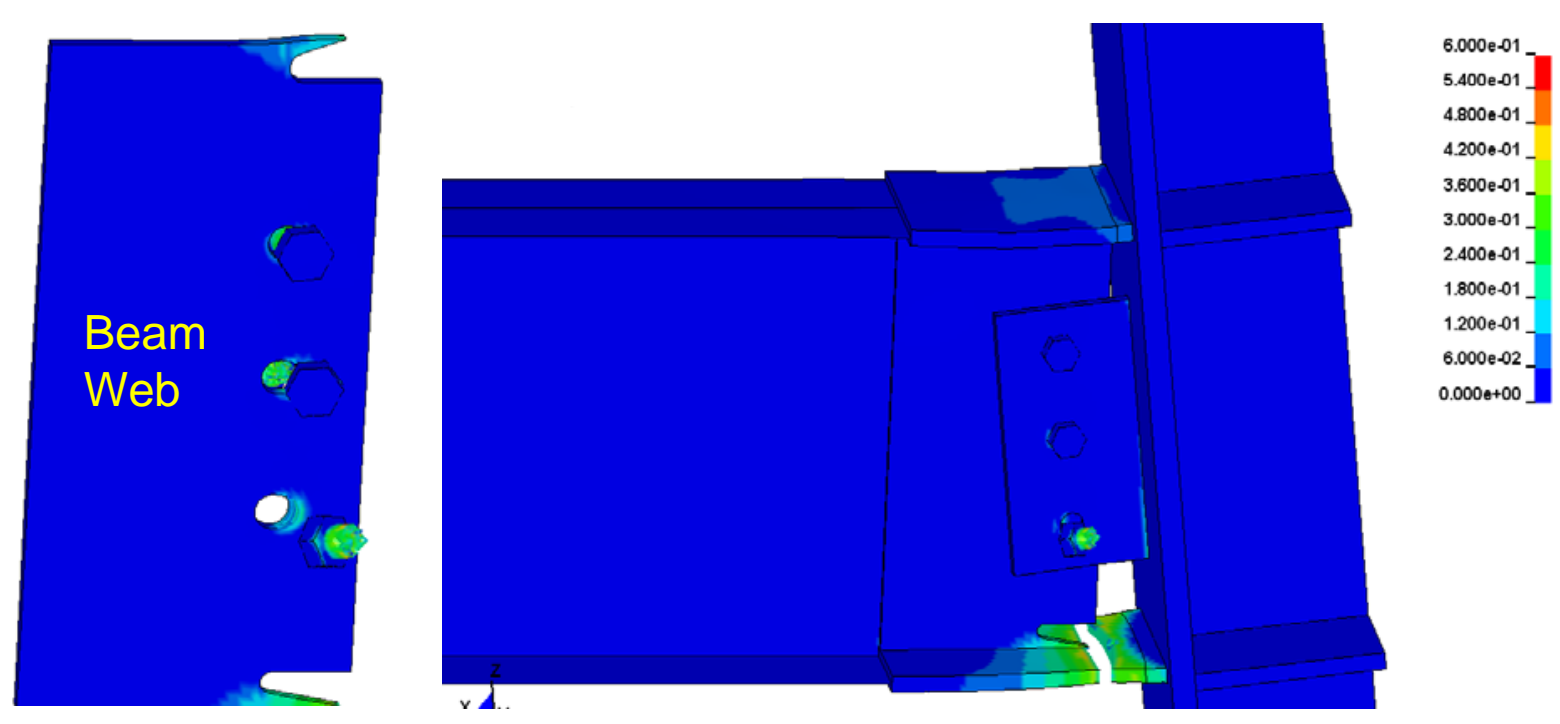

Figure 5-12 Failure mode of the WUF-B detailed model. Contours represent plastic strains

Figure 5-13 shows (a) the applied vertical load, (b) the beam axial force, (c) the horizontal (inward) displacement of the end columns at beam mid-height, and (d) the end column axial force, all plotted against the vertical displacement of the center column. These plots compare the experimental results with the results from the detailed finite element model presented in this section and with the results from the reduced model presented in Section 5.3.2. The plots show good agreement between the experimental and computational results, providing validation for the finite element models. 
(a)

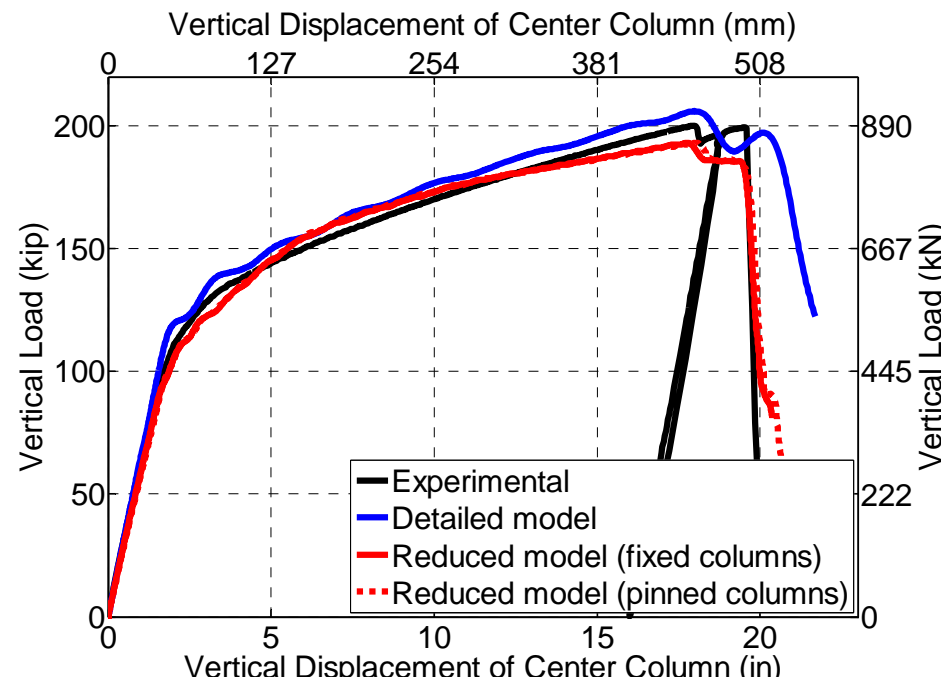

(c)

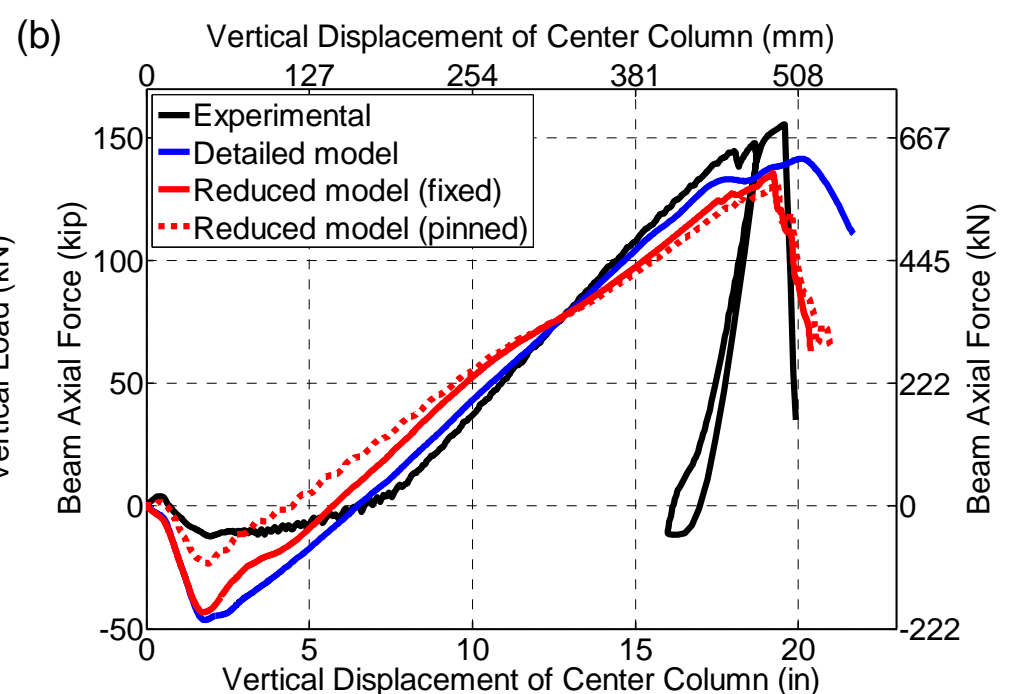

$\widehat{(d)}$

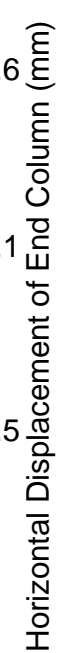

Vertical Displacement of Center Column (in)

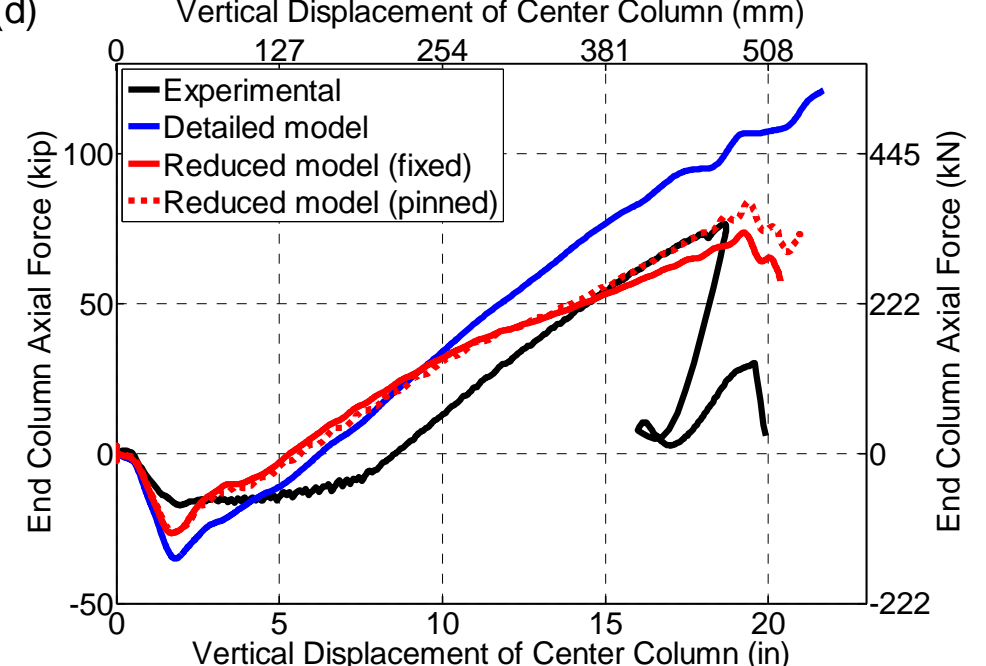

Figure 5-13 (a) Applied vertical load, (b) beam axial force, (c) horizontal displacement of end column at beam mid-height, and (d) end column axial force; all plotted against vertical displacement of center column for the WUF-B specimen 
Similar to the experimental results, the results of the detailed model shown in Figure 5-13(a) indicate that the assembly remained in the elastic range up to a vertical displacement of the center column of about 2 in $(50 \mathrm{~mm})$. The analysis indicates that in the early stages of the response the behavior was dominated by flexure, as indicated by the axial compression in the beams shown in Figure 5-13(b). With increased vertical displacement, axial tension developed in the beams and the behavior was dominated by catenary action. As Figure 5-13(b) indicates, the axial tensile force in the beams increased with increased downward displacement of the center column until the connection could no longer carry the combined axial and flexural stresses, resulting in the failure of the assembly. Similar to the experimental results, the results of the detailed model shown in Figure 5-13(d) indicate that in the initial stages of the response, the end columns were in compression, but with increased vertical displacement, axial tension developed in the end columns, as a result of the large compressive axial loads carried by the diagonal braces.

Figure 5-14 shows the bending moment-axial force interaction diagram for the WUF-B connection, based on the detailed analysis in this section and the reduced model analysis in Section 5.3.2. The bending moment and axial force were calculated at the face of the center column, where failure of the connection was observed. Superimposed on the connection response are the limiting bending moment-axial tension interaction diagrams for the gross beam cross section (W21x73) calculated based on the actual yield and ultimate strengths of the beam material. The limiting interaction diagrams for the beam cross section were calculated based on Chapter H of the 2005 AISC Specification (AISC 2005) using yield and ultimate stress values obtained from tensile tests (see Table 3-1). The figure shows that the capacity of the WUF-B connection exceeds the yield capacity of the beam gross cross section under combined axial and flexural loads, but is somewhat less than the ultimate strength of the beam.

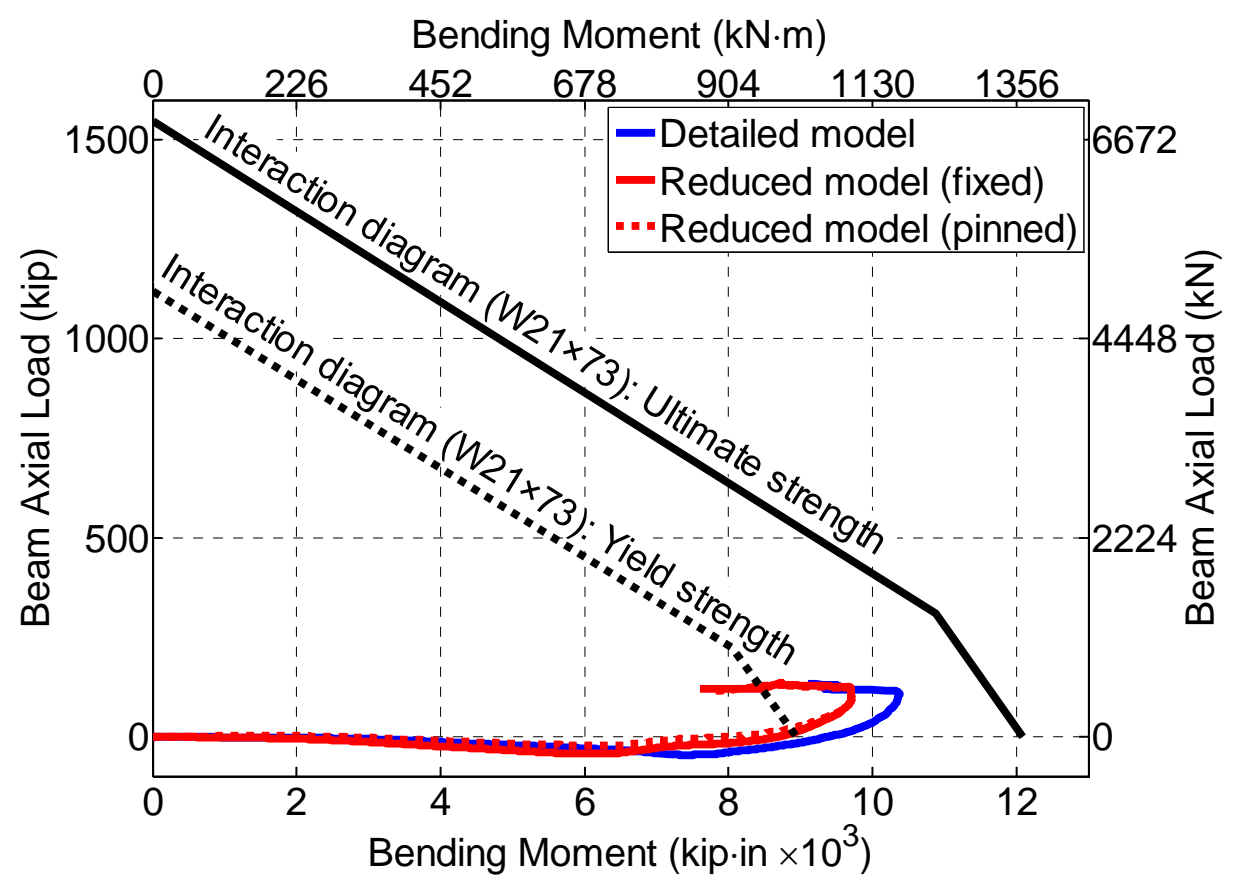

Figure 5-14 Comparison of the WUF-B connection moment-axial interaction diagram with the limit interaction diagram of the gross beam cross section 


\subsubsection{Reduced (Beam/Spring Element) Model}

The reduced model of the WUF-B specimen, shown in Figure 5-15, used Hughes-Liu beam elements (Hallquist 2007) to represent the beams and columns, as well as the shear tabs and beam flanges in the connection regions (see Figure 5-16). The Hughes-Liu beam elements used cross section integration with the proper cross-sectional geometry defined for each component. A piecewise linear plasticity model was used to represent the steel materials, with stress-strain curves based on tensile test data as discussed in Section 5.2.1. An arrangement of beam and spring elements connected with rigid links was used to model the WUF-B connections, as shown in Figure 5-16.

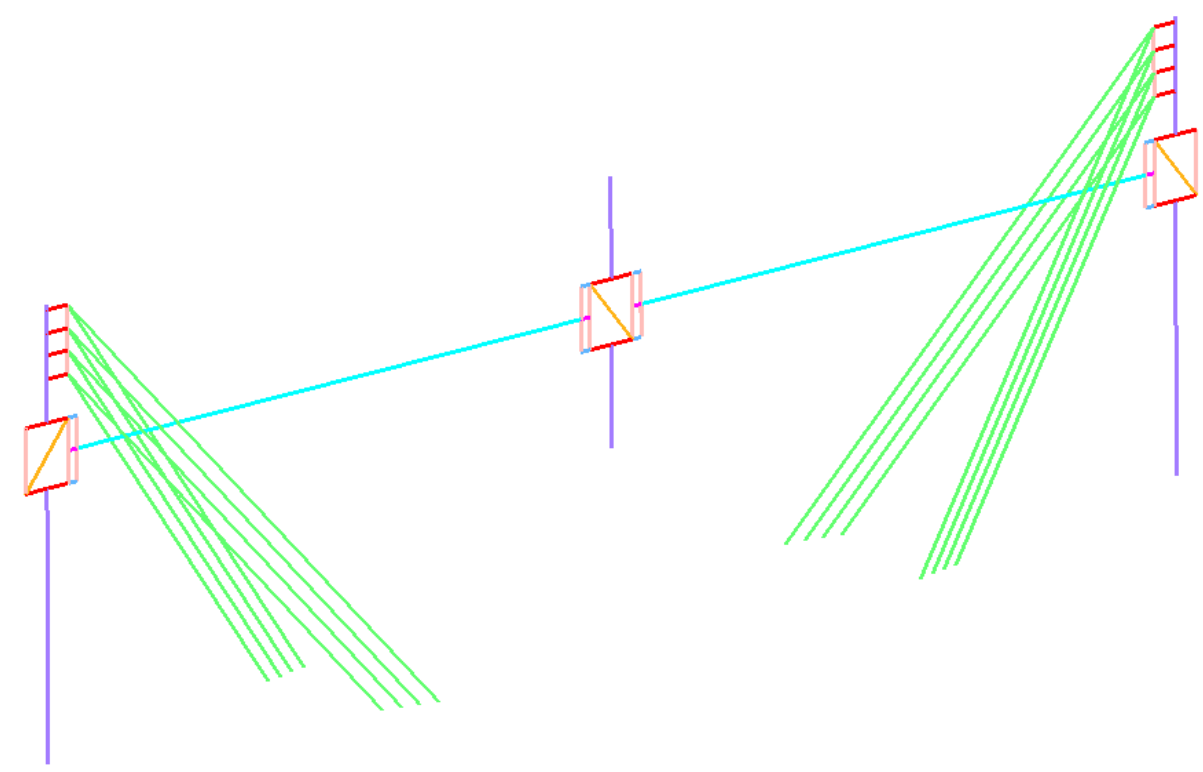

Figure 5-15 Overview of reduced model of the WUF-B specimen

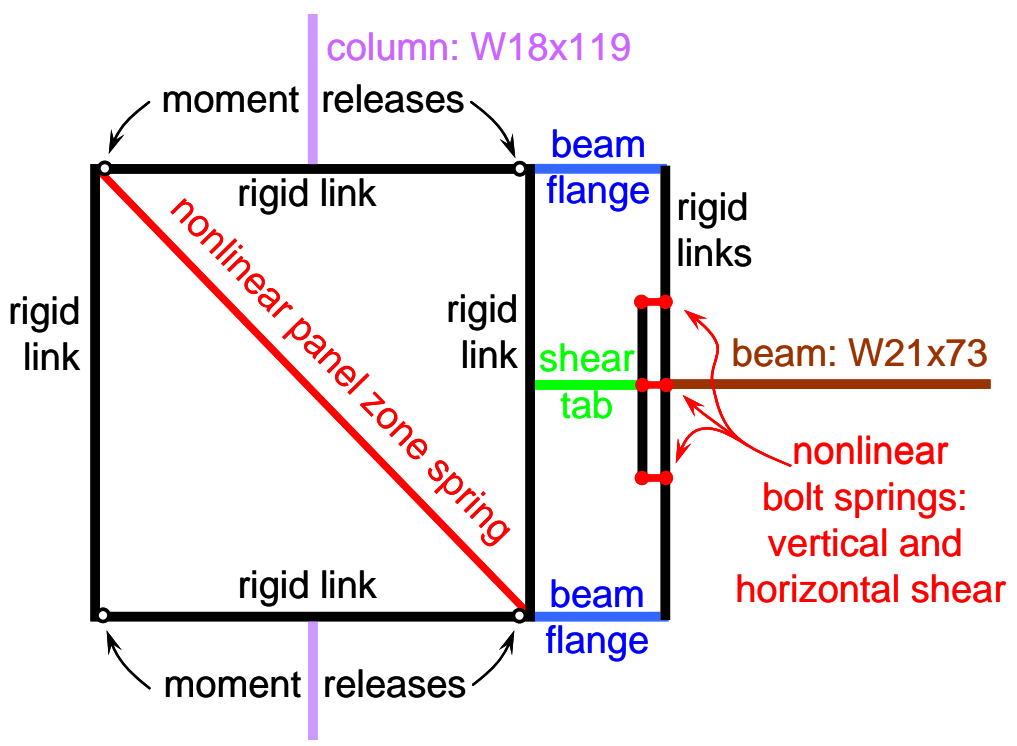

Figure 5-16 Detailed view of the WUF-B connection in the reduced model of the WUF-B specimen 
Zero-length spring elements (shown with finite length in Figure 5-16 for clarity) were used to model the shear behavior of the bolts, along with bearing-induced deformations of the shear tab and beam web, in the reduced model of the WUF-B specimen. These elements are capable of representing bolt shear in any direction in the vertical plane, allowing modeling of combined vertical and horizontal shear. The piecewise linear shear load-deformation curve shown in Figure 5-17 was used for the springs representing the bolts in the reduced model. This simplified piecewise-linear curve is based on the results of a detailed solid-element model of the bolted lap joint illustrated in the inset of Figure 5-17. The material properties and thicknesses of the two connected plates in this model correspond to those of the shear tab and the beam web used in the detailed model of the WUF-B specimen (see Section 5.3.1). One bolt was considered in the model, and the width of each connected plate was 4 in (102 mm), corresponding to the vertical spacing between bolts in the WUF-B connection. A shear load-deformation curve obtained from this model is also shown in Figure 5-17. Note that the failure displacement obtained from this single-shear model is more than twice the failure displacement of the bolt obtained from the double-shear model considered previously (see Figure 5-7), while the yield and ultimate loads are comparable. Note also that the plates considered in the single-shear configuration were approximately half as thick as those used in the double-shear configuration, resulting in much more extensive bearinginduced plastic deformations of the plates around the bolt holes. Deformation of the bolt holes in the single-shear configuration also permitted rotation of the bolt shank, evident in the inset of Figure 5-17. The larger failure displacement in the single-shear configuration therefore represents the combined effects of bolt shear deformation, bearing-induced plate deformation, and bolt shank rotation.

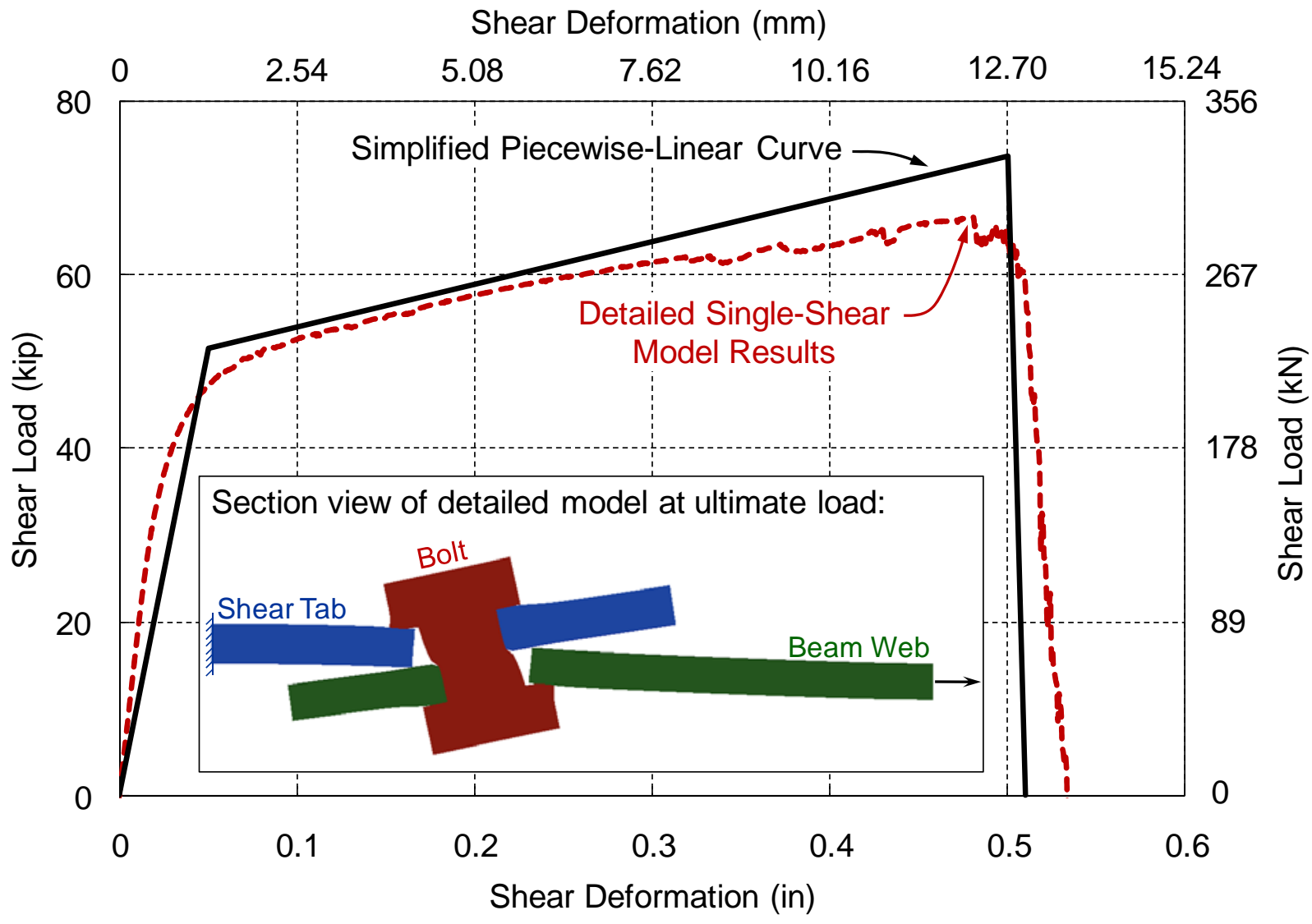




\section{Figure 5-17 Shear load-deformation curves for bolted lap joint}

Spring elements were also used to model the diagonal braces (see Section 5.2.3) and the shear behavior of the panel zone. For the panel zone, the diagonal springs had an elastic, perfectly plastic load deformation curve based on the stiffness and strength of the panel zone (Khandelwal et al. 2008). The stiffness of the panel zone spring, $k_{p z}$, was defined using equilibrium relationships that equate the response of the panel zone spring model with the column web in the panel zone region deforming in pure shear as:

$$
\begin{gathered}
k_{p z}=\frac{G\left(d_{c}-t_{c f}\right) t_{p z}}{\left(d_{b}-t_{b f}\right) \cos ^{2} \theta} \\
\cos ^{2} \theta=\frac{\left(d_{c}-t_{c f}\right)^{2}}{\left(d_{c}-t_{c f}\right)^{2}+\left(d_{b}-t_{b f}\right)^{2}}
\end{gathered}
$$

where $d_{c}$ is the column depth, $d_{b}$ is the beam depth, $t_{c f}$ is the column flange thickness, $t_{b f}$ is the beam flange thickness, $t_{p z}$ is the panel zone thickness, and $G$ is the shear modulus of steel. Using similar equilibrium relationships and using the panel zone strength equation in the AISC Seismic Provisions (2005), the yield capacity of the panel zone spring is:

$$
f_{p z}=\frac{0.6 F_{y} d_{c} t_{p z}}{\cos \theta}\left[1+\frac{3 b_{c f} t_{c f}^{2}}{d_{b} d_{c} t_{p z}}\right]
$$

Where $b_{c f}$ is the column flange width. Since the panel zone region is very ductile, it is unlikely that it will fail prior to other components in the model. Therefore, a failure deformation limit on the panel zone spring was not enforced.

Two analyses were conducted in which the bases of the end columns were modeled as either fixed or pinned. In general, the results from the reduced model were consistent with those from the detailed model. The deflected shape of the WUF-B specimen based on the reduced model with fixed column bases is shown in Figure 5-18. The failure sequence of the center column connection is indicated in Figure 5-19 for the reduced models with fixed and pinned column bases. The lowermost bolt connecting the beam web to the shear tab failed first, and was followed by the nearly simultaneous failures of the middle bolt and the bottom flange of the beam. This failure sequence is very similar to what was observed in both the experiment and the detailed model (see Section 5.3.1).

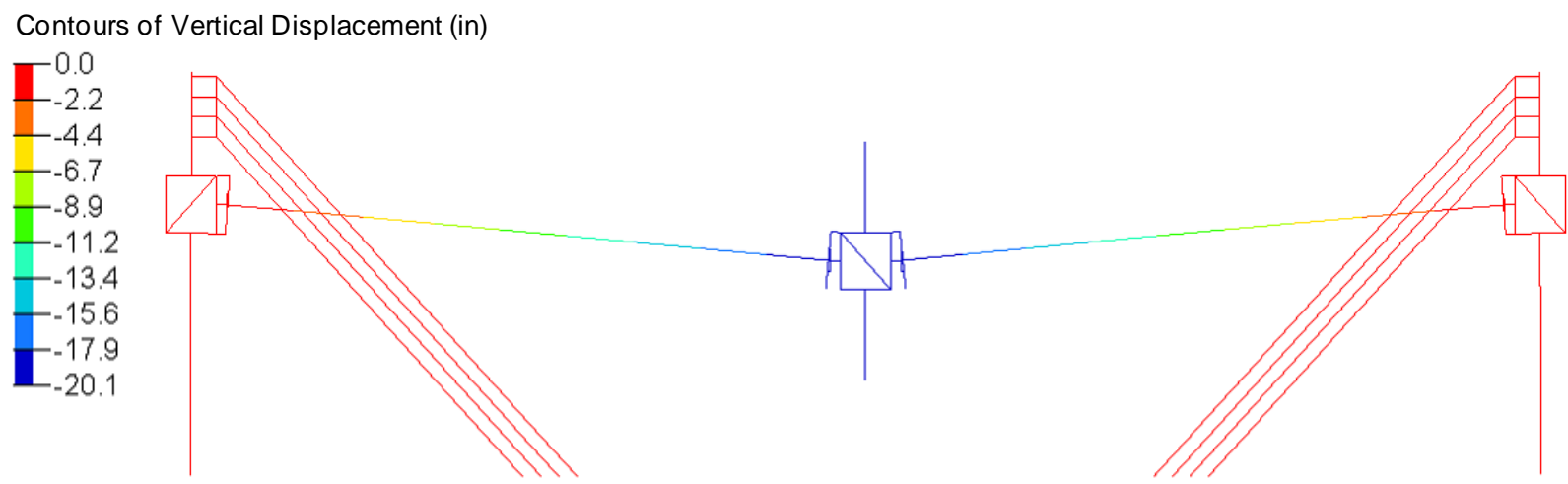

Figure 5-18 Deflected shape of WUF-B reduced model (fixed columns) at a center column vertical displacement of $20.1 \mathrm{in}(511 \mathrm{~mm})$. 


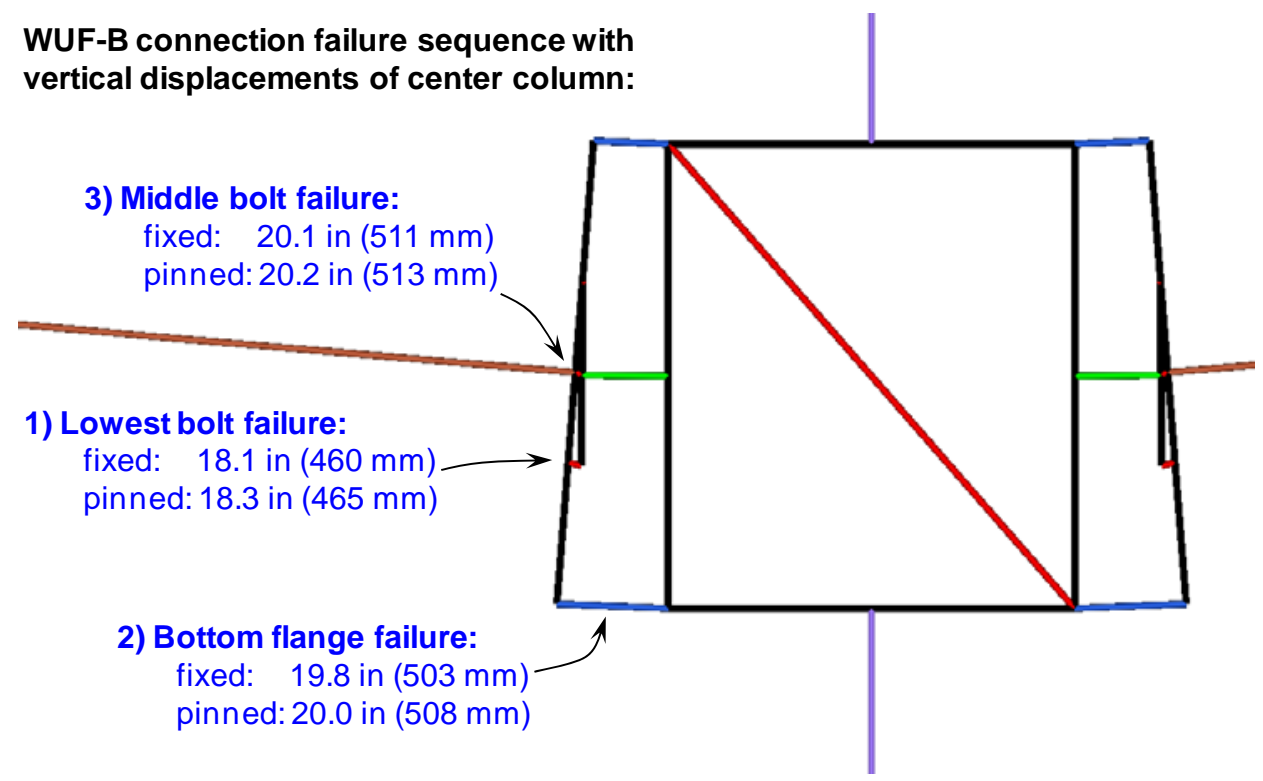

Figure 5-19 Failure sequence from the WUF-B reduced model

Figure 5-13 shows plots of the primary response parameters based on the reduced models (both fixed and pinned end columns), along with the results obtained from the experiment and the detailed model. The plots show good agreement between the results produced by the reduced model and those from the experiment and the detailed model, providing a validation of the reduced model. This indicates that while the reduced model uses fewer elements, it is capable of capturing the primary response characteristics and failure modes of the test specimen.

\subsection{RBS FINITE ELEMENT MODELS}

Similar to the WUF-B specimen, two finite element models of the RBS specimen were developed to study the response characteristics of the connections and to compare the calculated response with that measured during the experiment. The first was a detailed model of the assembly with approximately 235000 shell elements, while the second was a reduced model with about 130 beam and spring elements. The following sections provide descriptions of the models and the analysis results.

\subsubsection{Detailed (Shell Element) Model}

An overview of the detailed model used in the analysis of the RBS specimen is shown in Figure 5-20. The model consisted of shell elements representing the columns, beams, continuity and doubler plates, and welds. In the vicinity of the reduced section, the beams and columns were modeled using a fine shell element mesh with an element size of about $0.25 \mathrm{in}$. $(6.4 \mathrm{~mm})$, as shown in Figure 5-21. Away from the connection zones, the beams and columns were modeled using a coarser mesh with an element size of 1 in $(25 \mathrm{~mm})$. Spring elements were used to model the diagonal braces at the top of the end columns (see Section 5.2.3). All nodes were fixed at the bases of the end columns. Similar to the test configuration, out-of-plane lateral displacements of the beam flanges were constrained at mid-span. The steel materials for the beams, columns, and doubler and continuity plates were modeled using a piecewise linear plasticity model as described in Section 5.2. 


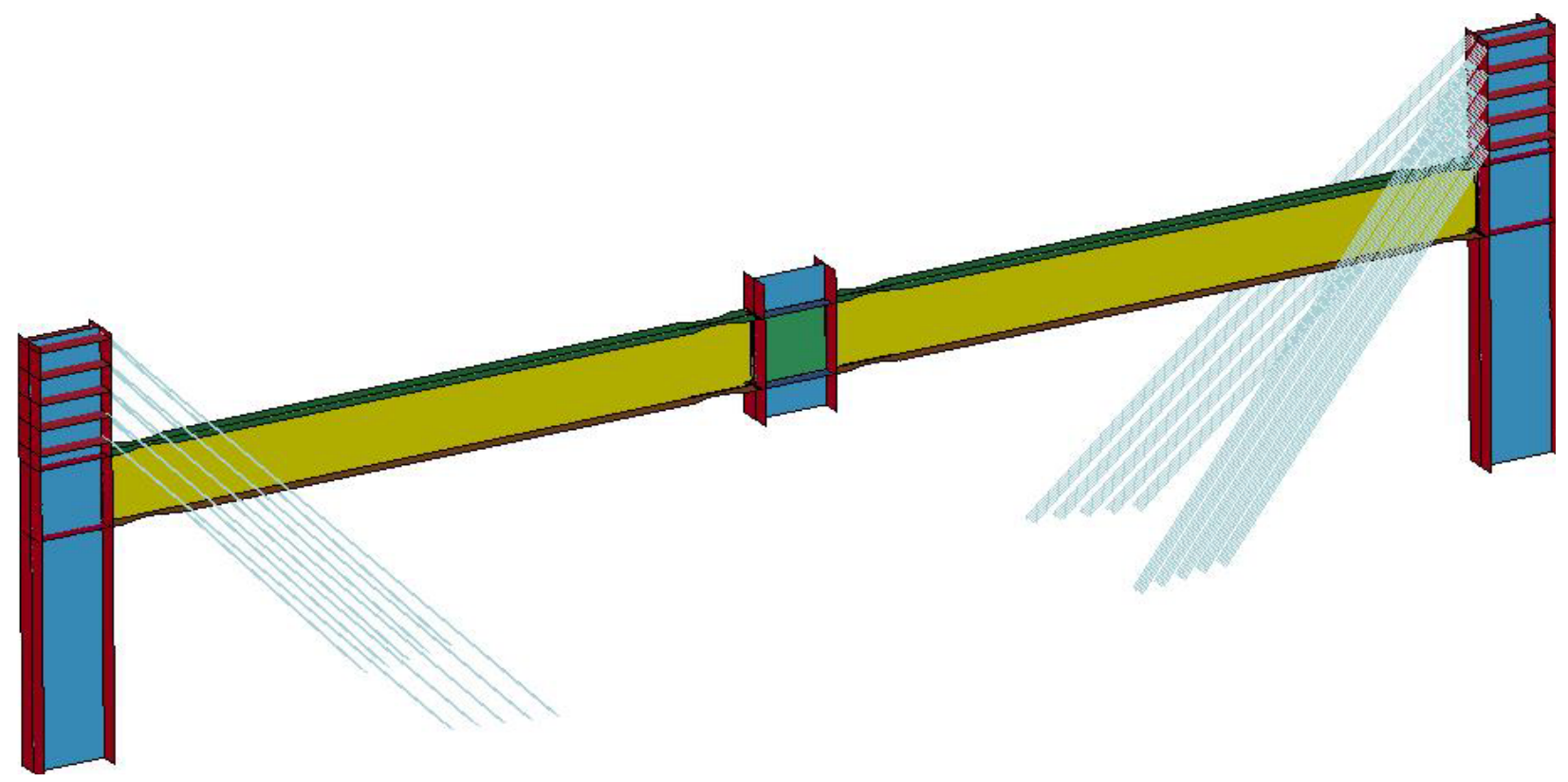

Figure 5-20 Overview of the detailed model of the RBS specimen

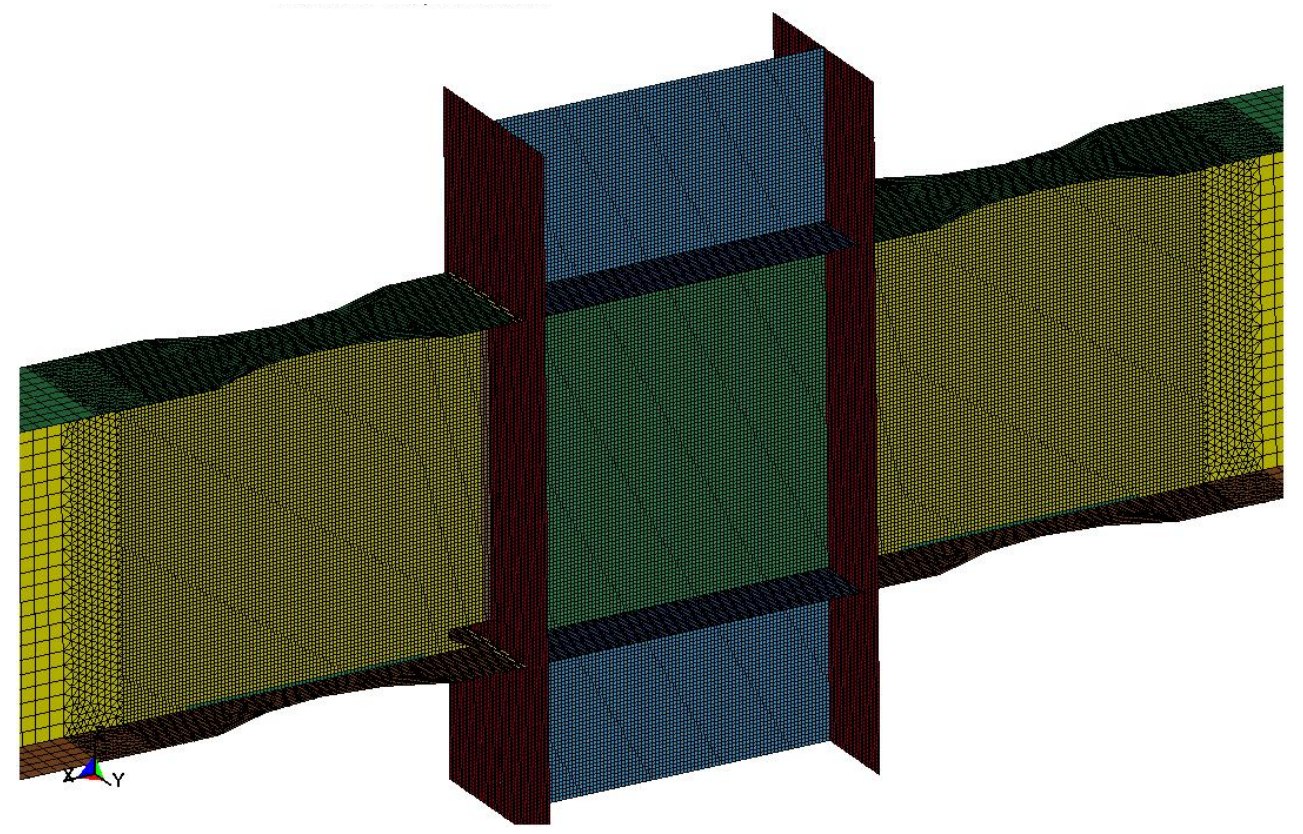

Figure 5-21 Detailed view of the RBS connection in the detailed model of the RBS specimen

The deflected shape of the RBS specimen based on the detailed analysis is shown in Figure 5-22. The beam-column assembly responded initially in a purely flexural mode before catenary action developed. The beam remained essentially elastic except for the reduced sections where significant yielding was observed. The failure mode of the connection according to the analysis, shown in Figure 5-23, was very similar to that observed in the experiment, shown in Figure 4-17. The failure was characterized by the fracture of the bottom flange in the reduced section near the center column, which displaced about 33 in $(838 \mathrm{~mm})$. The fracture immediately propagated through the web until the vertical load-carrying capacity of the specimen was lost. 


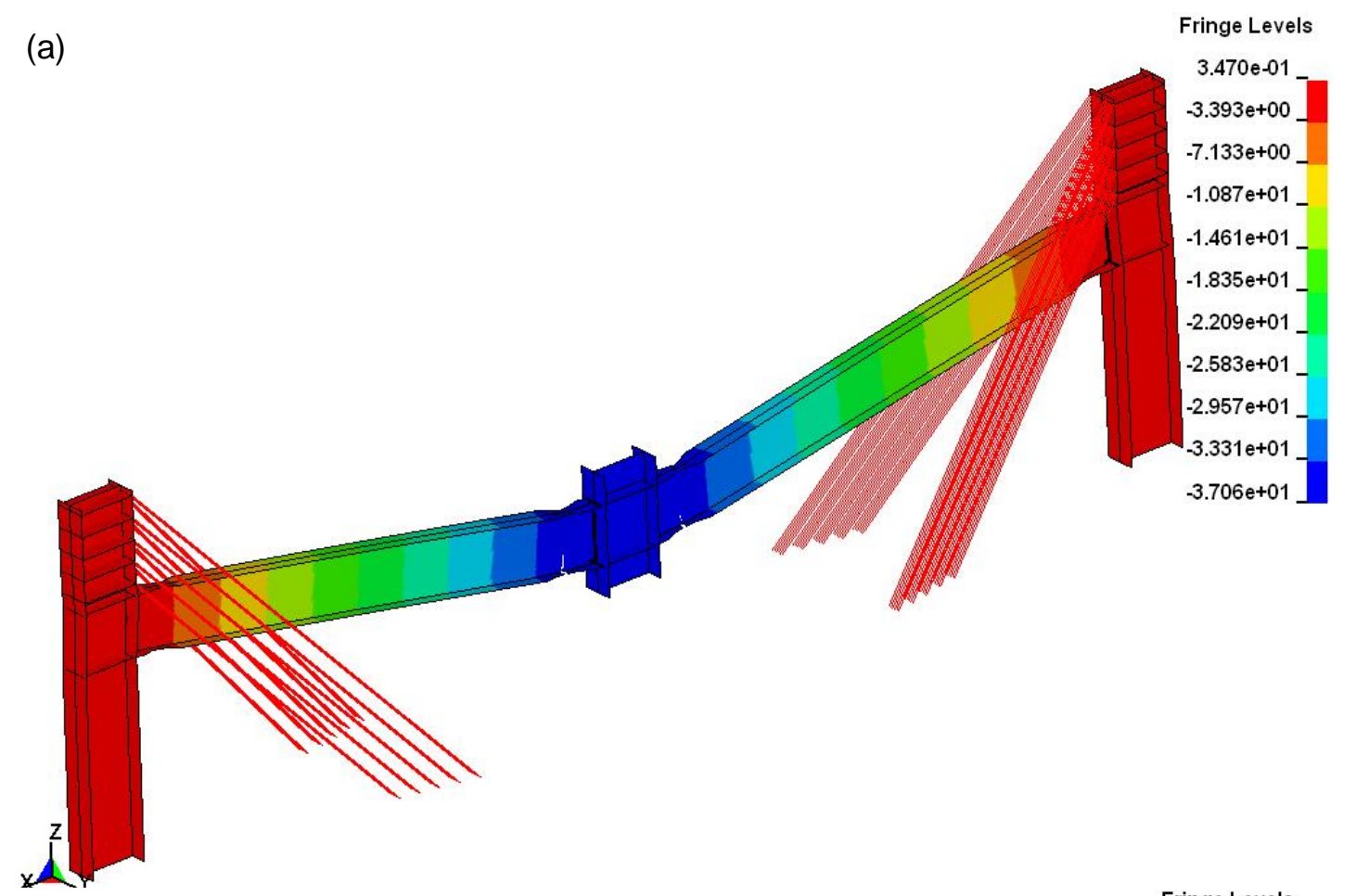

Fringe Levels

(b)

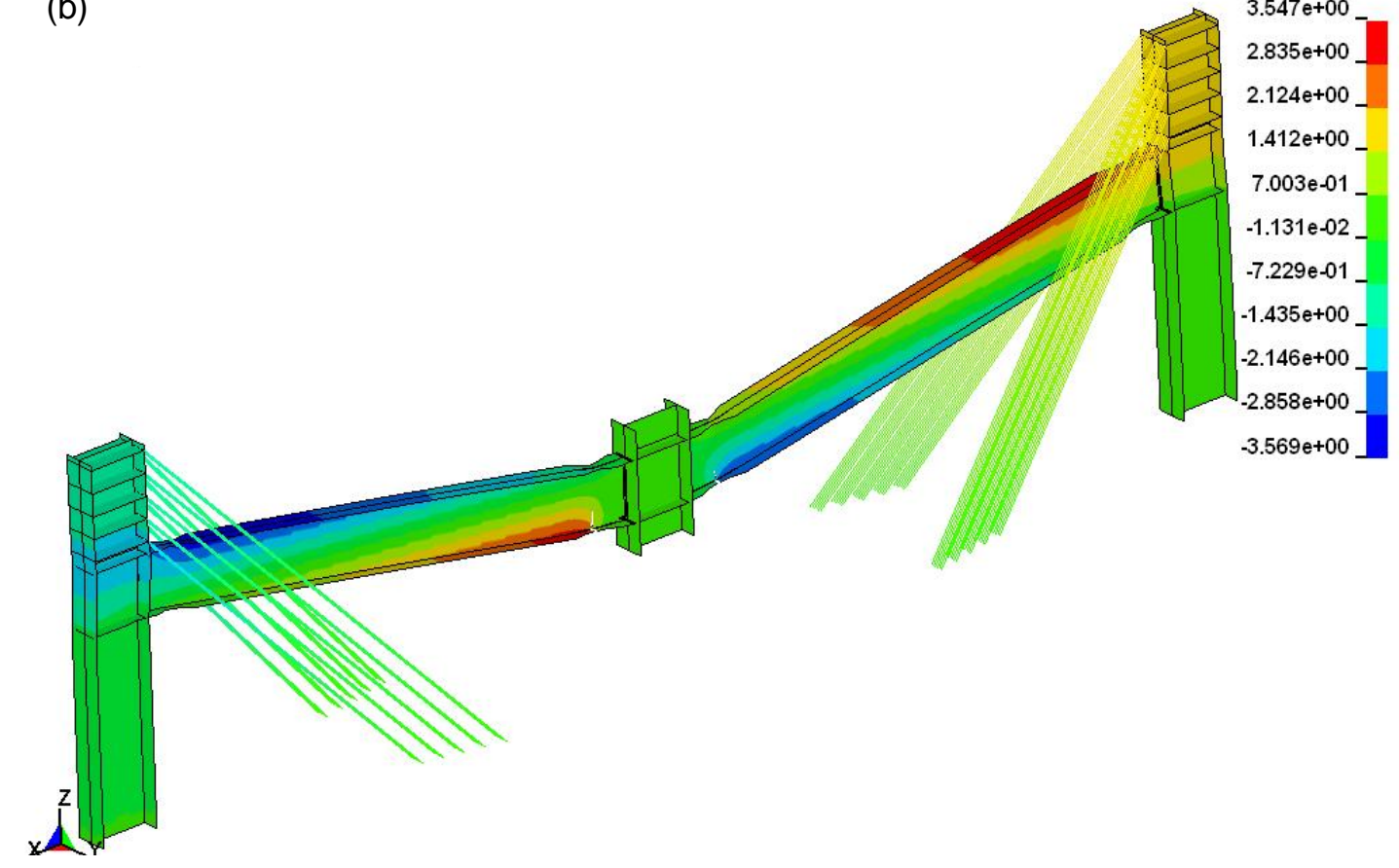

Figure 5-22 Deflected shape of RBS detailed model at a center column vertical displacement of $37 \mathrm{in}$ (944 mm). Contours represent (a) vertical and (b) horizontal displacements in inches. 


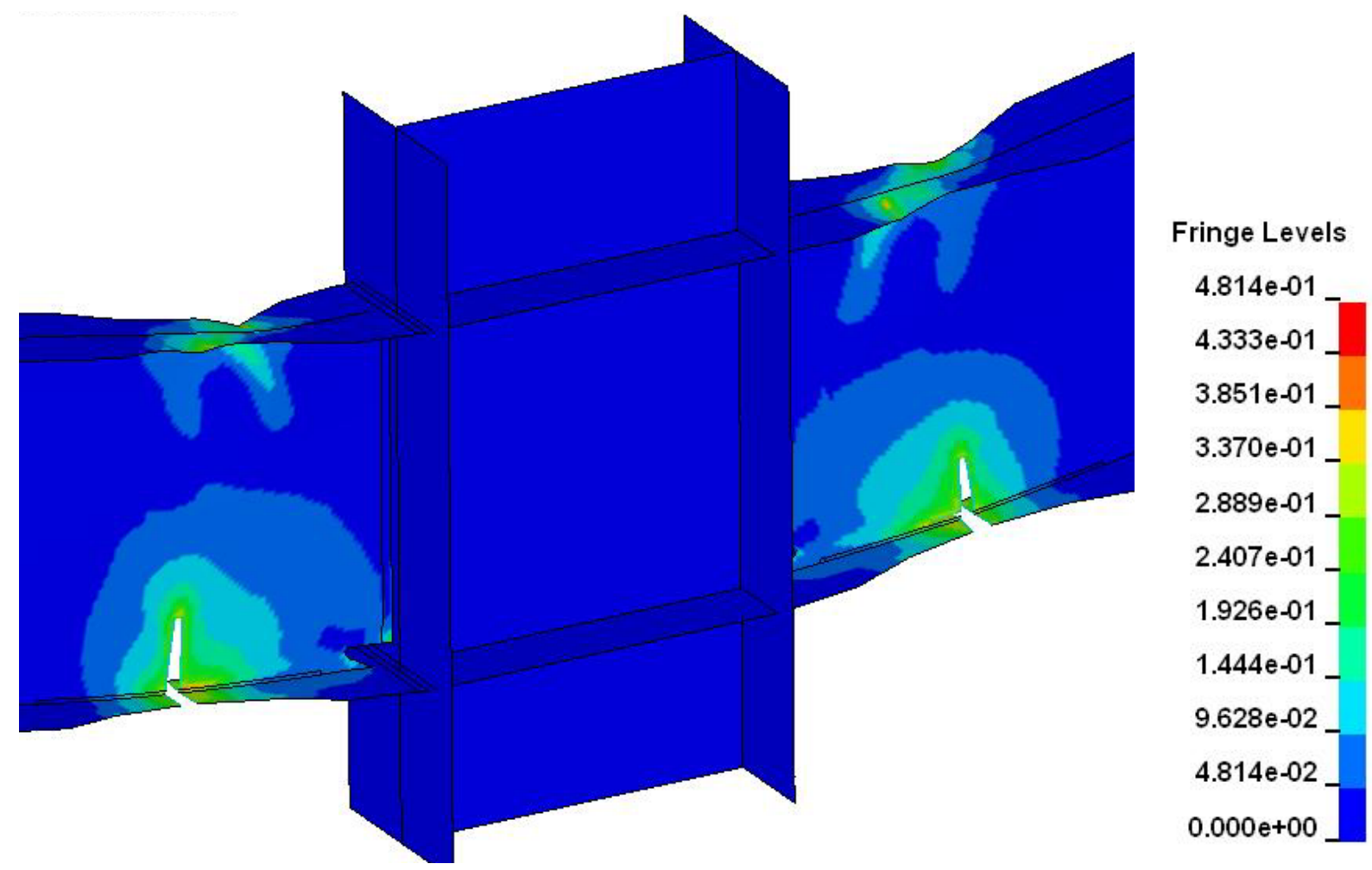

Figure 5-23 Failure mode from the RBS detailed model. Contours represent plastic strains

Figure 5-24 shows (a) the applied vertical load, (b) the beam axial force, (c) the horizontal (inward) displacement of the end columns at beam mid-height, (d) the horizontal (inward) displacement of the top of the end columns, (e) the end column axial force, and (f) the axial compression in each diagonal brace, all plotted against the vertical displacement of the center column. These plots compare the experimental results with the results from the detailed finite element model presented in this section and with the results from the reduced model presented in Section 5.4.2. The plots show good agreement between the experimental and computational results, providing validation for the finite element models.

Similar to the experimental results, the results of the detailed model shown in Figure 5-24(a) indicate that the assembly remained in the elastic range up to a vertical displacement of the center column of about 2 in $(50 \mathrm{~mm})$. The analysis indicates that in the early stages of the response, the behavior was dominated by flexure, as indicated by the slight compressive axial forces in the beams shown in Figure 5-24(b). With increased vertical displacement, tensile axial forces developed in the beams and the behavior was dominated by catenary action. As Figure 5-24(b) indicates, the axial tensile force in the beams increased with increased downward displacement of the center column until the connection could no longer carry the combined axial and flexural stresses (axial tension in excess of $500 \mathrm{kip}$ ), resulting in fracture of the bottom flange at the center of the reduced section. Similar to the experimental results, the results of the detailed model shown in Figure 5-24(e) indicate that in the initial stages of the response (when the response was dominated by flexure), the end columns were in compression. With increased vertical displacement, axial tension developed in the end columns, as a result of the large compressive axial loads carried by the diagonal braces, as shown in Figure 5-24(f). 
(a)

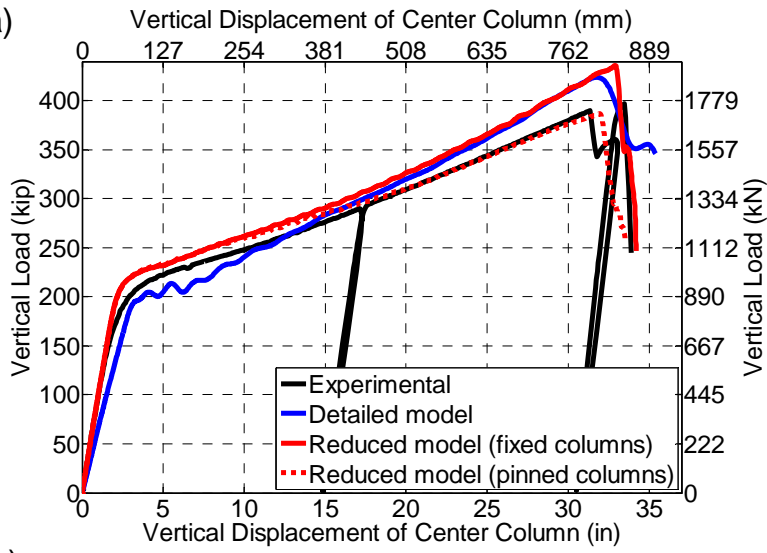

(c)

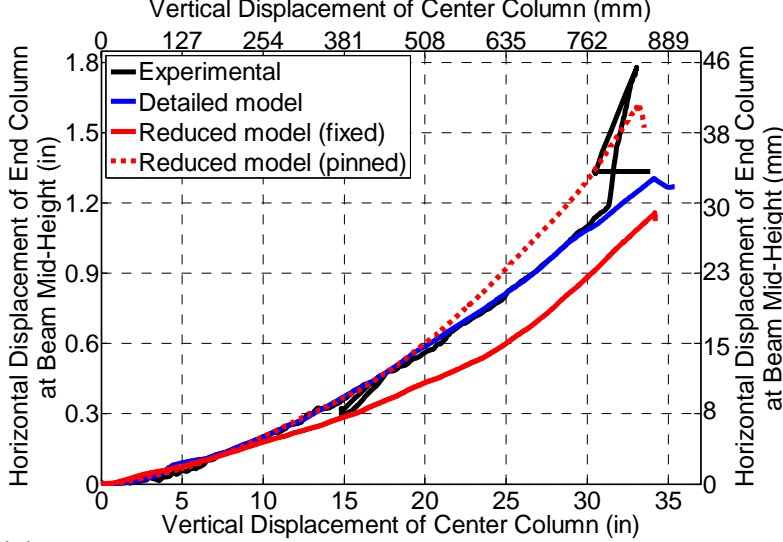

(e)

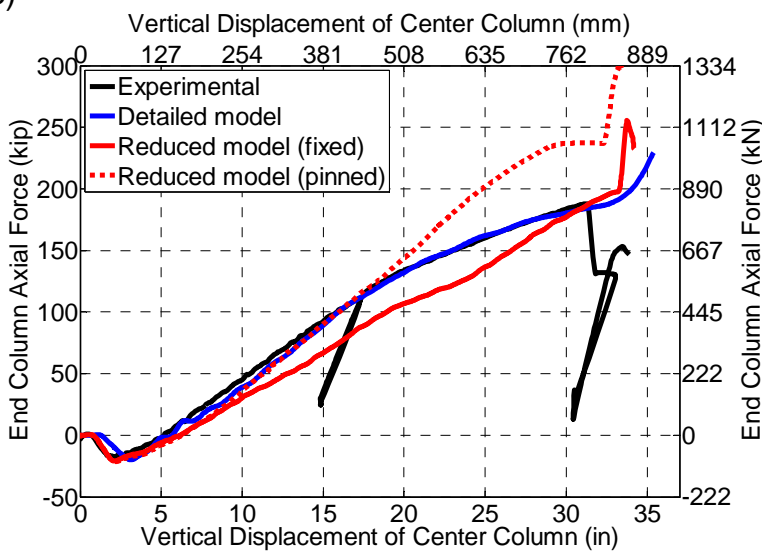

(b) Vertical Displacement of Center Column (mm)

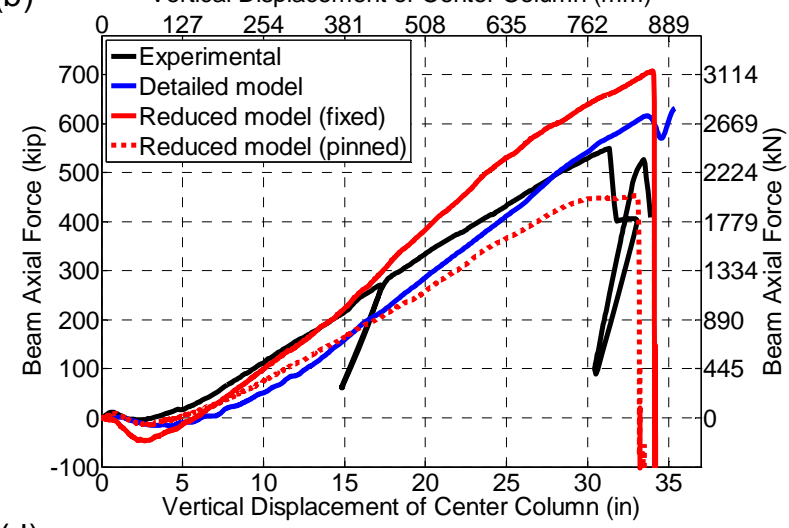

(d)

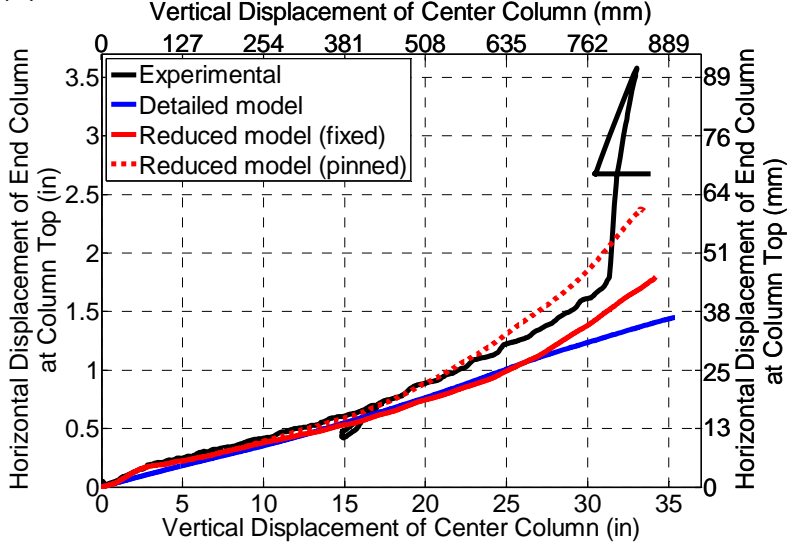

(f)

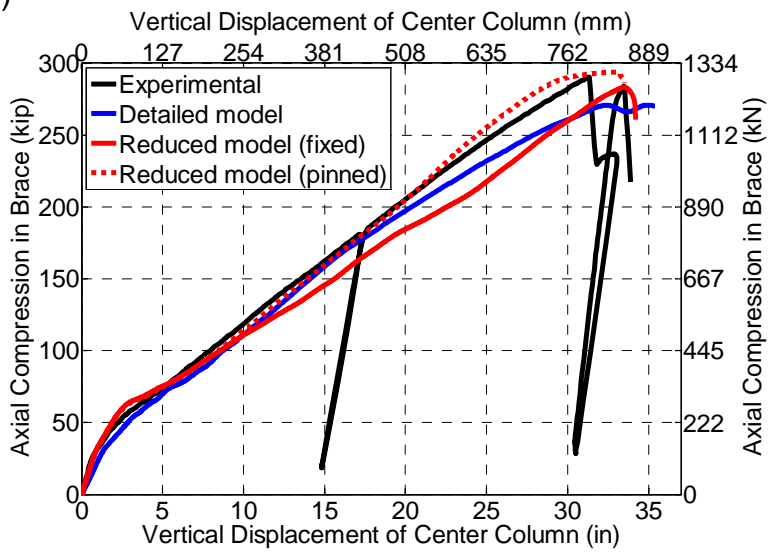

Figure 5-24 Vertical displacement of center column versus applied vertical load, and individual member forces and displacements of RBS specimen

Figure 5-25 shows the bending moment-axial force interaction diagram for the RBS connection, based on the detailed analysis in this section and the reduced model analysis in Section 5.4.2. The bending moment and axial force were calculated at the center of the reduced section near the center column, where failure of the connection was observed. Superimposed on the connection response are the limiting bending moment-axial tension interaction diagrams for the gross beam cross section (W24x94) and for the reduced beam section calculated based on the actual ultimate strength of the beam material. The limiting interaction diagrams were calculated based on Chapter H of the 2005 AISC Specification (AISC 
2005) using yield and ultimate stress values obtained from tensile tests (see Table 3-1). The figure shows that the capacity of the connection slightly exceeds the capacity of the reduced section under combined axial and flexural loads, as calculated based on the AISC Specification, but is less than the calculated ultimate capacity of the gross beam cross section.

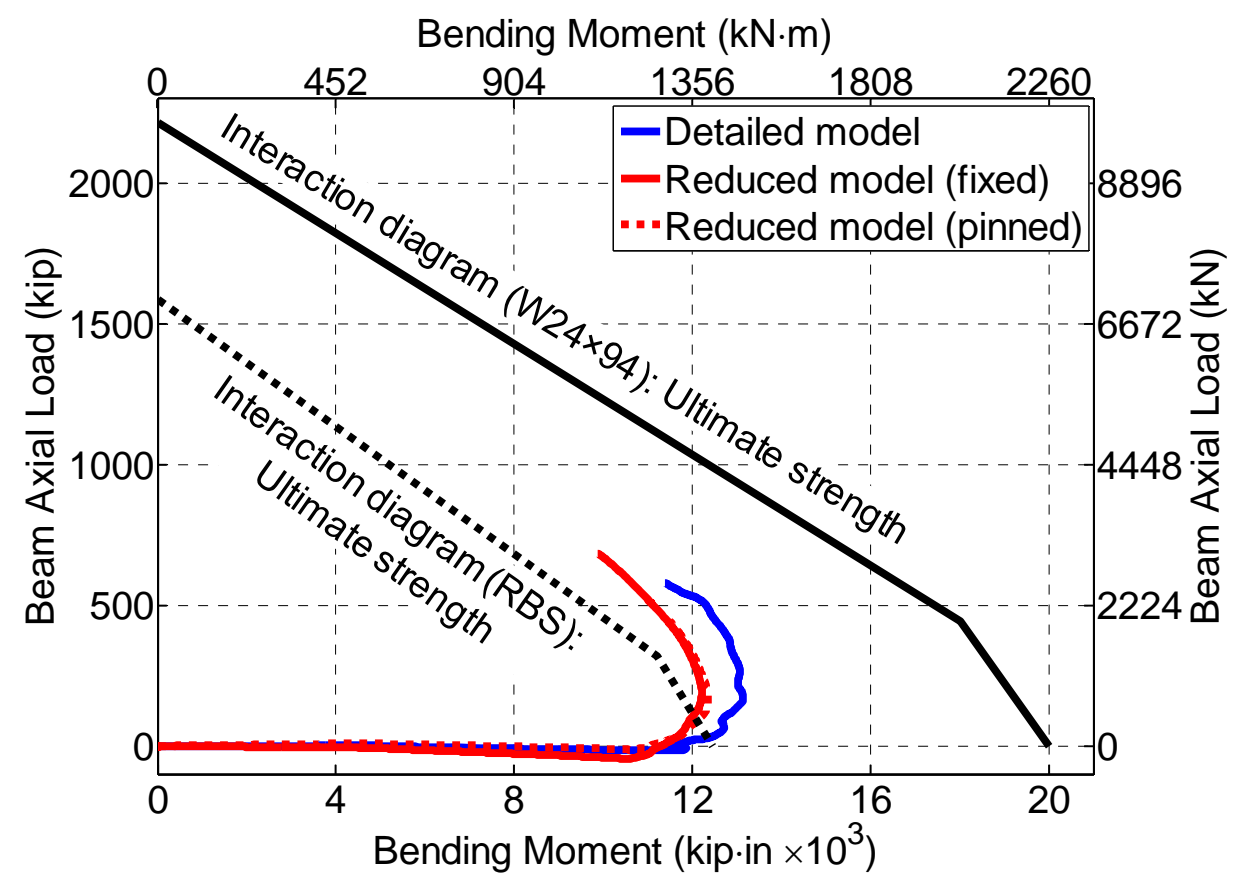

Figure 5-25 Comparison of RBS connection moment-axial interaction diagram with the interaction diagram of gross beam cross section

\subsubsection{Reduced (Beam Element) Model}

The reduced model of the RBS specimen, shown in Figure 5-26, consisted of Hughes-Liu beam elements representing the beams and columns in the specimen. In addition, each reduced beam section was modeled using five beam elements with varying section properties. The beam elements used cross section integration with the proper cross-sectional geometry defined for each type of section. A piecewise linear plasticity model was used to represent the steel materials, with stress-strain curves based on tensile test data as discussed in Section 5.2.1. Spring elements were also used to model the diagonal braces (see Section 5.2.3) and the shear behavior of the panel zone (see Section 5.3.2). Both fixed and pinned bases were considered for the end columns. 


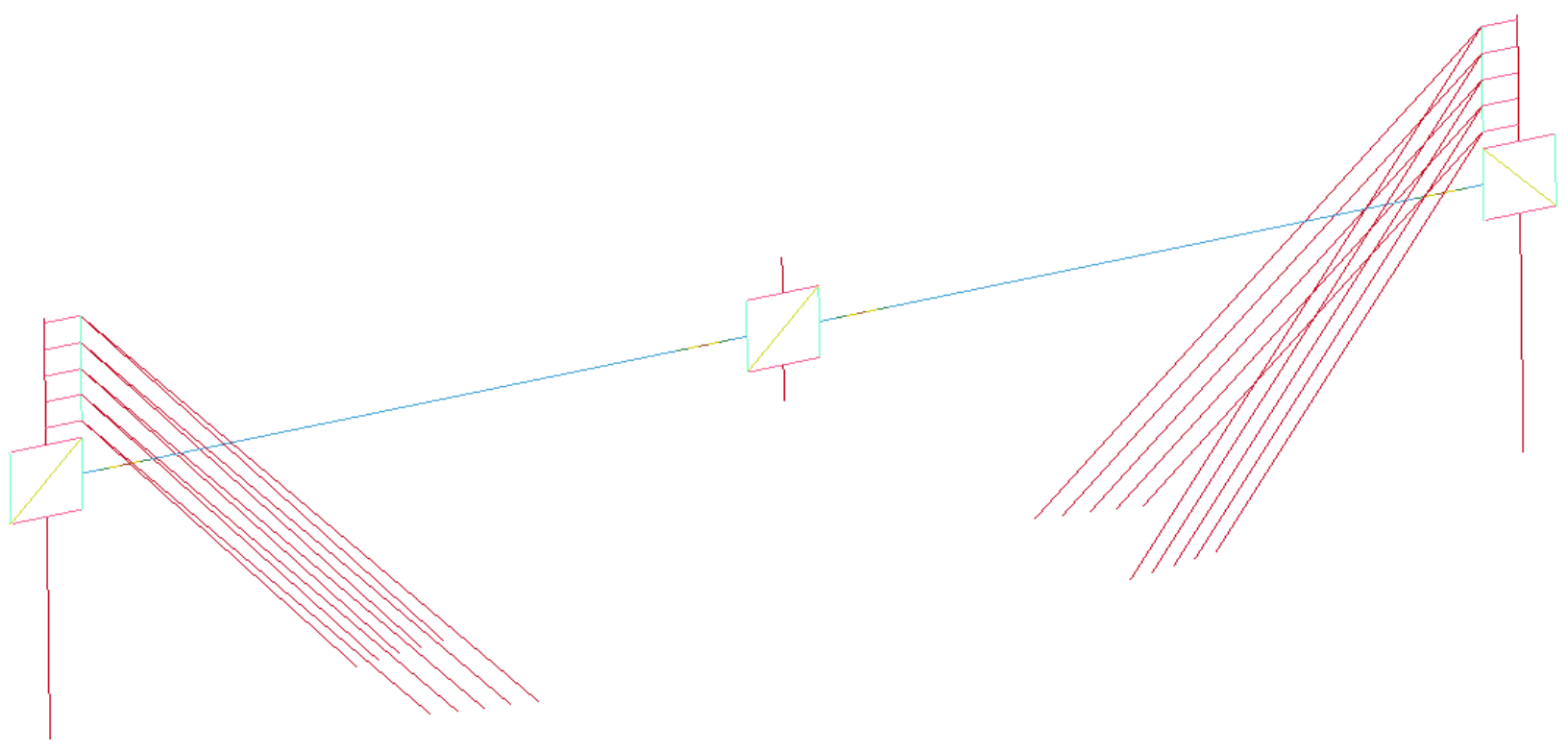

Figure 5-26 Overview of the reduced model of the RBS specimen

In general, the results from the reduced model were consistent with those from the detailed model. The deflected shape of the RBS specimen based on the reduced model with fixed column bases is shown in Figure 5-27. The failure sequence and mode of the connection based on this analysis (for both fixed and pinned end columns) were very similar to those observed in the experiment and detailed model. The beam element at the center of the reduced section experienced large strains, associated with combined flexural and axial tensile stresses. Once a critical strain was reached, the element was eroded, resulting in the failure of the assembly (see Figure 5-27).

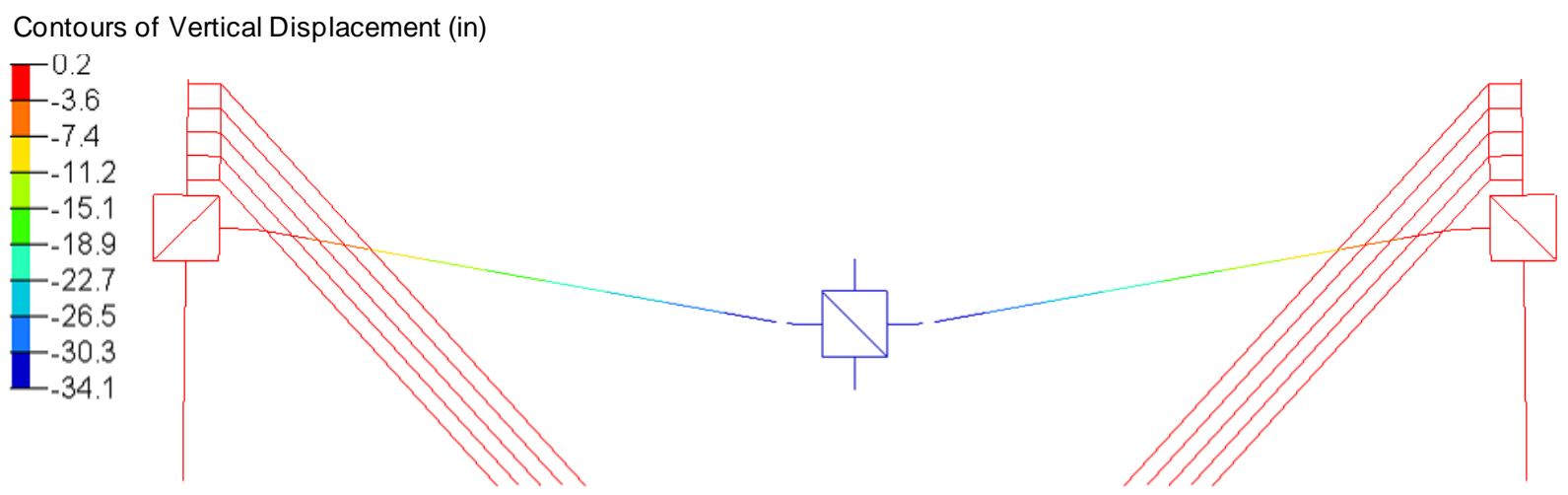

Figure 5-27 Deflected shape of RBS reduced model (fixed columns) at a center column displacement of 34.1 in $(866 \mathrm{~mm})$.

Figure 5-24 shows plots of the primary response parameters based on the reduced models (both fixed and pinned end columns), along with the results obtained from the experiment and the detailed model. The plots show good agreement between the results produced by the reduced model and those from the experiment and the detailed model, providing validation for the reduced models. This indicates that while the reduced model uses fewer elements, it is capable of capturing the primary response characteristics and failure modes of the test specimen. 


\subsection{SUMMARY AND DISCUSSION OF ANALYSIS RESULTS}

This chapter presented a computational assessment of the performance of beam-column assemblies with two types of moment resisting connections under vertical column displacement. The connections considered include (1) a welded unreinforced flange - bolted (WUF-B) web connection and (2) a reduced beam section (RBS) connection. The study considered two levels of modeling complexity: (1) detailed models with a large number of elements, primarily solid and shell elements, and (2) reduced models with a limited number of elements, primarily beam and spring elements. The analyses conducted using these models provided insight into the behavior and failure modes of the connections, including their capacity to carry tensile forces that developed in the beams.

This study indicates a good agreement between the experimental results and the computational predictions. Both detailed and reduced models were capable of capturing the primary response characteristics and failure modes. The validated reduced models developed in this study will be valuable in the analysis of complete structural systems for assessing the reserve capacity and robustness of building structures. The analyses confirm that the loads under a column removal scenario are resisted through catenary action, in which tensile axial forces develop in the beams. These tensile forces increase until the connections can no longer sustain the combined axial and flexural stresses and failure occurs.

\subsection{REFERENCES}

AISC (2005). Specification for Structural Steel Buildings, ANSI/AISC 360-05, American Institute of Steel Construction, Chicago, IL.

Hallquist, J. (2007), LS-DYNA Keyword User's Manual, Livermore Software Technology Corporation, Livermore, CA, Version 971.

Khandelwal, K., El-Tawil, S., Kunnath, S.K., Lew, H.S. (2008) "Macromodel-based simulation of progressive collapse: steel frame structures.” Journal of Structural Engineering, 134(7), 1070-1078.

Kulak, G. L., Fisher, J. W., and Struik, J. H. A., (1986), Guide to Design Criteria for Bolts and Riveted Joints, $2^{\text {nd }}$ Ed., John Wiley \& Sons, New York. 


\section{Chapter 6 \\ SUMMARY AND CONCLUSIONS}

This report presented an experimental and analytical study of two steel beam-column assemblies, each comprising three columns and two beams. The two beam-column assemblies represent portions of the structural framing system of two ten-story steel frame buildings. One building was designed for Seismic Design Category C (SDC C) and the other for Seismic Design Category D (SDC D). The beam-column assemblies were taken from the exterior moment resisting frames of these buildings. One test specimen, which was part of the SDC C building, had welded unreinforced flange-bolted web (WUF-B) connections, and the other, which was part of the SDC D building, had reduced beam section (RBS) connections. The specimens were subjected to monotonically increasing vertical displacement of the unsupported center stub column to observe their behavior under a simulated column removal scenario, including the development of catenary action in the beams. The vertical displacement of the center stub column was increased until the vertical load-carrying capacity was depleted.

The overall behavior of each beam-column assembly was analyzed using two levels of modeling complexity: (1) detailed models with a large number of elements, primarily solid and shell elements, and (2) reduced models with a limited number of elements, primarily beam and spring elements. The analyses conducted using these models provided insight into the behavior and failure modes of the connections, including their capacity to carry tensile forces that developed in the beams.

Based on the study reported herein, the following conclusions are reached:

1. For both the WUF-B and RBS connection assemblies, the behavior of the assemblies was dominated by flexure in the early stages of the response. With increased vertical displacement of the center column, the beam connections exhibited yielding and tensile axial forces developed in the beams and the behavior was dominated by catenary action.

2. Distinct modes of failure were observed for the two test specimens. The failure of the WUF-B test specimen was characterized by: (1) local buckling of the top flanges of the beams near the center column, (2) successive shear fractures of the lowest and middle bolts connecting the beam web to a shear tab at the center column, and (3) fracture of the bottom flange near the weld access hole immediately thereafter. The failure of the RBS test specimen was characterized by: (1) fracture of the bottom flange in the middle of the reduced section and (2) propagation of the fracture through the web until the vertical load-carrying capacity was lost.

3. The test results show that the rotational capacities of both the WUF-B and RBS connections under monotonic column displacement are about twice as large as those based on seismic test data. The rotations at peak load were about $0.081 \mathrm{rad}$ and $0.140 \mathrm{rad}$ for the WUF-B and RBS connections respectively, whereas the rotational capacities of these connections based on seismic testing data are approximately $0.047 \mathrm{rad}$ and $0.073 \mathrm{rad}$, respectively. Contributors to this difference include: (1) cyclic loading leads to significant degradation in the strength and stiffness of the connection, while no such degradation is expected under monotonic loading, and (2) the applied loads are resisted by different mechanisms in the two cases, with the connection in pure 
flexure for seismic loading but subjected to both flexure and tension under vertical column displacement.

4. This study indicates generally good agreement between the experimental and the computational results. Both the detailed and reduced models were capable of capturing the primary response characteristics and failure modes of the test specimens.

In summary, this study shows that analysis using reduced models consisting of beam and spring elements can accurately predict the response characteristics of both the WUF-B and RBS connections.

Furthermore, the validated reduced models developed in this study would be valuable in the analysis of complete structural systems for assessing the reserve capacity and robustness of building structures. 